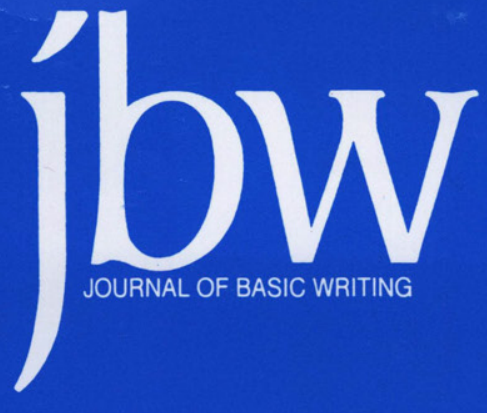

\title{
SPRING 1998
}

VOLUME 17 NUMBER 1

Dialogizing Response in the Writing Classroom:

Students Answer Back

Pamela Gay

Basic Writing: Curricular Interactions with New Technology Susan Stan and Terence G. Collins

Taboo Topics and the Rhetoric of Silence: Discussing Lives on the Boundary in a Basic Writing Class Candace Spigelman

Mediated Texts: A Heuristic for Academic Writing Eileen Biser, Linda Rubel, and Rose Marie Toscano

Assessing Our Assessments: A Collective Questioning of What Students Need--And Get Liza Bruna, lan Marshall, Tim McCormack, Leo Parascondola, Wendy Ryden, and Carl Whithaus

The Attack on Basic Writing--And After Harvey S. Wiener

Inequality (Still) Rules: Reply to Collins and Greenberg Ira Shor 


\title{
LANGUAGE ACQUISITION A Journal of Developmental Linguistics
}

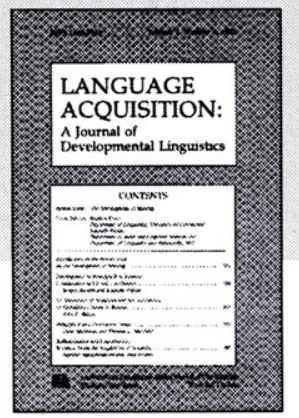

\author{
Robert Berwick \\ Massachusetts Institute of Technology \\ Thomas Roeper \\ University of Massachusetts, Amherst \\ Kenneth Wexler \\ Massachusetts Institute of Technology
}

\section{editorial scope:}

Contributions to this journal offer explanatory insights into, and advance our knowledge of, how language is acquired. Focusing primarily on experimental, linguistic, and computational approaches, the journal discusses the syntax, semantics, pragmatics, and phonology of language acquisition - merging the data of developmental psycholinguistics with recent discoveries in linguistic theory to yield a more adequate understanding of the growth of language. Coverage includes in-principle solutions to problems of how children select among possible grammars, discussions of relevant acquisition data, integrations of theoretical representations of languages to be acquired, and perspectives derived from second language acquisition, language impaired speakers, and other domains of cognition. Language Acquisition also discusses such topics as the relationship between disorders and acquisition, and studies of theoretical linguistics.

\section{audience:}

Researchers and professionals in linguistics, psycholinguistics, and developmentalists.

\section{Volume 7, 1998, Quarterly \\ Individual: $\quad \$ 39.50$ US/Canada $\$ 69.50$ All Other Countries \\ Institution: $\quad \$ 200.00$ US/Canada $\$ 230.00$ All Other Countries}

ISSN: $1048-9223$

\section{abstracted or indexed in:}

Linguistic Abstracts; MLA International Bibliography; PsycINFO/Psychological Abstracts; Current Index to Journals in Education/Educational Resources Information Center; Linguistics and Language Behavior Abstracts

Free Sample Issues Available.

Lawrence Erlbaum Associates, Inc. 10 Industrial Avenue, Mahwah, NJ 07430 201/236-9500 FAX 201/236-0072

Call toll-free to order: 1-800-9-BOOKS-9...9am to 5pm EST only. 


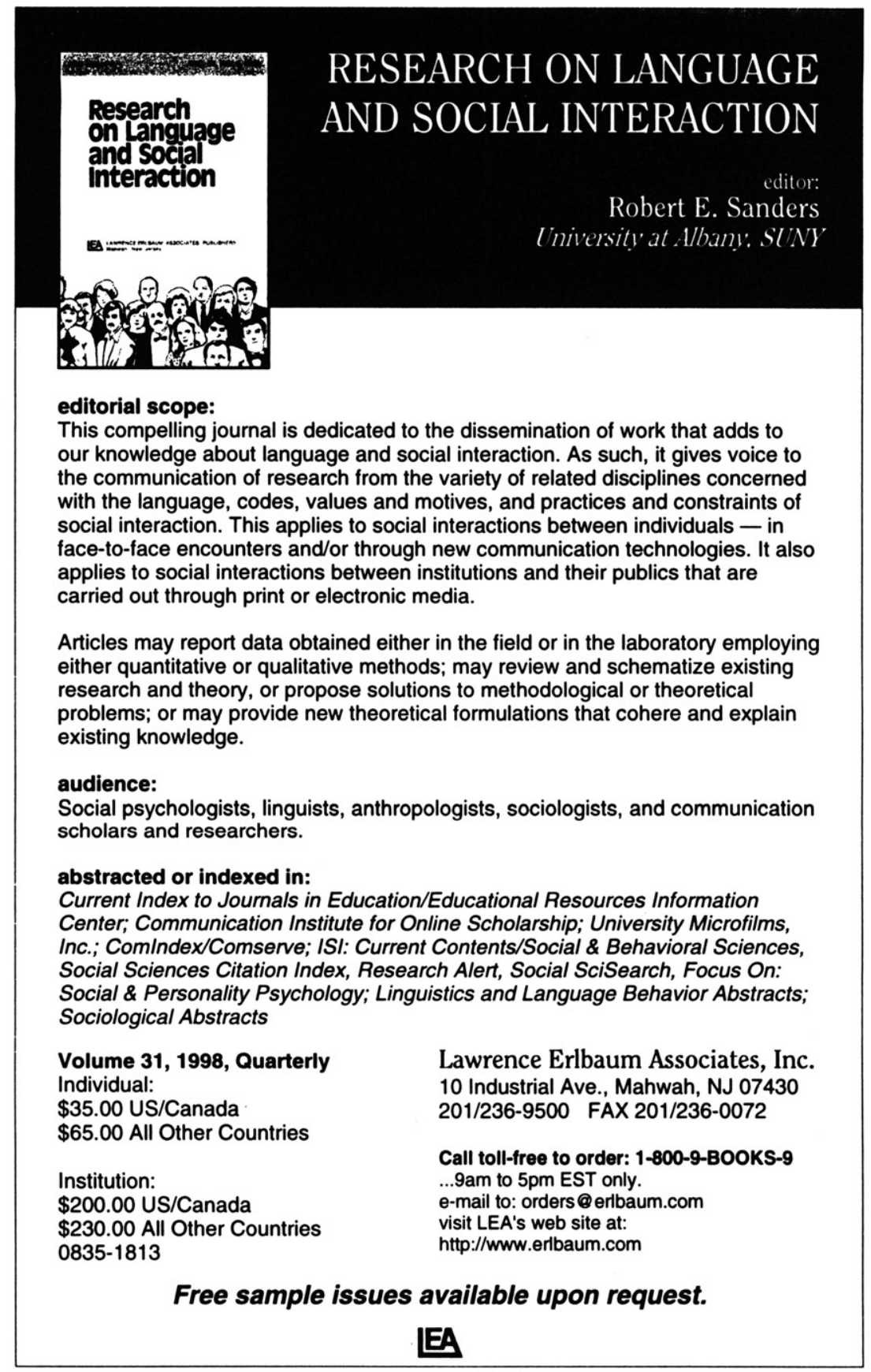




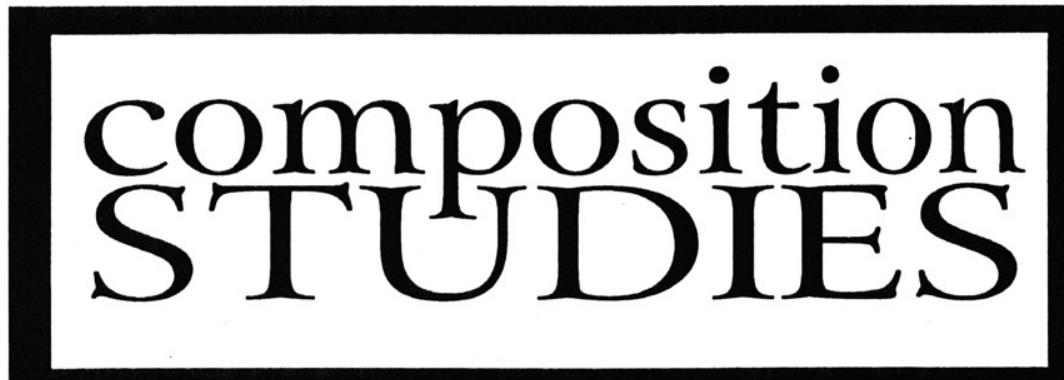

\section{Freshman English News}

\section{Volume 25, Number 1 Now Available}

Featuring essays by

John Clifford and Janet Ellerby, Lauren Sewell, and Teresa M. Redd

\section{Call for Papers}

Composition Studies requests submissions for its new feature on course design. This feature, which will appear regularly in future issues, allows writing/rhetoric teachers at all post-secondary levels a unique opportunity to publish full descriptions of curricular development. Visit our web site for the complete project statement and submission guidelines.

Quality essay submissions on issues of general interest to rhetoric and composition teachers and scholars are also strongly encouraged. Three titled, letter-quality copies conforming to current MLA guidelines for format and documentation, free of authors' names and other identifying references, should be accompanied by a cover letter.

\section{SUBSCRIPTIONS}

Individuals $\$ 12$ - Institutions $\$ 25$ • Graduate Students $\$ 9$

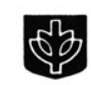

\section{DePaul University}

Department of English • 802 W. Belden Avenue • Chicago, IL 60614-3214 


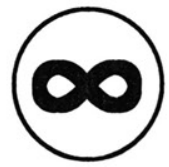

The paper used in this publication meets the minimum requirements of the American National Standard for Information Science -

Permanence of Paper for Printed Library Materials, ANSI Z39.48-1984.

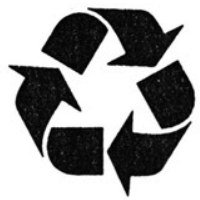

The text stock is also recycled.

\section{This publication is available in microform from UMI.}

Please send me information about the titles I've listed below:

Name

Title

Company/Institution

Address

City/State/Zip

Phone

\section{U.M.I}

A Bel I \& Howell Company

300 North Zeeb Road, Ann Arbor, M 48106 USA 800-521-0600 toll-free

313-761-4700 collect from Alaska and Michigan 800-343-5299 toll-free from Canada 



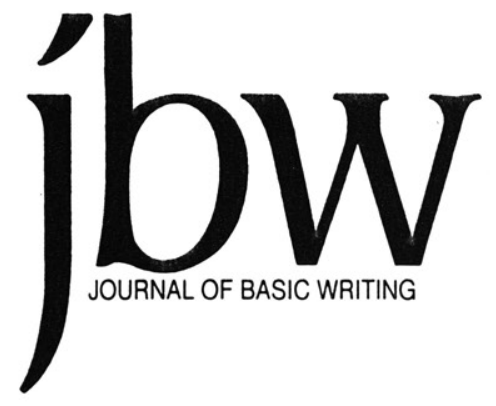

VOLUME 17 NUMBER 1

SPRING 1998

The Journal of Basic Writing publishes articles of theory, research, and teaching practices related to basic writing. Articles are refereed by members of the Editorial Board (see overleaf) and the Editors.

\title{
George Otte and Trudy Smoke Editors \\ Linda Camarasana and Carl Whithaus Editorial Assistants
}

\section{Mary E. Carney, Subscriptions}

The Journal of Basic Writing is published twice a year, in the spring and fall. We welcome unsolicited manuscripts and ask authors to consult the detailed "Call for Articles" in this issue. Subscriptions for individuals are $\$ 10.00$ for one year and $\$ 19.00$ for two years; subscriptions for institutions are $\$ 15.00$ for one year and $\$ 29.00$ for two years. Foreign postage is $\$ 5.00$ extra per year. ADDRESS:

\author{
Journal of Basic Writing \\ Instructional Resource Center \\ The City University of New York \\ 535 East 80th Street \\ New York, NY 10021
}




\section{JOURNAL OF BASIC WRITING}

\section{EDITORIAL BOARD}

Peter Dow Adams

Essex Community College, Baltimore

Akua Duku Anokye

University of Toledo

Chris M. Anson

University of Minnesota

David Bartholomae

University of Pittsburgh

\section{Sarah Benesch}

College of Staten Island, CUNY

Bill Bernhardt

College of Staten Island, CUNY

Patricia Bizzell

College of the Holy Cross

Lynn Z. Bloom

University of Connecticut, Storrs

Nancy Carriuolo

University of New Haven

Richard Courage

Westchester Community College,

SUNY

Donald Daiker

Miami University

Suellynn Duffey

Ohio University

Sarah Warshauer Freedman University of California, Berkeley

Karen L. Greenberg

Hunter College, CUNY

Brenda M. Greene

Medgar Evers College, CUNY

Muriel Harris

Purdue University

Irvin Hashimoto

Whitman College

Warren Herendeen

Mercy College

Myra Kogen

Brooklyn College, CUNY

\section{Patricia Ondek Laurence}

City College, CUNY

Elaine O. Lees

Carlow Hill College

Andrea A. Lunsford

Ohio State University

Jane Maher

Nassau Community College

Peter Miller

College of Staten Island, CUNY

\section{Susan Miller}

University of Utah

Nathaniel Norment, Jr.

Temple University

Jerrold Nudelman

Queensborough Community

College, CUNY

Jane Peterson

Richland College, Dallas County

Community College Distnct

Nell Ann Pickett

Hinds Community College

Charles I. Schuster

University of Wisconsin, Milwaukee

Tony Silva

Purdue University

Lynn Quitman Troyka

Oueensborough Community

College, CUNY, ret.

Karen S. Uehling

Boise State University

Billie J. Wahlstrom

University of Minnesota

Evelyn E. Webb

Mississippi State Board for

Community and Junior Colleges

Harvey S. Wiener

Marymount Manhattan College 


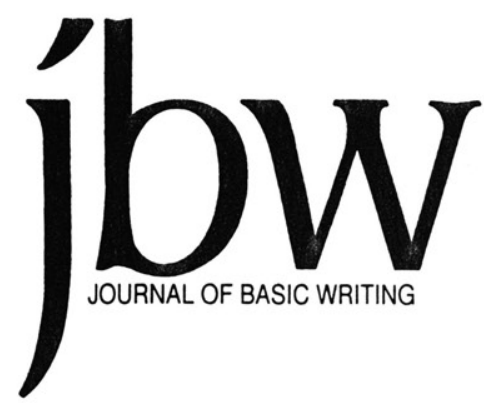

VOLUME 17

Dialogizing Response in the Writing Classroom:

Students Answer Back

Pamela Gay

Basic Writing: Curricular Interactions With New Technology Susan Stan and Terence G. Collins

Taboo Topics and the Rhetoric of Silence:

Discussing Lives on the Boundary in a Basic Writing Class

Candace Spigelman

Mediated Texts: A Heuristic for Academic Writing:

Eileen Biser, Linda Rubel, and Rose Marie Toscano

Assessing Our Assessments: A Collective

Questioning of What Students Need--And Get

Liza Bruna, Ian Marshall, Tim McCormack,

Leo Parascondola, Wendy Ryden, and Carl Whithaus

The Attack on Basic Writing--And After

Harvey S. Wiener

Inequality (Still) Rules: Reply to Collins and Greenberg

Ira Shor

News and Announcements 


\section{CALL FOR ARTICLES}

We welcome manuscripts of $10-20$ pages on topics related to basic writing, broadly interpreted.

Manuscripts will be refereed anonymously. We require five copies of a manuscript and an abstract of about 100 words. To assure impartial review, give author information and a short biographical note for publication on the cover page only. Papers which are accepted will eventually have to supply camera-ready copy for all ancillary material (tables, charts, etc.). One copy of each manuscript not accepted for publication will be returned to the author, if we receive sufficient stamps (no meter strips) clipped to a self-addressed envelope. We require the MLA style (MLA Handbook for Writers of Research Papers, $4 r d$ ed., 1995). For further guidance, send a stamped letter-size, self-addressed envelope for our style sheet and for camera-ready specifications.

All manuscripts must focus clearly on basic writing and must add substantively to the existing literature. We seek manuscripts that are original, stimulating, well-grounded in theory, and clearly related to practice. Work that reiterates what is known or work previously published will not be considered.

We invite authors to write about such matters as classroom practices in relation to basic writing theory; cognitive and rhetorical theories and their relation to basic writing, social, psychological, and cultural implications of literacy; discourse theory, grammar, spelling, and error analysis; linguistics; computers and new technologies in basic writing; English as a second language; assessment and evaluation; writing center practices; teaching logs and the development of new methodologies; and cross-disciplinary studies combining basic writing with psychology, anthropology, journalism, and art. We publish observational studies as well as theoretical discussions on relationships between basic writing and reading, or the study of literature, or speech, or listening. The term "basic writer" is used with wide diversity today, sometimes referring to a student from a highly oral tradition with little experience in writing academic discourse, and sometimes referring to a student whose academic writing is fluent but otherwise deficient. To help readers therefore, authors should describe clearly the student population which they are discussing.

We particularly encourage a variety of manuscripts: speculative discussions which venture fresh interpretations; essays which draw heavily on student writing as supportive evidence for new observations; research reports, written in nontechnical language, which offer observations previously unknown or unsubstantiated; and collaborative writings which provocatively debate more than one side of a central controversy.

A "Mina P. Shaughnessy Writing Award" is given to the author of the best JBW article every two years (four issues). The prize is $\$ 500$, now courtesy of Lynn Quitman Troyka. The winner, to be selected by a jury of three scholars/teachers not on our editorial board, is announced in our pages and elsewhere. 


\section{EDITORS' COLUMN}

Some time back in the process of putting it together, we started calling this our "dialogic" issue: so many of the pieces highlighted conversation, dialogue. Now it is of course a truism that articles in writing journals are "conversations," even "conversations about conversations." But this is true of the articles assembled here in such extraordinary ways that it behooves us to say why. So let us count the ways.

It hits you with the first word of the first article's title: "Dialogizing Response in the Writing Classroom: Students Answer Back" by Pamela Gay. Though "Dialogizing Response" may seem to court redundancy, Gay shows how, on the contrary, students experience teacher commentary and evaluation as a silencing, a pre-emptive strike on their own thinking about their success, even their intentions. Left unarticulated, students' reactions to teachers' responses can have little impact on our work, much less theirs, but Gay challenges us to hear the responses to our responses, to let students talk back to feedback.

Feedback plays a crucial role in "Basic Writing: Curricular Interactions with New Technology" by Susan Stan and Terence G. Collins: beginning with an expansive view of how technological developments and pedagogical change have paralleled each other, Stan and Collins are not content to describe technological innovations and trace general trends in their use (though that, surely, would have been helpful enough); they use their nationwide survey to identify specific practices, successes, and needs. Instructors who have made the technology work for their basic writing students-and also those who need help to do that - get a voice in this article.

Voices that might go unheard include unarticulated silences, resistances to giving voice to certain kinds of thought. Candace Spigelman's "Taboo Topics and the Rhetoric of Silence: Discussing Lives on the Boundary in a Basic Writing Class" gives particular attention to what students don't want to talk about. Mike Rose's important book gave rise to some very effective discussion and writing from her students, but Spigelman is particularly interested in the critical point at which discussion shut down, the conversation stopped. And she engages Mike Rose in a conversation about what to do to get it going again.

"Mediated Texts: A Heuristic for Academic Writing," by Eileen Biser, Linda Rubel, and Rose Marie Toscano, is about translating -in literal and significant ways - student conversation into academic prose. Seeking accommodations for their deaf students, the authors have developed a means of having students talk through a second draft with an interpreter, working from that transcript to develop a final version. Though this talking is in American Sign Language, Biser, Rubel, and

DOI: 10.37514/JBW-J.1998.17.1.01 1 
Toscano suggest and even spell out the relevance and power this "talking through" stage can have for basic writing and ESL students.

"Talking through" might also be a powerful heuristic for academic scholarship, something we find borne out by the outcome of what we think is a very successful experiment. We were so impressed with panel presentations of some graduate students in composition and rhetoric (and with their conversation afterward) that we invited them to hold an online, potentially publishable discussion of the issues that most concerned them and their basic writing students. The result, "Assessing Our Assessments: A Collective Questioning of What Students Need-And Get," is a rich, probing, provocative conversation, one that ought to be a source of pride to the participants: Elizabeth Bruna, Ian Marshall, Tim McCormack, Leo Parascondola, Wendy Ryden, and Carl Whithaus.

Talk among colleagues is one thing, Harvey Wiener reminds us, and productive talk with those outside the academy is quite another. His "After the Attack on Basic Writing - And After" analyzes the vituperation and misunderstanding visited on basic writing in politics and the press, typically under the banner of "standards." Wiener, who once held the City University deanship created for and by Mina Shaughnessy, carefully articulates how the field of basic writing has been misrepresented by those on the outside and inadequately represented by those of us within, too quiet about our successes, too inattentive to public perceptions, too busy with specific students and classes to put together the kind of data that would defend an educational enterprise now so generally assailed. Reviewing controversies so recent only deadlines could keep headlines from becoming more new sources, Wiener has given us some bracing predictions about the changes the field of basic writing will likely see before long.

Our last piece continues a conversation started by its author, Ira Shor. In last spring's issue of $J B W$, his article "Our Apartheid: Writing Instruction and Inequality" provoked considerable discussion, including two written responses submitted to JBW, one by Karen L. Greenberg and one by Terence G. Collins. Here, Shor responds to those responses, and in a way that ensures that, not just for these three scholars but for all of us, the thinking and the discussion will go on. Since the conversation is about whether basic writing (less as a field of scholarship than as a site of instruction) will go on, that much, at least, is reassuring. And it is emblematic, in a way, of all the conversations (about conversations) in this issue. Taken together, they constitute an important promise to all of us associated with basic writing. Rife with perils, beset by threats, basic writing is also productive of some of the best teaching practices and the best thinking to be found in any field. The pieces gathered here offer a compelling testimony to that, and they promise that the conversation(s) will continue. 
Pamela Gay

\title{
DIALOGIZING RESPONSE IN THE WRITING CLASSROOM: STUDENTS ANSWER BACK
}

\begin{abstract}
While informed teachers of writing have moved toward more dialogic approaches, "we" still have colonial tendencies when responding to student writing. While students are addressed by the teacher, they are not generally expected to answer back, except in the form of "better" writing, and certainly not to talk back. Drawing on the work of Mikhail Bakhtin, Gay suggests that if we are going to help students understand the dialogical nature of language, then perhaps they should take up our words as we take up theirs. Based on her observations of students' initial reactions to teacher commentary, Gay suggests an activity that invites students to talk back to the teacher-reader as a means of helping them move more effectively toward revision. Dialogizing response, however, requires teachers to become dialogized. Gay wonders how many will take the risk: teachers may be more resistant than resilient.
\end{abstract}

Every word is directed toward an answer and cannot escape the profound influence of the answering word that it anticipates.

M.M. Bakhtin, "Discourse in the Novel."

The Dialogic Imagination

Any utterance - the finished, written utterance not excepted-makes response to something and is to be responded to in turn. It is but one link in a continuous chain of speech performances.

\author{
V.N. Voloshinov/M.M. Bakhtin, \\ Marxism and the Philosophy of Language
}

Informed teachers of writing have moved toward ever more collaborative/dialogic approaches; however, we still have colonial tendencies when assigning and responding to student writing - to students, to them. While we have progressed more in responding to writing (through multiple drafts, writing workshops, and portfolios) than

Pamela Gay is Associate Professor of English and Women's Studies at Binghamton, State University of Newv York, where she directs Writing Across the Curriculum. She was formerly Director of Basic Writing and has published a textbook Developing Writers: A Dialogic Approach (1995) as well as numerous essays in professional journals and anthologies. She is currently exploring the problems and possibilities of cross-cultural Internet-based classroom communities. E-mail: pgay@binghamton.edu 
we have in assigning, which is still largely viewed as the teacher's sole responsibility, we still have a ways to go.

Students write in response to an assignment. They "answer" (to use Bakhtin's term) in writing, and teachers frequently answer back in the form of written commentary. Teachers expect an "answer" to their remarks in the form of "better" writing. Sometimes before this writing is produced, there is a conference in which a student seeks some clarification or further direction. A student may even argue a point or express feelings caused by the teacher's commentary. The teacher acts or performs her role as someone who must "answer" student writing, and the student reacts to the teacher's action.

More often than not, however, teachers do not know how students have answered or responded to their comments beyond the writing that students subsequently produce. Sometimes we look at their writing and wonder whether they even read our comments or whether they misread them. Sometimes we joke about all the time we spend on commenting and how useless this work seems. We imagine students crumpling our words and tossing them into the wastebasket. We also know students talk to each other about teacher responses to their writing. WHAT IF students answered back to the teacher in the classroom space rather than behind her back in the institutional hallway?

\section{Classroom Scenes}

[Writing workshops] are, like any social situation, multifaceted, shifting scenes full of conflicting and contending values and purposes, played out by a cast of unique actors - students, teachers (and observers). These performers view the ongoing scene from their own shifting perspective within it, as they negotiate their identities amid the cacophony of voices and social roles around them.

Joy Ritchie "Beginning Writers" (153)

\section{Scene 1}

Lisa's students looked disgruntled while reading through her remarks to what must have been at least a second draft. I was puzzled. Lisa was a state-of-the-art commenter. After listening to the sighs, groans, and silences, I encouraged everyone to begin writing back to Lisa. I noticed that the rough-typed drafts ran about five pages. Students had done considerable work. This particular assignment was also difficult, involving quite a process before writing and then rewriting. The assignment required them to locate two different news reports of the "same" event and then examine how choices of language and of material to include or exclude in each report biased their reading. ${ }^{1}$

"I worked so hard on this," one student shook her head, ignoring 
the encouraging remarks in the commentary and instead focusing on the questions she raised. This student wanted to be done with her work. She didn't want thoughtful commentary. She didn't want to revise any more. Another student grumbled, defending her point of view and arguing with Lisa, though already beginning to surrender to The Teacher as she had undoubtedly been conditioned to do through her years of schooling.

What seemed most important, especially given the difficulty of the assignment and the late-draft stage, was for the students to be given some "vent" or reaction time. I shuddered to think what their revisions would have looked like without going through a process of reaction to revision. What would have happened if their drafts had been returned at the end of class and they had been left on their own, as is most often the case in classes across the curriculum?

"The two news reports weren't that different," one writer told me after her initial reaction. Taking this statement as a signal that she was ready to move toward revision, I asked her to read to our small group her findings. She had detailed very well the different choices of language in each account and a number of differences in what was selected for inclusion, helping me see these news reports as quite different. This writer, however, hadn't backed away from the close work of her research to look from a new, informed perspective. In this draft, the writer had spent much time, head down, scrutinizing the news reports. Understandably, she wanted to be rewarded for this effort. While Lisa had praised this student for her work, she had also pushed her to consider how the inclusion and exclusion of information affected a reader's reading of the news. After venting her frustration with sighs and complaints and taking another look at her instructor's commentary, this writer was able to move to another level of revision. Sitting and listening to her and members of the group interact, I felt I had witnessed an important development in this struggling writer's life, and as a teacher, I learned from her the importance of engaging students in response.

\section{Scene 2}

I learned still more when I visited another TA's class. Laura was having some problems with several students who were basic writers. After talking several times about the increasing resistance of her "problem" students, Laura asked me to visit her class so that I could see for myself. In a memo to basic writing instructors for discussion at our next meeting, I wrote the following:

If you make written comments on drafts and ask students to revise, try asking students to write back to you during class when you return these drafts and comments. No matter how 
good you are at commenting, students (who are not confident writers, remember) will probably balk at some of your comments. They may get upset because they worked hard "and look at all these comments!" They may get defensive ("She doesn't understand. I wasn't saying that. I-"). They may get angry and slam their papers down. They may feel discouraged, perhaps thinking they were done and now they have to write more ("I don't see why I have to-"). You will be surprised I think at how students respond to our written comments and how they perceive "us." I think it's best to have students respond to the written responses immediately upon receiving them so they can react first and then you can help them move toward revision. I would be glad to visit your class when you try this out and work with you.

Laura suggested we try out this activity. As in Lisa's class, I would sit with the resistant students (who always grouped together). I would see close-up how they were engaging with her through their response to her written commentary.

Laura returned the second drafts of the "Reading the News" project, the same assignment Lisa's students had been working on, and she gave the same instructions. Initially everyone in all three groups began talking rather than writing, but my group resisted writing the longest. When I urged them to begin, several reluctantly began writing. "I'm just going to follow what she says," the student to my right said to me, as if this were a waste of time. "I find her comments helpful. I don't mind," another student piped up. A student across from me sputtered, "This looks like a Christmas tree" and let a computer printout of her draft decorated with comments fall dramatically over her desktop. Once again this response seemed surprising given that, like Lisa, Laura wrote thoughtful commentary. If anything, she was perhaps too considerate and accommodating. I knew that she had spent a long time reading and reflecting on each draft, writing helpful comments and questions in the margins and a final, brief, personal letter aimed at helping students revise.

Tanya, the student to my left who had estimated that the teacher spent ten minutes reading and commenting on her draft, was busy writing. Across from me another student stared, not even attempting to take out a pen or find piece of paper to write on. I broke her stare: "Do you need a piece of paper?" I asked matter-of-factly. "I don't have a response," she shot back. "That's a response," I replied, handing her a pen and paper. "Write that." And she did. When it was her turn to read aloud to the group, she read, "I don't have a response." When I questioned her about why she wrote that, she explained that the teacher had a different interpretation of an article: "I just see it 
differently," she shrugged, reminding me of the students who defend their work with "That's just my opinion." I knew, however, that this student hadn't explained her viewpoint well, that Laura was prodding her to do so, and that Laura would not impose her viewpoint on a student. Still, this student read the teacher as arguing for "her" opinion. What was going on? I wondered.

When Tanya's turn came to read her response, she burst out with how upset she was about her mid-course portfolio evaluation. She had gotten an "A-" and she wanted an "A." She wanted all "A's" in college: "I WANT A's," she announced loudly. She was very frustrated about writing: "I write and rewrite and it's never good enough. There's always more, more. I go to the Writing Center and they don't fix anything. They try to help me find my own mistakes. I don't have time. I'm happy with this draft," she exclaimed, slapping the palms of her hands down on her paper. "I don't want to read all these comments after I did all this work. It's frustrating. I hate writing. I hate this class!"

During this scene, the student to my right was reading over her teacher's comments and making notes. The Student Who Had No Response was writing a "P.S." to her response to this teacher and making an appointment to see her. I looked at the draft of the angry, frustrated student.

I asked Tanya to read one paragraph aloud to the group along with her teacher's suggestions for rewriting. She had made a point and then given examples. Her teacher had praised her for what she had done and then tried to push her to use the examples to argue her point. Angry, Tanya explained to me what she was trying to say in this paragraph and how and why she was using these examples. "What you've said is what you need to put in your essay," I replied. "That's an 'A."'

\section{Teacher Commentary}

Most students, perhaps because of years of following teacher directives, tend to read teacher commentary as monologic or what Bakhtin refers to as "authoritative discourse," not to be questioned (or answered). In fact, Bakhtin's only reference to teachers is as spokespersons of authoritative discourse. The teacher's "utterance" is not usually treated as provisional or open to response (See Hunt 259; Klancher 93; Welch 500). Although audiences, even captive audiences, as Leith and Myerson explain in The Power of Address (1989), are seldom, if ever, inactive participants, most students do not speak back/up. They are addressed by the teacher but are not expected to answer back and certainly not to talk back. (One possible exception is a dialogue begun by 
a student's reflection letter to the teacher-reader that accompanies a portfolio. As with any tool, however, the use of portfolios does not assure authentic dialogue.)

What prevents students from being active participants, particularly from "talking back"? The work of Leith and Myerson can offer us insight into the context that makes establishing authentic dialogue difficult, namely when they discuss "performance." While the term "performance" tends to evoke the theatre or concert hall or even the lecture hall, Leith and Myerson take a rhetorical view of performance as a speaker addressing an audience: the lecture is "framed" in a distinct arrangement of space such as the lecture hall in which students gaze at the lecturer. Framing can occur, however, in other situations. Even in a workshop setting, teacher commentary, as performance, is usually viewed as markedly different from student or peer commentary. The teacher, as Paulo Freire has continually pointed out, is still the teacher. There is a shared expectation that the teacher will, more or less, direct.

Performance, Leith and Myerson continue, may also be seen as "privileged acts of utterance, ones which ... attract a level of attentiveness not accorded less focused kinds of interaction" (6). Part of the privileging, they argue, derives from the status of performers themselves. Teachers, for example, are cloaked with institutional authority. Even if a teacher uses state-of-the-art commentary (e.g., comments that are written in response to students' letters about their essays), teacher power remains merely disguised unless students find an authentic way to really answer back, unless there is some genuine to-ing and fro-ing.

When we write or speak, generally we expect to be understood, or we wouldn't even attempt dialogue. We imagine, at least for the moment, that we are going to be understood. We imagine, according to Bakhtin, a higher-order or ideal response. (When we comment, we perhaps have in mind a "Yes, Socrates"-type dialogue.) We seek what Bakhtin calls "responsive understanding": "Every dialogue takes place ... against the backdrop of the responsive understanding of a present but invisible third entity hovering above all the participants in the dialogue (the partners)." (See Todorov 305-6). This "super-receiver" absolutely understands. Rather eerie, isn't it? Perhaps our dialogue is a little more crowded than we thought. ${ }^{2}$

\section{Dialogizing Response}

How can we turn students into speaking subjects whom the teacher actually hears, who, in turn, increasingly authorize their writing performance? How can we dialogize teacher/reader-student/ 
writer response and move students out of the hostile receiver role to become active, willing participants? How can we address each other?

Kathyrn Evans (1995) has proposed a model of communication that capitalizes on "interpretive difference" as a learning opportunity. For example, a teacher confronts a student with a problem. Teacher: "Please indicate your sources." (You will have a "better" paper.) But, as it turns out, the student's fear of plagiarism prevented her from using sources. (That's really the problem.) The teacher and student then discuss this problem. Usually, however, we are not even aware of what's going on (in the absences and silences). That's the real problem.

The model Evans proposes would replace the "problematic" model of communication that (1) views moments of interpretive difference as "aberrations, failures, or stopping places"; (2) bases the "success" of our response primarily on whether or not the student has "understood" our intended meaning; (3) has no way of monitoring whether students have received our intended meaning; and (4) blames students for not "understanding" or applying what we tell them. Furthermore, this model assumes that we have received the student's intended meanings and thus have correctly identified the student's "problem," which brings "us" back to the colonizing "What's their problem?" Our response practice, Evans argues, should be based on a more productive model of communication in which we see moments of interpretive difference as "normal" and we don't assume that students receive our intended meanings and that we receive theirs. We need to become aware of interpretive differences and then to account for the differences.

How can we uncover interpretive differences? Evans suggests we actively solicit information. Why do we think what we do? Why do students think what they do? What's really going on? One way to find out, at least to some extent, is to invite students to initiate a discussion of their writing by asking them to write an accompanying letter. They write about their specific goals, their own views about the quality of their writing, some evaluation of their writing process, and what they'd like the teacher to focus on in response. Indeed, as Evans recognizes, this practice, especially with the increased use of portfolios, is not uncommon. What Evans is advocating, however, is a model of communication that informs practice: "Not just any kind of conferencing, cover letter, etc. will be optimally effective. Less effective will be response sessions informed by the implicit assumption that communicative problems are rooted in interpretive difference itself, rather than in lack of awareness of interpretive difference." She suggests finding ways of giving students a chance to respond to teacher commentary, such as writing responses to teacher responses.

Let's return then to the Student Who Had No Response from 
Classroom Scene 2. You'll recall that she believed her teacher had and required a different interpretation. You may also recall, however, that it soon became apparent from her response in her small group that she was frustrated by the amount and kind of work she was actually being required to do in college, especially with regard to writing. That is quite a different problem, one crucial to uncover not only for her development as a writer but, even more important, for her survival as a student. This seemingly defiant student is caught in a struggle about more than her writing and about more than competing and colliding voices. It appears that she is trying not only to construct her "own" evolving voice (to authorize herself) but also to negotiate (navigate?) the voices she hears (and the teacher's voice is powerful) while she is struggling to enter a relatively foreign academic culture. No wonder she feels at sea.

As Andrea Lunsford put it in her opening address at the (1995) NCTE Conference on Assigning and Responding to Student Writing, “We've got to start looking at the 'between' - the relationship between teacher and student.... We need more inclusive and expansive ways of responding to student writing, ways not so easily commodified." 3 We need to find various ways of dialogizing response- of de-privileging, as best we can, teacher commentary - we need to find more ways of making the process of revision more interactive. ${ }^{4}$

Ewald (1993) argues that it is our responsibility to introduce dialogism into our classrooms. "To be answerable" within Bakhtin's concept of addressivity, explains Ewald, requires us to consider the other," "to be aware of the differences between our responses ... and those of others" (342-343). Teaching writing within a framework of answerability could include some articulation of what's going on behind our responses to student writing. We could put our words sideby-side and talk back and forth with our students rather than "hold forth."

How can we as teachers find ways to provide "talk-back" opportunities for our students? For some students (first-year, and basic writers in particular) we might include some means of reaction (some reaction time) as one movement toward revision. Based on my experiences working with Lisa's and Laura's students, I created the following "talk-back" assignment. ${ }^{5}$ It appears here in the form of a handout to students.

Students could use this "talk-back" form as a guide for talking with their teacher-reader and peers about their writing-rewriting process. Student responses could be used for in-class discussion or follow-up conferences or a combination of the two. My students now publish their work on the Internet, and commentary (teacher and peer) can be attached to drafts. I ask students to e-mail me back a response to my comments and then we talk further. As an exercise, I asked 


\section{Responding to Teacher Commentary: Talking Back to the Teacher-Reader}

Directions: (1) After reading my comments on your draft oncethrough, write a few lines describing your overall response. What's going through your mind? What is your first response? Write openly what you are actually thinking and feeling and saying to yourself, not what you might say in a conference in the teacher's office a day or two later.

(2) Respond to each response. Copy the remarks or marks and set it up as a script or dialogue.

Example

Overall Response:

Teacher:

Student (Use Your Name):

Teacher: \& so on.

What kind of responses? Respond as you actually do when reading each mark or remark by the teacher. Here are some possibilities:

VENT Vent your feelings (frustration, excitement, anger, and so on) and explain why.

COUNTER Argue a point/defend. Raise questions, con -cerns.

QUESTION Ask for clarification, information, or for further direction.

EXPLAIN Explain why you did or didn't do somethingor your different understanding.

NOTE Note something that you need to look up or remember or that you want to think about more before you rewrite. 
graduate students in a "Teaching Writing" course to find an old paper with comments that they would like to have addressed and write a letter to the teacher (just to air in class, not to send). I don't know why I was surprised by the strong responses of these graduate studentsteacher commentary is powerful. These teachers never knew how these students felt and what they had to say back.

Dialogizing response requires not just recognition of interpretive differences but a more complex recognition and "admission" of multiple voices, the multiple voices of our many selves and of the many "others" who are audience to our texts. Thomas Recchio (1991) recommends we do a Bakhtinian reading of student writing "with an eye toward locating the multiple competing and/or intersecting discourses" in order to help students negotiate the claims of each "as they work toward developing a consciously critical point of view on what they read through what they write" (447). Nancy Welch (1993) asks us "to listen and speak to a student's many voices during 'the complicated process of making the word one's own'" (497). She suggests having students keep writing logs in which they reflect not only on their writing but also on their readers' responses.

Robert Schwegler (1995) recommends we make students aware of our many voices when we respond and that we curb the urge to unify our responses as teacher authorities. No utterance, to draw on Bakhtin again, is single-voiced, including the teacher as reader. Helping students realize that there are differences not only between readers, as they discover in a writing workshop, for example, but also within a reader can help with the ongoing process of becoming writers.

Let's look at another developing writer at work. Student writer Ricardo Sewell wrote a narrative about several incidents of violence he witnessed on Easter in New York City. ${ }^{6}$ At the end of his account, I imagine he paused and listened to some teacherly voice: "You need to write a conclusion now. You need to sum this up." He then wrote the following:

Easter just isn't the same anymore in the city. It is not a religious holiday anymore. I don't look forward to Easter anymore like I used too. Now I wish they will just get rid of the holiday completely in the city. Maybe if they get rid of it some of these innocent people won't get robbed or killed. This is one holiday that I won't ever enjoy again.

Of course, there are other voices at play here. There's the voice of Ricardo growing up and looking back to his childhood: his life isn't the same. There's also the voice indicating Ricardo's awareness that 
life everywhere isn't the same. Not only Ricardo's world but the greater world has changed: religion isn't as powerful a force as it once was, and violence has increased. I imagine still another teacherly voice intruding and Ricardo's reply: "I must offer some solution to the problem I presented." But how can Ricardo possibly write a tidy conclusion? As Lester Faigley asked me in the margins of an earlier version of this essay, how can he accomplish what American society has failed to accomplish?

Both the student-writer and the teacher-reader might (to quote Welch again) "hear the authoritative voice that says all essays must come to a neat and complete close and the internally persuasive voice that says this is an experience and an expression of it that are not so easily ended" (498). A Bakhtinian reading, Welch explains, encourages "both teacher and students to listen and speak back to their dialogically-charged words" (498). A Bakhtinian dialogue can begin with the teacher asking a genuine question, which, Welch qualifies, is "not a prescription masquerading beneath a question mark" (498), such as "Ricardo, how could you improve your conclusion?" Rather, a genuine question "has the heuristic power to awaken new words and evoke response: it also highlights writing, reading, and responding as communicative activities and points to the kinds of confusion, interest, and desire for further thinking and discussion that accompany the act of communication" (449).

I could then respond to Ricardo's conclusion by making him aware of the competing voices I myself hear. I might sympathize with his dilemma and pose the problem of tidying up what can't be tidied. Then he could answer back. Perhaps the move away from writing a "school" conclusion to engaging with a genuine reader would enable him to converse with his own many voices and eventually to authorize his experience:

[I]f both teachers and students use descriptive, dialogic responses - sharing reactions, asking questions, dramatizing the complex and evocative interplay between reader and textthey construct an internally persuasive discourse that is creative, communicative, and productive. Through such conversations with a number of readers, students can begin to resist and revise the belief that the teacher's voice is the only voice that is backed by authority and must be obeyed. (Welch 500)

Welch also brings up the problem of what we mean by "improvement" or "better" writing, a problem we have addressed off and on in composition studies and one we need to keep talking about. Ricardo's revised conclusion is likely to be unfinished and may even be more contradictory than his first draft. He may even let in (or out) more 
voices. Should we teach him to conceal this dialogic tension, cover up contradictions, and fake coherence? Or should we encourage him to keep going (read: growing)? "It is through this continuing dialogic and revisionary process," answers Welch, "that students grow as critically aware writers, readers, and learners" (501).

\section{A Borderline Conclusion}

Language ... lies on the borderline between oneself and the other. The word in language is half someone else's.

M.M. Bakhtin,

("Discourse in the Novel" 293-4)

We've come a long way in responding to student writing since the colonial (products-only) period, and we've come along since the early "process" days in the late 1970s. A teacher's response will probably never be just another response or voice. However, if we are going to help students understand the interactive, dialogical nature of language, to develop what Comprone (1989) calls "dialogic literacy," then perhaps they should take up our words as we take up theirs. We need to encourage a new kind of student resistance that challenges, interrogates, and interrupts the flow to tidy closure in the ongoing struggle for power.

"The change," Ewald warns, "will not come easy." Echoing Mina Shaughnessy (1977), Ewald writes, "Simply reconfiguring seating arrangements, introducing interactive activities into syllabi, and promoting a classroom environment that fosters collaborative learning will not necessarily alter the monologic patterns of discourse used in the large circle, the small group, or the peer team." Ewald continues, sounding now more like bell hooks ("there are always colonizing tendencies"): "Indeed, students (and instructors, for that matter) may simply repeat old patterns of monologic discourse in these new settings. Teachers may find it difficult to break out of the old molds, even when they want to do so (344) ${ }^{7}$ And even if classroom communities open up to dialogic uses of language, how prepared are teachers for this change?

Opening up our classrooms to multiple voices may not produce the "hum" of heteroglossia that Ritchie (1989) imagines. While, as Ritchie says, "the tension students experience as they attempt to articulate their ideas in the midst of conflicting and complementary values ... provides rich opportunities for growth and change," this tension, this after all, dialogic tension, may be unsettling not only for students but for teachers as well.

To dialogize response requires teachers to become dialogized, which means, as Klancher (1989) put it, exposing ourselves "to the risk 
and surprise of heteroglot encounter" (93). But how far are teachers prepared or willing or even able to go? Are we fully prepared to dialogize response and lose all privileges? We may find that teachers are more resistant than resilient.

\section{Notes}

1. They were working on the "Reading the News" project from my textbook Developing Writers: A Dialogic Approach (Belmont, CA: Wadsworth, 1995).

2. Robert Schwegler (1995) points to a possible further complication. He suggests that the teacher-reader responds to an inferred author based on a reading of not only the immediate text but on memories and perceptions of previous student texts. What writers do we infer when we read? What kind of a writer/author is this? a teacher, consciously or not, might ask when reading student writing.

3. In her keynote address at the 1996 Commonwealth Women Writers' Conference in London, Susan Bassnet also stressed the importance of "in-between" as a location. "The discourse of colonialism ignores the threshold. There is no pause in the crossover," she said. What if we viewed "between-ness" as a liminal space and a desirable place to be?

4. "One strategy for encouraging thoughtful responses to feedback is to require students to write a revise-and-resubmit letter, analogous to what scholars produce when they submit a revised manuscript to a journal after receiving reviews. In such letters, writers systematically review the feedback they have received, explaining how they have addressed the readers' comments and why they may have disregarded some of them" (Ferris 331).

5. This activity is similar to "inkshedding," a strategy I first learned about at a poster sessions at the 1995 Computers and Writing Conference in El Paso, Texas. At the 1994 conference, after listening to a speaker, the audience was invited to respond informally in writing immediately afterward. These responses were shared at the moment, then photocopied and made available for further discussion, and later discarded. Interestingly, when I asked why inkshedding wasn't being used again, I was told that some of the presenters had found it upsetting. Hunt (1994) has also written about this strategy as a way of getting students "to use written language in dialogic ways" (248). Hunt believes, incidentally, that the word "inkshedding" is originally from Carlyle but says he owes the word to his colleague Jim Reither. There's 
even an annual Inkshed conference! according to Hunt. I use computer-networked discussions as variations of what I can now call "inkshedding."

6. His essay "New Easter" appears in full in Developing Writers: A Dialogic Approach (Belmont, CA: Wadsworth, 1995).

7. See Bleich's critique of the monologic classroom that fixes the roles of teachers and students "by not allowing language use in the classroom to change the class" (his emphasis), cited in Ewald's essay. David Bleich. The Double Perspective. New York: Oxford UP, 1988.

\section{Works Cited}

Bakhtin, M.M. "Art and Answerability," in Art and Anszuerability: Early Philosophical Essays by M. M. Bakhtin. Trans. Vadim Liapunov. Ed. Michael Holquist and Vadim Liapunov. Austin: U of Texas P, 1990. $1-3$.

- - - "Discourse in the Novel," The Dialogic Imagination: Four Essays. Trans. Caryl Emerson. Ed. Michael Holquist. Austin: U of Texas P, 1981.

Comprone, Joseph J. "Textual Perspectives on Collaborative Learning: Dialogic Literacy and Written Texts. ." The Writing Instructor 8 (1989): 119-128.

Evans, Kathyrn. "Rethinking Response, or, Interpretive Difference as Opportunity." NCTE Conference on Assigning and Responding to Student Writing, Colgate University, Hamilton, New York, August 1995.

Ewald, Helen Rothschild, "Waiting for Answerability: Bakhtin and Composition Studies." College Composition and Communication 44 (1993): 331-48.

Ferris, Dana R. "The Influence of Teacher Commentary on Student Revision," TOESL Quarterly 31 (1997): 315-337.

Gay, Pamela. Developing Writers: A Dialogic Approach. Belmont, CA: Wadsworth, 1995.

Hunt, Russell, "Speech Genres, Writing Genres, School Genres, and the Computer," Learning and Teaching Genre. Ed. Freedman and Medway. NH: Heinemann-Boynton/Cook, 1994. 243-62.

Klancher, Jon. "Bakhtin's Rhetoric." Reclaiming Pedagogy: The Rhetoric of the Classroom. Ed. Donohue and Quandahl. Carbondale: Ill: Southern Illinois University Press, 1989. 83-96.

Leith, Dick and George Myerson. The Power of Address: Explorations in Rhetoric. London and New York: Routledge, 1989. 
Lunsford, Andrea. "What Matters Who Writes? What Matters Who Responds? Issues of Ownership in the Classroom." NCTE Conference on Assigning and Responding to Student Writing. Colgate University, Hamilton, New York. August 1995.

Recchio, Thomas. "A Bakhtinian Reading of Student Writing." College Composition and Communication 42 (1991): 446-454.

Ritchie, Joy S. "Beginning Writers: Diverse Voices and Individual Identity." College Composition and Communication 40 (1989): 152-74.

Schwegler, Robert. "Responding to Students, Texts, and Errors." NCTE Conference on Assigning and Responding to Student Writing. Colgate University, Hamilton, New York, August 1995.

Shaughnessy, Mina. Errors and Expectations: A Guide for the Teacher of Basic Writing. NY: Oxford , 1977.

Todorov, Tzvetan. Mikhail Bakhtin: The Dialogical Principle. Trans. by Wlad Godzich. Minneapolis and London: U of Minnesota P, 1984. Voloshinov, V.N./ Bakhtin. Marxism and the Philosophy of Language. Trans. by L. Matejka and IIR. Titunik. New York: Seminar Press, 1973.

Welch, Nancy. “On Student's Many Voices: Reading, Writing, and Responding with Bakhtin." Journal of Advanced Composition 13 (1993): 493-502. 


\title{
Susan Stan and Terence G. Collins
}

\section{BASIC WRITING: CURRICULAR INTERACTIONS WITH NEW TECHNOLOGY}

\begin{abstract}
Based on a survey of Basic Writing teachers across the country, this article reports a variety of ways in which developmental writing curricula have been changed by introduction of new technologies. The authors present findings related to classroom practice, teacher development, and distribution of resources. In Basic Writing and developmental writing sites, several general patterns of computer use emerge: resistance, lack of infrastructure, uneven access to professional development among staff (many of whom are temporary or part-time), and lack of visibility for successful efforts. In addition, isolated successes and imaginative implementations of emerging technology are reported.
\end{abstract}

This essay surveys the interactions among Basic Writing students, Basic Writing curricula, and new technologies in higher education. We began the project with the goal of identifying curricular transformations which had occurred as a result of such interactions. ${ }^{1}$ Rather than a single set of transformations, what we found in our survey was a landscape of basic writing instruction dotted with a variety of curricular transformations. Some of these involved new technologies. But it is not likely that these transformations occurred as a result of the technologies which are featured in them. Rather, it is more likely that several factors - the historical confluence of reform in Composition Studies, the availability of new, relatively inexpensive computer and networking technology, and Basic Writing's growth in sophistication over three decades of open-admissions - have sponsored a great deal of change in the writing curriculum for developmental students, change involving a variety of technologies and uses.

Susan Stan is completing her seventh year as an instructor in the Basic Writing Program in the General College at the University of Minnesota-Twin Cities. In addition to her focus on technology and writing, she is a specialist in literature for children and young adults. In the fall of 1998 she will join the English faculty at Central Michigan University in Mt. Pleasant to teach composition and children's literature. Terence Collins is Morse-Alumni Distinguished Teaching Professor of Writing and Literature in the General College at the University of Minnesota-Twin Cities, where he is Director of Academic Affairs and Director of the Center for Research on Developmental Education and Urban Literacy. He has written about basic writing, writers with disabilities, and computers and composition. 


\section{Background}

The emergence of Basic Writing as an area within postsecondary developmental education is more or less coincidental with the rise of "computers and writing" as a branch of Composition Studies, so such interactions might have been expected. Indeed, both Basic Writing and computers-and-writing emerged as areas of study during the 1970s, at a time when the very nature of writing instruction was being transformed. In that period, the current-traditional paradigm and so-called "product" orientation were supplanted by a range of process pedagogies derived from social constructivist, cognitivist, and postmodernist strands in Composition theory and research (Crowley; Hawisher et al.).

Basic Writing expanded rapidly in response to the social demands for equal access to higher education following the civil rights movements of mid-century. New commitment to access led to new policies of open-admissions in many colleges and universities and resulted in the rapid expansion of open-admissions community colleges to accommodate large numbers of "new students" (Shaughnessy). These new students who entered higher education under open-admissions presented startling opportunities, frequently articulated as problems, for self-critical evaluation of habitual writing pedagogy and for rethinking the goals and content of the Composition curricula.

Research in teaching strategies for basic writing courses called into question the "current traditional paradigm" of Composition, as well as the formalist, belletristic dispositions which were at its center. The profession's examination of how we teach writing resulted in a new set of assumptions in Composition, which have in turn shaped Basic Writing. When the research was boiled down, Composition teachers saw that students across a broad spectrum of backgrounds, in a wide range of institutions, learn how to write best in teacher-directed workshops with structured opportunities for purposeful writing, response, and revision (Hillocks). This general trend in Composition's re-thinking of itself found a hospitable site in Basic Writing. The writing of previously excluded students, many of whom were unpracticed in what had been thought of as college writing, brought into focus the pedagogical flux and the vexing politics of Composition's paradigm shift. In one of her earliest essays, Mina Shaughnessy asserted that within Basic Writing there is an uneasy tension:

The special conditions of the remedial situation, that is, the need to develop within a short time a style of writing and thinking and a background of cultural information that prepare the student to cope with academic work, create a distinctive ten- 
sion that almost defines the profession - a constant, uneasy hovering between the imperatives of format and freedom, convention and individuality, the practical and the ideal. Just where the boundaries between these claims are to be drawn in basic writing is by no means clear. ("Open Admissions" 152)

In positing that this tension "almost defines" the profession of basic writing, Shaughnessy was prescient, for the tension persists. From the earliest reflective practitioners associated with Shaughnessy and her colleagues at City University of New York, through a middle phase of scholarly and curricular "legitimacy" (Bartholomae \& Petrosky), to post-colonial $(\mathrm{Lu})$ and postmodern theorists (Sirc), the emphasis has been on individual students as writers, on their writing, on the cultural dynamics of privilege-and-language, and on situated instruction, with a view of the Basic Writing student as unpracticed and unskilled in composing specific forms of texts valorized traditionally by faculty. Basic Writing is marked, from the beginning, by a struggle between authentic expressionism and institutionally validated, constrained text production (Bartholomae; Stuckey). The tension remains unresolved.

Not surprisingly, within Computers and Writing has run a parallel version of the tension between authenticity and constraint to which Shaughnessy pointed. While introducing revolutionary technologies into Composition classrooms, writing teachers have struggled with the implications of their acts, as documented in any number of places, from the archives of the Alliance for Computers and Writing listserv (http://english.ttu.edu/acw/acw-l), to the history of computers and writing chronicled in detail by Hawisher, LeBlanc, Moran, and Selfe. A ready example is the way computers used in networked modes have been central to the promotion of social constructivist writing pedagogy and the emergence of new textual forms. The ways students write (alone? in groups? with face-to-face colleagues? with associates at a distance? from a linear outline? hypertextually? for a private audience? for a world-wide audience?) and what students write (history papers? riotgrrrrl hypertext sex-fem 'zines? course websites?) have been genuinely transformed in the networked setting. At the same time, early adopters of the networked technology which has been the vehicle for this revolution were naive, even quaint, in their expectations that the network would mediate familiar, traditional classroom decorum and controlled discourse (George; Kremers).

These tensions between the revolutionary and the conventional, arising from various uses of computers in writing courses, have been played out very dramatically in Basic Writing curricula. In his evaluation of the ENFI Consortium Project, for instance, David Bartholomae notes that "ENFI" class essays produced by basic writers at the University of Minnesota's open-admissions General College (written in a 
local area network setting which was used heavily for on-line conversations and heuristic questioning) were more engaged, more authentic, and more intellectually vital than were the essays produced by basic writers at the same site in a more traditional classroom ("I'm Talking"). While Bartholomae notes the exciting dimensions of this "counterwriting," as he calls it, he is also quick to assert that some might see the writing produced by the ENFI Basic Writing students as "a threat to academic values." If anything, it appears, some uses of computers in Basic Writing classrooms simply amplify the tension Shaughnessy asserted to be so fundamental to the enterprise.

Yet not all applications of computers in the Basic Writing classroom cause such obvious ambivalence. For instance, Collins found that simple word processing improved the writing of college students with learning disabilities and reduced their writing apprehension. Computers have changed the way writing teachers imagine revision, and text-editing software has made it easier for unskilled or unpracticed writers to address a variety of errors in the surfaces of their texts. Now commonplace, such innovations were truly stunning for Basic Writing teachers and their students in the mid-1980s.

Access to higher education is the challenge to which development of Basic Writing has been, in part, a solution. But access to new technologies among students who are the most disenfranchised in the academy poses further problems. As we surveyed the ways in which basic writers, teachers of Basic Writing, and the Basic Writing curricula have been shaped, even transformed in the presence of new technologies, we were confronted by the simple fact that the dominant form of new, privileging technologies - the small personal computer and its connectivity - is not aggressively integrated at sites where Basic Writing instruction takes place most typically. In its 1996 Campus Computing Survey, for instance, the League for Innovation in the Community College found fairly low rates of access to and rewards for developing meaningful uses of technology in teaching. This is not surprising. Many of the obstacles to Basic Writing on campus are also obstacles to widespread innovation in the curriculum by way of computers. Building programs on the use of part-time and transient faculty, proficiency test-driven curricula which emphasize production of "safe" texts, constrained budgets, vexed institutional standing - all of the familiar forces which limit BW programs - likewise stand in the way of widespread investment in facilities, training, and institutional ecologies which might sponsor transformative practices in the Basic Writing curriculum mediated by strong uses of new technologies.

Yet we were surprised, even sometimes astounded, by the achievements of individual teachers and colleagues in departments who work in Basic Writing. As captured in detail at our searchable website $<$ www.gen.umn.edu/research/currtran>, dozens of site-specific inno- 
vations and transformative practices in basic writing courses are in place in a range of institutions around the country . (We invite your submissions to further this work.) Writing teachers in developmental education sites do not often have support for extensive evaluation and publication of their curricular innovations (Reynolds 3-4). As a consequence, much good work featuring uses of computers and related technology in the developmental writing classroom is realized locally but is not disseminated widely. But it should be. As Bruce argues, all innovation is situated. That is, a curricular approach or a theoretically derived pedagogy will be formed into a local practice as a result of the many-layered reality of the local situation. Whatever generally transforming directions might be discerned across Basic Writing sites where technology is embedded in the curriculum, these directions are realized one classroom at a time, one teacher at a time, in a thoroughly situated instance of Basic-Writing-using-technology. Surveyed below are such developments described in the literature, in syllabi on the web, in personal correspondence - in short, in sources both formal and fugitive. Taken together, they map the rich landscape we've surveyed.

\section{Recent Research}

In an early overview of computer-assisted instruction in the Basic Writing classroom, Lisa Gerrard observed that of all writers, basic writers are the most sensitive to the effects, both positive and negative, of computer technology. Although no single profile defines all basic writers, in general these students are inexperienced at writing and lack self-confidence as writers; in Errors and Expectations, Mina Shaughnessy suggested they be thought of as beginning rather than as poor writers. The basic writer's lack of self-confidence frequently manifests itself as an anxiety toward writing. When asked about their relationship to writing, these students often say, "I can't write" or "I hate to write." Research shows that, depending upon the ways in which computers are used in instruction, this technology can serve to alleviate or even transform a basic writer's anxiety about writing - or it can erode still further a basic writer's confidence.

Relative to the amount of published research about the use of computers in writing instruction, studies that are situated in developmental writing courses and/or focus on basic writers are sparse. And yet some of the most innovative uses of technology have been developed around basic writers. Bruce Horner reminds us that the discourse of Basic Writing, beginning with Shaughnessy, has cast the field as the "pedagogical West," a view that frees teachers to explore and experiment without losing their credibility. The Basic Writing classroom has been the site of much exploration and experimentation with technol- 
ogy, some of which has been documented in the form of journal articles or conference papers or has emerged in the form of new software programs. Specialized listserv discussion groups provide a forum for basic writing instructors to share experiences and expertise. Much information, however, remains unpublished and/or undiscussed.

Both research and anecdotal evidence point to the positive effect of computers on students' attitudes toward writing, and a number of studies specifically focus on the segment of writers designated as developmental or basic. Pamela Gay reviewed eighteen studies conducted between 1984 and 1990 that examined some aspect of using computers in basic writing instruction. The most consistent thread running through the studies was the contention that word processing improves students' attitudes toward writing. Harder to measure were the ways in which writing on a word processor might affect the quality of a basic writer's work. While some researchers reported improvement, others did not, and still others reported mixed findings within the same study (gains in some areas, such as organization, and no progress in others, such as usage).

In search of explanations for such apparent contradictions, Gay looks beyond the results of each study to the instructional methods used by the writing teachers of the student-subjects. The wide range of assignments, lessons, and teaching approaches suggests to Gay that pedagogical practice and theory play a large role in research in this area, affecting not just how students interact with computers in the classroom but also what researchers measure as indicators of improved writing quality.

In a classroom study in which both the instructors and the basic writing students kept logs of interactions (student-teacher discussions about the piece of writing on the screen), D'Agostino and Varone revealed the impact these "in-process interventions" had on the student's writing. As they note, suggestions offered during the writing process are more likely to be acted on, or at least considered, than comments written on a paper after it is returned. Student logs also reminded the researchers that comments and suggestions are not always perceived by the student in the way the instructor intended, and that sometimes a teacher's comments serve to move the writer further away from, rather than nearer to, his or her intended meaning.

Since Gay's review of research on technology and the basic writer appeared, a few more research studies involving basic writers have been published. Batschelet and Woodson's study at the University of Texas at San Antonio was designed to measure the attitudes of basic writers toward writing on computers. Administering questionnaires to an experimental group of students that met in a computer classroom at least $50 \%$ of the time and to a control group of students that met in a traditional classroom the entire time, they found that the atti- 
tudes of both groups of students toward writing - which ranged from ambivalent to negative-remained unchanged at the end of the course. Yet the responses of the students in the experimental group to a separate question about writing papers on a computer revealed a positive change in their attitudes. This discrepancy suggested to the researchers that students appeared to be making a distinction between two activities - the process of writing and their experiences of writing on a computer - which are fused in the minds of experienced writers. A similar study conducted with adult developmental writers (HansmanFerguson) seems to indicate that adult developmental writers, at least, can make the connection between activities; the researcher found that student apprehension about writing decreased after a semester in a computer-based writing course.

In a five-year study of students at Cincinnati University's University College (Meem), researchers compared the work and activities of students writing in traditional classroom settings, students writing on computers equipped with word processing programs (Bank Street Writer II), and students writing on computers equipped with both word-processing and thinking aid programs (Bank Street Writer II and Writer's Helper). While pre-test and post-test comparisons revealed no significant difference in the quality of writing among the three groups, students in the two groups using computers rated both the courses and the instructors significantly higher across the board in their end-of-course evaluations, conforming to the findings of earlier researchers.

One segment of students in the third group, however, did show remarkable improvement in writing quality, although this gain was not enough to make the overall group figures statistically significant. That segment consisted of adult non-traditional students who were placed in the University's Pre-Technology program. Interpreting the results of their study, the researchers speculated that access to Writer's Helper "eliminated the academic disadvantage suffered by most PreTechnology students compared to their traditional counterparts" (66).

Meem's five-year study is unusual. Most empirical research available about developmental writing instruction in a computer environment has been conducted by researchers in their own classrooms over one or two terms only, ruling out the possibility of discovering any longitudinal effects. Because becoming a better writer takes time and practice, researchers have not been surprised when they couldn't document any statistically significant improvement in student writing after a ten- to fifteen-week computer-based writing course. Consistently, however, researchers have been able to identify changes in students attitudes toward writing, and this finding has been generally accepted as a first step toward subsequent writing improvement. Batchelet and Woodson's study serves as a reminder to those of us who teach devel- 
opmental writers that part of our work involves modifying our students' conceptions of themselves as writers - we must help them find ways to integrate the reality of their newfound skills into their outdated self-images as poor writers.

Most writing teachers who advocate the use of computers in the classroom see ease of revision as one of the advantages of writing on a word-processor. Evelyn Posey's findings in a study of basic writers at the University of Texas at El Paso suggested that using computers to compose did not improve the quality of student writing, even though computer users did generate more drafts and share their writing more frequently than those who wrote with pen and paper. Posey challenged teachers to show students how to use the computer in revision so that it becomes more than merely a tool for word processing.

At least one experimental research study has documented improved quality in writing in basic writers. Cynthia Louise Walker's dissertation is based on data she collected in courses taught at East Texas State University. Her purpose was to determine if the revision activities of developmental students would improve (as measured both by quantity and depth of revisions) when revising on screen as opposed to on paper. She structured the study so that the same students would perform revision in both ways: one half of the students revised their first two papers on paper and their second two on screen, while the other half reversed the process. Student rough draft and final papers were scored holistically by independent scorers, and Walker compared the resulting scores. She found that revision on screen improved the paper's score in all but two cases. Students spent more time and more effort on these papers and developed a greater interest in them. They produced twice as many revisions on screen as they did when revising on paper, and their revisions included a greater proportion of meaning level changes.

\section{Software and Networking Applications}

Composing and revising on computers requires only "worldware," word processing programs such as WordPerfect or MS Word originally developed for office and home use, although many specific software programs have been developed to target these processes. As far back as 1979, writing teachers who were also becoming interested in computers were quick to see possibilities for their use in the writing classroom. Some of the teachers who had an elementary knowledge of programming used it to develop software to assist students at certain stages of the writing process.

Among these early programs was WANDAH, an acronym for Writing AND Author's Helper, developed in the early 1980s at UCLA 
by Ruth Von Blum, Michael Cohen, and Lisa Gerrard. WANDAH (renamed HBJ Writer when commercially published) combined prewriting, word processing, and revision features and was used primarily in basic writing classes by students who, for the most part, had no prior experience with computers. Gerrard recalls that the program engaged the students to such an extent that they personified the computer while writing, addressing it, referring to it as her, and even, in one case, including WANDAH in a paper's acknowledgment (97).

Similarly, Writer's Helper evolved out of William Wresch's work with students at a junior college and the "lack of organization and development" he consistently saw in their writing (Hawisher et al. 45). Consequently, the first version of his software combined a group of prewriting programs with a tailormade word processing program and a set of programs to analyze their writing. Writer's Helper and its subsequent revision, Writer's Helper II, have been used extensively and with positive results in high school and college settings. Other prewriting programs developed by writing teachers include two by Helen Schwartz, SEEN and Organize, and Mimi Schwartz's Prewrite.

Writing and thinking aid software does present pitfalls for basic writers, whose insecurity as writers often makes them suspend their own judgment and conform rigidly to whatever rules the computer program presents, no matter what the situation (Gerrard). Yet, as James Strickland observes, "the computer allows teachers of writing to offer a variety of prewriting strategies at the time when most needed-during the composing process itself" (53). For writing aids to improve the quality of student writing, one study finds, they must be used with an element of "induced mindfulness" - that is, a deliberate sense of purpose that can be fostered by the teacher (Hicks). The technique used in this study consisted of instructing students to learn the features of the software well enough to be able to tutor others in the future.

Many learning centers contain tutorial programs designed to teach grammar, spelling, and punctuation, which students use at their own pace outside class time. When used by developmental writers, according to one study, these programs actually cause the number of student errors to increase (Downs and Linnehan). Further, "grammar tutorial programs can encourage disproportionate and premature concern with error correction" (Gerrard 100).

Gerrard's discussion of computers and basic writers, based on research published up to 1989 , focused mainly on such tools as wordprocessing software, prewriting and revision aids, grammar tutorials, and style analyzers. Since then, both local area networks and the Internet have emerged as technologies with classroom application, and sophisticated software programs capitalizing on these and other newly available technologies continue to be developed. 
The potential of local area networks for conducting discussions in writing classes was first recognized by Trent Batson, who termed the application ENFI (Electronic Networks for Interaction) and imported it into his classroom at Gallaudet University in 1985 as a way of enabling his deaf students to converse. Soon after, the software Realtime Writer (RTW) was developed to support this application, and the Daedalus Integrated Writing Environment (DIWE) also incorporated ENFI into its system as InterChange. DIWE, developed by graduate students in composition at the University of Texas at Austin in the late 1980s, was conceived of as an electronic workshop with features designed to facilitate writing and promote collaboration and sharing of texts. Similar in purpose and pedagogical approach is another software package, Aspects.

The benefits of using networked systems with basic writers have been variously enumerated in conference presentations and published articles. Typical of the advantages are those Ethel Russell observed using the Waterloo MacJanet Network in a community college setting: it provided a built-in sense of audience, changed the role of the instructor from evaluator to audience, enabled electronic exchange of messages and distribution of assignments, and enhanced subsequent student collaboration in a traditional classroom setting. Networked discussions also offer some students who have never found a voice in face-to-face discussions the opportunity to speak (Fey). Offsetting these findings are studies that bear a cautionary message, suggesting that sometimes synchronous conferencing, while promoting participation on the part of many students, may cause other students to be further silenced (Rickly; Romano).

Two other software packages, both designed by composition teachers, deserve mention as embodying the workshop approach to writing instruction. Norton Textra Connect, developed by Myron Tuman of the University of Alabama, supports the move toward courses conducted wholly online. The program's strength lies in its classroom management capabilities: instructors can distribute assignments or tailor them to specific student needs; students can exchange papers for peer feedback or post assignments to the network for discussion; instructors can collect assignments online and return them with comments and a grade, embedding optional links to an online handbook where desirable. Students do not have to learn elaborate rules for naming files and keeping assignments straight - the program does it for them.

CommonSpace, developed by Paul LeBlanc while he was teaching at Springfield College, focuses on shared reading and/or writing of texts by providing a multi-column interface. While a main text-a student paper, for instance, or the draft of an article-fills one column, the additional columns can be used for comments, peer feedback, and 
even voice annotations. The software also contains chat and conferencing functions that can be used independently or in conjunction with the document on screen.

StorySpace, a nonlinear program developed by Michael Joyce, Jay Bolter, and John Smith, represents a completely different approach to writing. Joyce, a compositionist and novelist, was looking for a way to create interactive fiction, stories that change with each reading or reader. StorySpace enables writers to create a set of text spaces on screen - boxes that might contain single words, phrases, or whole paragraphs of text. The writer can manipulate them at any point, nesting boxes, clustering them in groups, and connecting any one box to another.

In addition to its use in creating hyperfiction, StorySpace has numerous applications in the writing classroom, as Martha Petry has found. She credits StorySpace with freeing her basic writers from "the tyranny of traditional print." For example, when she is working with students on revising a narrative paper, she turns to StorySpace as a new kind of brainstorming technique. Students use StorySpace to make boxes for attributes of an element of their paper, such as a person or place, and then write the corresponding details in each box. This process allows them to write as much text as they want without being hampered by where it will go; they can later import it selectively into their paper. Petry also finds it helpful to use StorySpace when generating ideas in a discussion, rather than listing ideas in a linear format.

Petry turns to StorySpace not only during writing instruction, but also when she want to model interactive reading processes. She types the first paragraph of an assigned reading into the computer, uses an LCD to display it, and begins reading aloud. With each word, phrase, or idea, she opens a box and asks a question of the students in the darkened room, typing their comments into the boxes as they call them out. In this way, students see what it means to interrupt the text as they read.

Since the mid-1990s, when the World Wide Web became readily accessible to most Internet users through net browsers (Mosaic, followed soon by Netscape and Internet Explorer), it has been viewed with interest by some compositionists. They see it variously as an enlarged audience for student writing (a means of making student writing public beyond the confines of the classroom), as a resource for both conducting research and teaching research techniques, or as a manifestation of an altogether different form of composition, one that uses images and sounds in addition to the written word for effective communication.

Jeffrey Maxson, who incorporated web page projects into one of his basic writing courses, offered the following rationale: 
First, students already possess expertise in understanding and interpreting images, sounds, both musical and otherwise, and video materials. They can in most instances be considered more expert than their teachers in the ways of popular cultural presentation. Secondly, many students, particularly those in the basic skills curriculum, are oriented toward the above means of information presentation much more than they are oriented towards text. ... Hypermedia authorship can thus serve to introduce them to academic literacy through means with which they are familiar. In addition, it teaches them, through handson effort, the similarities and differences, the strengths and weaknesses of each of these modes of communication. Thirdly, these activities are intrinsically motivating, for all of the above reasons and because of the unique nature of the presentations students are able to produce.

His final point speaks to the academy's need as much as to the student's: "Basic writers in particular, by virtue of their not having been successful as students by traditional measures, are uniquely positioned to contribute to the re-visioning of academic literacy taking place with the introduction of new hypermedia communications technologies."

\section{Nationwide Survey}

To assess the extent to which composition teachers are using technology in their developmental writing courses - and to uncover some of the reasons others aren't using technology in the classroom - we conducted a nationwide survey of developmental writing teachers. These surveys were directed at instructors whose names had been supplied by administrators belonging to either the National Association of Developmental Education or to the League for Innovation. All of the respondents taught at community colleges or in developmental programs within universities or four-year colleges. Viewed as a whole, their responses indicate great disparity in use of technology, a disparity that does not always correlate to the type of institution. In the main, however, their responses reinforce the findings of the empirical studies cited above. The comments of respondents quoted in the sections to follow can all be found at the Curricular Transformation website at <www.gen.umn.edu/research/currtran>.

\section{Kinds of Technology in Use}

For some of the writing teachers in this survey, the presence of a 
lab on campus where students are able to word-process their papers was the closest connection they could make between computers and writing. Having access to a computer lab in which to hold class periodically was a high priority on their wish lists. Other respondents taught in networked computer classrooms with an Internet connection, enabling them to make use of e-mail and the World-Wide Web in their pedagogies. To these seasoned users, the idea of computers as word-processing tools was such a given that it was not even worthy of mention. They were already looking forward to technology that is beginning to emerge from the development stage, such as CUCME (see you, see me) video conferencing.

The most prevalent kind of technology identified on the surveys was the computer, whether part of a fully-equipped writing classroom or off somewhere-usually in inadequate numbers - in a learning lab, department lab, or campus lab. The software available on these computers ranged from the minimal word processing package (several respondents mentioned world-ware programs such as PFS Write, WordPerfect, and MS Word) to grammar and mechanics checking programs (e.g., Grammatik) to tutorial programs such as SkillsBank or Invest. Diagnostic and placement software was also mentioned frequently. Two respondents specifically mentioned software packages (MS Office, WordPerfect Works and Microsoft Works) that enable students to integrate graphics into their writing assignments and oral presentations.

Three software packages developed specifically to support the workshop approach to writing instruction were also mentioned. The Daedalus Integrated Writing Environment features Interchange, an electronic discussion forum, along with a series of invent and respond prompts, a word processing program, and a bibliography preparation tool. CommonSpace supports peer editing by enabling students to comment on each other's papers in separate columns that run alongside the text column. Norton Connect is a system in which students can share their work electronically with others, turn it into the instructor electronically, and follow links to sections of a grammar or style manual that can be imbedded in the instructor's feedback.

Relative to the number of responses that named hardware and resident software as instructional tools, significantly fewer respondents mentioned Internet-related technologies as items in their pedagogical bookbags. This figure, under ten percent, most likely reflects the proportion of developmental education programs with equipment that provides Internet access. Of those who did mention the Internet connection, e-mail was cited most often, both in terms of its ability to facilitate communication among students and between student and instructor. In a few cases, students hand their papers in via e-mail. Larry Silverman at Seattle Central Community College uses e-mail to match 
his students up with students in other states and even countries: "I've had my developmental writing class correspond with students in Hawaii, and next quarter they will correspond with a group of students in Japan." To find these classes, he advertises on a listserv designed to make these connections.

Some writing teachers on campuses with access to the World Wide Web use it as a way to teach research techniques and a place to conduct research and gather information. One respondent makes full use of the Internet and World Wide Web technologies, posting his syllabus to the web and using an e-mail distribution list to assign homework. He has students post their comments about reading assignments to a class listserv and initiates them in the use of a MOO (a virtual meeting place) so he can hold class even on those days when he can't be in the room.

Two respondents listed CD-ROMs among the technologies available to their students. A teacher in adult education uses Grolier's Encyclopedia on $\mathrm{CD}$ as a text for writing: "The database set-up allows students to access all kinds of information. They then write anything from research papers to outlines to summaries."

Devices for projecting images onto large screens for all students to view are a staple of instruction in the writing classroom. The overhead projector enabled teachers to create transparencies for use in lecture situations or as a means of displaying examples and supplanted the need to laboriously write out such information ahead of time on the chalkboard or reproduce multiple copies for students. The development of liquid crystal display panels (LCDs) and computer projectors that plug directly into a computer's central processing unit has added a dynamic quality to this instructional tool. A handful of respondents reported having access to LCDs or computer projectors, either as part of the basic classroom equipment or available on a cart for checkout.

Jack Sexton of Paradise Valley Community College, part of the Maricopa Community College District, puts the LCD to multiple uses in his writing classroom. To teach editing skills, he might put a student paper on the screen and ask students as a group to discuss possible revisions, keying in changes as the students agree on them. For a lesson on thesis statements, he will ask students to type their thesis statements into a common file at the beginning of the class period and then work through them, one by one, so that everyone has access to all of the examples.

In short, the use of computers in instruction ranged from computer-aided instruction (CAI), exemplified by tutorial programs, to computer-assisted composition (CAC), where students did much of their composing at the keyboard, to computer-mediated communication $(\mathrm{CMC})$, where the emphasis was on electronic communication 
using software packages such as Daedalus InterChange and Norton Connect and technologies such as computerized projectors, e-mail, and the World Wide Web.

\section{Impact of Technology on Teaching and Learning}

Basic Writing instructors who have introduced elements of technology into their courses are mixed in their evaluation of its impact on student learning. While one instructor states that he has not found technology to improve student writing ("I believe computers are basically a gimmick"), another asserts that technology has made his an entirely different course that has resulted in more literate students.

Responses tend, not surprisingly, to cluster around other factors, such as the level of commitment a department or institution has made in hardware, software, and training. The instructor who stated he saw no improvement in writing, for instance, teaches in a department with access to a "room with computers," no training, and little technical support, while the instructor who felt that teaching with technology was producing more literate students teaches at an institution that provides workshops to train faculty in new forms of technology and has access to the Internet and the World Wide Web, as do his students. Cause and effect is difficult to sort out in these situations.

Whether they were making use of the computer to deliver computer-aided instruction in a venue outside the classroom, such as a writing or academic resource center, or using the computer as a writing tool, holding class sessions in the computer lab or a computer classroom, instructors reported largely similar results. The positive evaluations of using technology overwhelmingly outweighed the neutral or negative ones, and the rewards noted by instructors fall naturally into four groups: positive impact on students' attitudes toward writing; improved appearance of papers; improved student writing, in terms of both quantity and quality; and an increase in efficiency on the part of the instructor.

Again and again, instructors noted that working on computers has positively altered students' attitudes in their writing classes. "Using technology has made the basic English requirements more interesting and relevant for vo-tech students," observed one respondent. In related observations, other instructors stated that students see the computer as a useful tool and feel they are learning the technology of the future when they work on a computer. Instructors variously reported that students have more confidence in their writing when using the lab and develop self-esteem by working at their own pace to accomplish writing tasks. Among other reasons cited: students respond well to computer-based instruction; working on a computer provides 
variety and adds interest; computer-related assignments increase student involvement in their own educations.

Simply turning in word-processed papers, instead of the often illegibly handwritten ones, was noted by some instructors as a positive change brought about by technology. Most often, however, instructors saw this "improvement" as benefiting themselves as much as the student. Yes, word-processed papers are a "neat end product," as one teacher put it, presumably offering satisfaction to the student upon completion, but even more to the point, they are easier to read and make writing teachers' time more productive.

By far the most frequently cited examples of ways in which using technology had had an impact on developmental writing courses were outcome-based and revolved around both the process and products of student writing. The ease with which documents can be changed has significantly affected the amount of revision that is taking place. Teachers can insist on revision and editing if they choose; students are more likely to exercise some editing and revision strategies on their own work with or without pressure from their instructor. Spelling checkers not only help to eliminate surface errors in final drafts, but their mere existence encourages some writers to try words they aren't sure they can spell, knowing they'll be able to correct them in a later draft. Students just plain write more-more words, more pages, more drafts. And teachers say they are able to fit more writing assignments into a term because computers speed up the editing and revision processes.

There were some contradictions in what writing instructors had to say. One asserted that meeting in a computer lab changed the structure of the class so that more time was spent writing and less on grammar lectures or demonstration. For another, meeting in a computer lab required the instructor to spend more time teaching word-processing and computer skills and less time on writing instruction. No doubt both are true.

Whereas most of the successes cited were student-related, the majority of the problems mentioned by instructors were institutional in nature. Lack of funding for adequate equipment was the biggest issue: not enough computers to serve all students in a class, outdated hardware that doesn't support new software, hardware and software that doesn't perform as promised. Insufficient faculty training (or none at all) and not enough technical support were also seen as roadblocks to increased use of computers in developmental writing courses. Instructors reported problems with specific software as well as general system malfunctions and breakdowns. One respondent specifically mentioned that the administration is supportive of technology in the classroom - for the engineering and science departments. Convincing them that the writing program should receive the same level of fund- 
ing has been a greater effort.

The fact that students arrive in writing classes with minimal or no computer skills is perceived by almost all instructors as a problem, as they are required to show students how to use the machines before they can ask them to work on writing assignments. Most agreed that while this lack of computer experience does create a problem in the beginning, it disappears as students become more familiar with the hardware and software. Almost all instructors surveyed agreed that students offer little if any resistance to technology. Several noted that anxiety seems to be age-related and that returning students, who are usually older, are most prone to it. Even their fears, however, dissipate quickly.

Some students, however, lack keyboarding, or typing, skills, which is a decided disadvantage. "A small handful of students," noted one instructor, "refuse to even hunt and peck on the keyboard, get frustrated, and fall way behind." Should knowledge of word-processing be a requirement for entry into a basic writing course? At one college, the instructor who teaches word-processing thinks it should and wants students to take his class first. Only one instructor reported that students use technology as an excuse for not completing assignments on time, saying, for instance, that they couldn't get to the lab.

Perhaps because these surveys were sent to people who had been recommended by administrators at their institutions as teachers who were using technology as part of their developmental writing courses, many of the instructors who responded to the survey complained of not having colleagues who were similarly involved. These people became the sole instructors taking students into the computer lab or lobbying for more equipment; their colleagues were often reluctant to get their feet wet, for any number of reasons, including technophobia.

\section{Faculty Training}

In cases in which the instructor is the department technology expert or the only teacher to be using computers in writing instruction, he or she has usually been propelled by a personal interest in computers and has been self-taught. One person wrote of "sitting in the basement computer lab until 4 a.m. until I figured this stuff out." These people consulted manuals, called helplines, and learned by trial and error. Many of them credited other people-colleagues, computer science department staff members, patient friends, and others, such as secretarial staff members, who were already using the particular hardware or software.

Some teachers were first introduced to ways that computers could enhance writing instruction in graduate school or at conferences or 
workshops put on by professional organizations such as the Conference on College Composition and Communication (CCCC) and the National Association for Developmental Education (NADE), and by federally funded or privately funded organizations such as the National Endowment for the Humanities and the Epiphany Project. Epiphany, a project funded for two years by Annenberg/CPB in collaboration with the American Association for Higher Education and the Alliance for Computers and Writing and now continuing as a nonprofit organization, conducts three-day intensive institutes around the country to introduce teachers to pedagogies involved in using computers in writing instruction. Interestingly, among its recommendations is that schools send people in teams of two or more, a strategy that provides synergy when participants return to their own institution and helps to eliminate the sense of isolation reflected in many of the completed surveys received.

As evidenced in the responses, some colleges are providing training for their writing faculty. It is often the early adopters - those instructors who discovered technology on their own - who end up organizing workshops to teach others in their departments or institutions. Some instructors reported attending workshops offered at the institutional or district level, and a few reported that their institutions have instructional technology committees. Still, the profile is uneven. Many instructors who have integrated some technology into their courses report that they do not even have computers in their offices, and many more report that their institutions have not yet geared up to provide access to e-mail for faculty members, much less students.

\section{Visions of the Future}

The great disparity among the levels of technology currently in place across the country in colleges and universities with developmental education programs means that individual and departmental goals for the implementation of technology in writing instruction also vary widely. One teacher's dream is in effect another teacher's reality. Some instructors long for more equipment, better computer classrooms, or networking capabilities, while others have all that and simply want more time in which to explore these tools or develop assignments around them. Still others envision kinds of technology or software programs that have yet to be developed. A lone voice expressed the sentiment that "we would be satisfied if the student just came every day with paper, pencils and pen, and textbook."

No matter what may be the vision of implementing technology, pervasive in the responses are indications of writing pedagogies that these technologies support. At either end of the spectrum are teachers 
who believe that a collaborative environment leads to learning. The instructor who reports that her college encourages its faculty members to get training in multimedia still forthrightly states, "I don't see much use for multimedia in basic writing. . . . I rely heavily on the photocopier and chalkboard. I type worksheets based on students' writing and duplicate them for class members to discuss. We do a great deal of collaborative work." Her counterpart in another college has a different way of facilitating collaboration - by using the computer projector to display samples of student text to be discussed. These two technologies, the former far more labor-intensive for the instructor, fulfill the same purpose in the writing classroom, allowing students to see writing as a dynamic process and one in which the effective communication of ideas is paramount.

Another principle underlying the workshop approach to writing is that of writing for an audience other than the teacher, whether that means one's classmates or the portion of the world funneled through the World Wide Web. Those respondents whose students use e-mail to conduct a text-based conversation with students elsewhere or who post their papers to the Web quickly develop, in the words of one respondent, "a sense of what their readers need to understand the texts they produce."

The approach to developmental writing instruction that emphasizes the mastery of discrete skills is also very much in evidence in these responses. Despite the existence of research that suggests that grammar tutorials, style analyzers, and other tutorial programs are detrimental to developmental writers, many writing instructors continue to rely on them. Without polarizing writing instruction pedagogies as either product or process, repeated comments that focus on appearance of text (e.g., "a neat end product") or promote excessive dependence on style checkers nonetheless suggest that technology is sometimes being used to reinforce, perhaps unwittingly, a product-oriented view of writing.

When instructors were asked to comment on what their writing courses will be like in the future, most conceived of courses along the lines of current models but enhanced by more and better hardware and software. Only a few people considered that future writing instruction might undergo a total transformation in form while still grounded in the same theory. Several respondents suggested that their classes might be offered in an electronic format-over the web or Internet-and one envisioned an interactive CD-ROM teaching module, but then noted that "the institutional pedagogy is moving away from any individualized learning, so whatever it is, it better be communal!" 


\section{Issues and Policies}

Whether in their capacity to foster collaborative learning, enrich opportunities for student research, encourage students to write longer papers of a higher quality, or simply modify students' negative attitudes toward writing, computers have already made an incalculable impact on the field of writing instruction. As the results of our survey have shown, however, only a fraction of developmental writing teachers are in a position to incorporate technology into their courses to the extent that they would like. They are stopped by factors both economical and political: lack of support for technology at the department or institutional level (as manifested in funds for equipment, space that has been retrofitted with the appropriate wiring, and technical support), and lack of clout within the department for access to the computer facilities that do exist.

Faculty training has emerged as another roadblock, since many of the people who teach developmental or Basic Writing courses carry heavy courseloads that cannot accommodate time-outs for training without compensatory release time. To compound the problem, many departments employ adjunct or part-time faculty to teach their developmental writing courses; even if training sessions are offered, these instructors cannot always be available to attend them. To ensure that access to technology does not become a factor dividing institution from institution, department from department, and ultimately student from student, those of us with access must find ways to eliminate the impediments in the paths of those without access.

These obstacles, which occur not just in Basic Writing sites but also in Composition departments (which in turn are often situated in English departments), are topics of frequent discussion on listserv groups devoted to issues of writing pedagogy or technology in higher education. Such discussion groups have created virtual communities of teachers and administrators with like interests and goals who often pool their experiences and expertise to address problems presented to them. Need recommendations from users to bolster your request to purchase a new kind of writing instruction software? Go online. Need suggestions for the most effective layout for a computer classroom? Go online. Need data to convince a hesitant chair that the expense of a computer classroom is warranted? Go online. Many of the respondents to our survey remarked that, as the resident "expert," they felt isolated at their institutions; listservs provide them with the chance to develop virtual colleagues.

While listserv discussion groups represent informal sites for sharing information, websites (including the website developed by this 
project and the many web resources linked to it) are more formal sites for the sharing of information about writing pedagogy and technology. Such websites can be productive as entry-level places to learn about everything from terminology to available technologies; they can also act as information exchange sites and clearinghouses to put inexperienced technology users in touch with experienced teachers at nearby institutions.

Sending a group of Basic Writing faculty members to conferences and workshops to learn about new uses of technology is an expense beyond the budget of most departments. The trend toward cyber-conferences and satellite conferences responds to this situation by bringing the workshop or the conference to faculty members who may have neither the time nor the financial support to travel. Electronic conferences, or cyber- conferences, can either occur asynchronously (a highly regulated form of listserv discussion), or they can take place synchronously in a MOO. Satellite conferences, in which presenters are projected live onscreen in an auditorium setting, can be particularly affordable if the conference costs are being shared by several institutions simultaneously.

In addition to providing a place for new users to learn about technology, cyber sites (e.g., listservs, websites, electronic conferences) provide a way to capture what we earlier termed fugitive information: classroom practices that do not appear in traditional print sources. The innovative work of so many instructors with part-time status and heavy courseloads goes unpublished and thus remains hidden to all but their immediate colleagues. Searchable websites such as ours, where these teachers can post lessons developed around specific technologies, will augment the amount of information available and provide a more realistic picture of how technology is being used to enhance Basic Writing pedagogy. Taken together, all of these efforts - emerging communities of support, online collection and dissemination of information, and electronic venues for training - represent an initial step in lessening the disparity between the kinds of technology available to basic writers in learning institutions throughout the nation.

Note

1. The authors gratefully acknowledge the support of the Annenberg/ $\mathrm{CPB}$ Projects Initiative II and the General College Center for Research of Developmental Education and Urban Literacy, which funded Curricular Transformation and Technology in Developmental Education, a crossdisciplinary collaboration at the University of Minnesota. 


\section{Works Cited}

Bartholomae, David. "'I'm Talking about Allen Bloom': Writing on the Network." Networked-Based Classrooms: Promises and Realities. Eds. Bertram C. Bruce, Joy Kreeft Peyton, and Trent Batson. New York: Cambridge UP, 1993. 237-62.

- - - "Inventing the University." When a Writer Can't Write. Ed. Mike Rose. New York: Guilford, 1985. 134-65.

Bartholomae, David, and Anthony Petrosky. Facts, Counterfacts, and Artifacts. Upper Montclair, NJ: Boynton-Cook, 1986.

Batschelet, Margaret and Linda Woodson. "The Effects of an Electronic Classroom on the Attitudes of Basic Writers." National Council of Teachers of English, Seattle, 22-27 November, 1991.

Bruce, Bertram. "Innovation and Social Change." Networked-Based Classrooms: Promises and Realities. Eds. Bertram C. Bruce, Joy Kreeft Peyton, and Trent Batson. New York: Cambridge UP, 1993. 9-32.

Collins, Terence. "The Impact of Microcomputer Word Processing on the Performance of Learning Disabled Students." Computers and Composition 8.1 (1990): 49-67.

Crowley, Sharon S. "Around 1981: Current Traditional Rhetoric and Process Models of Composing." Composition in the Twenty-First Century: Crisis and Change. Eds. Lynn Z. Bloom, Donald A. Daiker, and Edward M. White. Carbondale: Southern Illinois UP, 1996.

D'Agostino, Karen Nilson and Sandra D. Varone. "Interacting with Basic Writers in the Computer Classroom." Computers and Composition 8.3 (1991): 39-50.

Downs, Judy R. and Paul J. Linnehan. "Computers as Writing Tutors." Conference on College Composition and Communication, San Diego, 21 March-3 April, 1993.

Fey, Marion Harris. "Finding Voice through Teacher-Student Collaboration in a Feminist Research Project: Long-Term Effects." Conference on College Composition and Communication, Nashville, 1619 March, 1994.

Gay, Pamela. "Questions and Issues in Basic Writing and Computing." Computers and Composition 8.3 (1991): 63-81.

George, E. Laurie. "Taking Women Professors Seriously: Female Authority in the Computerized Classroom." Computers and Composition 7 [Special Issue] (1990): 45-52.

Gerrard, Lisa. "Computers and Basic Writers: A Critical View." Critical Perspectives on Computers and Composition Instruction. Ed. by Gail Hawisher and Cynthia L. Selfe. New York: Teachers College Press, 1989. 94-108.

Hansman-Ferguson, Catharine Ann. "Writing with Computers: A Study of Adult Developmental Writers." Diss., Ball State University, 1995. 
Hawisher, Gail, Paul LeBlanc, Charles Moran, and Cynthia L. Selfe. Computers and the Teaching of Writing in American Higher Education: 1979-1994: A History. Norwood, NJ: Ablex, 1996.

Hicks, Sandy Jean. "Cultivating Metacognitions within a Learning Environment: The Case of the Computerized Writing Partner." Diss., University of Arizona, 1993.

Hillocks, George. Research on Written Composition. Urbana, IL: National Council of Teachers of English, 1986.

Horner, Bruce. "Discoursing Basic Writing." College Composition and Communication 47.2 (1996): 199-222.

Kremers, Marshall. "Sharing Authority on a Synchronous Network: The Case for Riding the Beast." Computers and Composition 7 [Special Issue] (1990): 33-44.

LeBlanc, Paul. Writing Teachers Writing Software: Creating Our Place in the Electronic Age. Urbana, IL: NCTE and Computers and Composition, 1993.

Lu, Min-Zhan. "Conflict and Struggle in Basic Writing." College English 54.8 (1992): 887-913.

Maxson, Jeffrey. "HTML and the Politics of Academic Literacy: Basic Writers on the Web." Paper presented at 12th Annual Computers and Writing Conference, 31 May, 1996, Logan, Utah.

Meem, Deborah T. "The Effect of Classroom Computer Use on College Basic Writers." Research and Teaching in Developmental Education 8.2 (Spring 1992): 57-69.

Petry, Martha. Telephone interview. 31 March 1997.

Reynolds, Mark. "Writing for Publication." Teaching in the Two-Year College 24.1 (1997): 3-4.

Rickly, Rebecca. "What's Good for the Goose is (Not Necessarily) Good for the Gander: Gender's Influence on Participation Levels in Oral and Online Classroom Conversation." Computers and Writing Conference, El Paso, 19 May, 1995.

Romano, Susan. "The Egalitarianism Narrative: Whose Story? Whose Yardstick?" Computers and Composition 10.3 (1993): 5-28.

Russell, Ethel. "Networking in the Developmental Writing Class." Collegiate Microcomputer 14.2 (May 1993): 149-51.

Sexton, Jack. Response to Curriculum Transformation and Technology in Developmental Education Project Survey. 22 Oct. 1996.

Shaughnessy, Mina. "Basic Writing." Teaching Composition: Ten Bibliographical Essays. Ed. Gary Tate. Fort Worth: Texas Christian UP, 1976. 137-67.

- - - Errors and Expectations. New York: Oxford UP, 1977.

- - - "Open Admissions and the Disadvantaged Teacher." Mina P. Shaughnessy: Her Life and Work. Ed. Jane Maher. Urbana, IL: National Council of Teachers of English, 1973. 249-54. 
Silverman, Larry. Response to Curriculum Transformation and Technology in Developmental Education Project Survey. 8 Oct. 1996.

Sirc, Geoffrey. "Never Mind the Tagmemics, Where's the Sex Pistols?" College Composition and Communication 48.1 (1997): 9-29.

Strickland, James. "Planning, Drafting and Writing on the Computer." Research and Teaching in Developmental Education 9.1 (Fall 1992): 4555.

Stuckey, J. Elspeth. The Violence of Literacy. Portsmouth, NH: BoyntonCook/Heinemann, 1991.

"Survey Shows a Growing Emphasis on Instruction and User Support." Signals: League for Innovation in the Community College Jan. 1997: 1,3 .

Walker, Cynthia Louise. "Computers, Revision, and the Developmental Student: A Case Study of Student Revision in the Computer Classroom." Diss., East Texas State University, 1994. 


\section{Candace Spigelman}

\section{TABOO TOPICS AND THE RHETORIC OF SILENCE: DISCUSSING LIVES ON THE BOUNDARY IN A BASIC WRITING CLASS}

ABSTRACT: This article considers the ritetorical implications of silence as a contestatory strategy in a basic zuriting class where Mike Rose's Lives on the Boundary was the course text. Though the students zere successfully reading and zuriting about complicated topics, they zuere reluctant to critique educational processes and institutions or to discuss the issues of poiver raised in Rose's book. Students' silence may be read as evidence of complex cultural and educational conflicts operating discursively and materially in some zuriting classrooms. Using remarks from correspondence zuith Professor Rose, the article concludes with a recommendation for re-imagining a sensitized approach to critical pedagogy.

Among the many challenges to the field of composition, the basic writing classroom remains a site of political and educational conflict. With shrinking budgets and new priorities, many universities are withdrawing their commitment to developmental education and focusing their resources exclusively on courses "worthy" of academic credit. Given this point of view, freshmen who place into today's basic writing courses are potentially more marginalized and silenced than the students who preceded them. With a goal of empowerment, most developmental writing programs try to prepare students for the increasing demands of a college education while encouraging them to think critically about language, literacy, and the way that they are positioned within the institutional setting. Ironically, however, our basic writers may be disinclined to enter the conversation of critique or to engage in discussions of institutional power relations. I would like to suggest that we take seriously students' silence on these topics and that we read their silence as a rhetorical act of resistance.

My argument derives from my experiences teaching four sections of basic writing at a branch campus of Penn State University. In the

Candace Spigelman, Assistant Professor of English at Pelm State, Berks-Lehigh Valley College, teaches developmental zuriting, composition, and nonfiction literature. She has zuritten several articles about the teaching of writing and has forthcoming publications in CCC (May 1998) and in Perspectives on Plagiarism and Intellectual Property in a Postmodern World(eds. Lise Buranen and Alice Roy, SUNY P), this most rewent work addresses issues of intellectual property in student turiting groups. 
discussion that follows, I describe in some detail the expansive and fruitful conversation that accompanied my students' reading of Mike Rose's Lives on the Boundary, the course's central text. Then I turn to their silent refusal to engage with me in educational or cultural criticism. I suggest alternative "readings" of their silence and explore the implications of their response, as evidence of ideological conflicts operating discursively and materially within writing classrooms where radical critique is practiced. Finally, I draw from Rose's work to consider how a sensitized critical pedagogy might be imagined.

\section{Lives on the Boundary in a Basic Writing Course}

Beyond instruction in basic skills, the course was framed by three additional goals. First, I wanted to teach basic writing as serious academic activity, by asking students to grapple with what was for them a difficult and demanding text. I also wanted to teach literacy skills within a framework in which the students' identities and personal experiences could be foregrounded without encouraging confessional discourse. Finally, I wanted to provide for my students a medium through which they might examine and critique educational practices and institutions, as these directly affected their own "boundaried" lives. For these reasons, I chose Lives on the Boundary as the course text.

By means of narrative, autobiography and vignette, Lives on the Boundary creates a richly textured argument for the educational potentiality of all students. It traces out Rose's own educational encounters as the child of immigrants in a Los Angeles ghetto, as an "outsider" college student, and ultimately as a university writing instructor. Using examples from his school days and from the students he came to tutor and teach, Rose explores the terminology of failure implicit in labels like "remedial" and "deficient" and exposes many of the hidden assumptions relating to class, culture, and student potential that perpetuate this failure in American classrooms. Lives on the Boundary is, in John Trimbur's words,

a story worth telling, especially at a moment in our collective history when "reform" movements in education are calling for higher standards, national testing, teacher accountability, discipline and a return to a canonical curriculum. It is a story to break the prevailing silence in public discourse about education by speaking of democratic aspirations to increase access, to open opportunity, and to remove educational barriers to the poor and working class. (42)

Writing in the first person, Rose subverts traditional political and cultural associations relating to personal achievement to insist that the narrative of an individual's life is both the product and process of sur- 
rounding social and educational narratives.

My course design was influenced largely by theorists like David Bartholomae, Patricia Bizzell, and Mike Rose himself, who have shown that, given appropriate guidance, inexperienced writers are quite capable of handling the challenging reading and writing assignments that are part and parcel of any authentic preparation for actual college writing. In addition, I was motivated by a change in the configuration of my writing classes that prompted me to re-evaluate my formerly expressivist approach to basic writing instruction. For much of the fifteen years that I had taught basic writing at a branch campus of Penn State University, my students fit the description of "true" basic writers: either returning adults who needed a semester to remember what college writing was about or traditional students who had experienced difficulty in English in the lower grades or who had little instruction in composition. The cultural configuration of my basic writing classes was reflective of the racial and economic composition of the campus: the students were largely from working and middle class communities; more than three-quarters of the eighty basic writing students I taught that semester were white, sixteen students were African-American, three were Hispanic.

Over the years, however, my basic writing population had begun to change, not in its sociological makeup but in its educational vantage point. In addition to the students I just described, I was seeing a large number of students (both African-American and white) who had, in fact, been successful in high school, students who thought of themselves as "good" students and "good" writers, students who had been rewarded for following required formulas and prescriptions. I wanted a course that would challenge, through intellectually rigorous reading, discussion, and writing, the complacency that these students' talk and writing often revealed. But I also chose Rose's text because I felt that it would strike a chord in those "traditional" basic writers, who might identify with Rose's high school and early college days, since the vocational curriculum of Rose's experience translates directly to the lower academic tracks of many public high schools today.

And so we read and talked and wrote about academic struggles and literacy "moments," educational bureaucracies, tracking and labeling, barriers and entrance to the academic "conversation," the perplexities of choosing a major, and the problems of students with various special needs. We read each chapter separately, discussing highlights of the reading in groups and writing essays on each of the chapters. In their papers, I encouraged students to reflect on their own experiences as well as to engage more broadly the issues that the text evoked, which involved citing Rose and examining Lives on the Boundary as a critical source. 


\section{Reading and Writing about Boundaried Lives}

I was quite amazed at what the students were able to do with the assignments - given their limited reading experience and the difficulty of the text. And I was impressed by their forays into the complexities and contradictions of the cultural arena. For example, in one paper, Brian, a student from the working class Frankford section of Philadelphia, chose a passage from Rose's chapter on "The Politics of Remediation" in which Rose discusses, among other things, the alienation and loneliness of the freshman experience: "The huge lecture halls, the distance from the professor, the streams of students you don't know" (Lives 174). Rose explains that for some students this alienation is compounded by the realization that, after years of preparation, they are simply inadequate to the task. Brian focuses on a quotation from this section: "But a much deeper sense of isolation comes if the loneliness you feel is rooted in the books and lectures that surround you, in the very language of the place" (Lives 174), explaining that

the terms "books and lectures" are not limited to the school environment, but may also include home, work, and everywhere else in society. The "books" may be newspapers or signs and the "lectures" may include television and radio programs. The two terms may be used for any situation in society where reading or listening is necessary. The "language" that the quote refers to can be substituted with "the culture or beliefs" of an environment in which you isolate yourself.

In order to explain, Brian refers us to an earlier chapter in Lives. He writes,

Mike Rose felt separated and isolated in his transfer from high school to college. Most of the people in his college classes came from and lived in a world very different from Rose's. The majority of the students attending Loyola were from the upper-middle class and he came from the lower social class of South Vermont [Avenue]. The cultures of the two were as far apart as day and night. This difference between Rose and the other students caused him to fortify himself with barriers. He did not join any social or academic clubs because he felt they seemed "exclusive and a little strange" (43). Rose also did not go to see teachers at their offices because he had this idea in his head that he was stupid. Mike Rose was surrounded by 
"books and lectures" with a language very different from his own and this forced him to isolate himself from students and teachers at Loyola.

Brian goes on to apply the quotation to his own experience as a new student at Penn State who "felt inferior to others and just not cut out for college. . . . As my test scores lowered, my fear of asking for help grew. I was just unable to grasp the 'language' of college," and he likens his difficulties to those of his neighbor, Neila, a Russian immigrant, who, because of her limited English skills, could not work as a nurse, the field for which she had been trained, and worked instead in "a sweat shop for long hours and low wages." Brian concludes:

Isolation is common in our society and we see it everywhere we go. There are men sleeping on grates down town, the immigrants that come to our country, and the college students that are unfamiliar with the college atmosphere. Everybody, at one time or another, feels isolated because they are unfamiliar with the culture, language, backgrounds or anything else that can be used as a barrier.

As he struggles to make sense of the literature, Brian suddenly recognizes the relevance of Rose's narrative to issues within and beyond the school setting. His essay illustrates the level of possibility for students who themselves are labeled and placed in basic writing classes -classes where despite the years of research in composition studies, quite often students spend a semester writing paragraphs describing their bedrooms, where the grade for the course depends more on whether they have overcome comma splices than whether they can use writing to interpret, to analyze, and to create meaning.

\section{Silence as a Rhetorical Act}

In recent years, many of us in composition have moved to what might be called a cultural studies perspective - we have seen the ways in which language is complicit in the maintenance of many unjust social structures, and we have tried to bring that understanding to our students as we teach them about the power and powerlessness of writing. This means that we show students how to question what they heretofore have taken for granted and to see that there are no simple or uncomplicated answers. This was indeed my third goal in using Lives on the Boundary, and it was here that my efforts were resisted.

Throughout his text, Rose describes individuals who are failed by the system. The examples themselves are detailed and colorful, 
and the characters were very real for my students. But Rose intends the images as representative examples, and his book continually exploits the personal in order to accomplish serious cultural work. While Lives on the Boundary offers hope on the local scale, it raises serious questions about the ways American education is handled, about the complex, imbricated collaborations of racism, classism, and ethnocentrism that allow for the creation of what Rose terms an "educational underclass." My students, however, were unwilling to investigate or accept the complicity of the system itself: education offered hurdles, they contended, but individuals with true grit, determination, and resourcefulness could overcome obstacles, not only to succeed academically but to succeed in life. Their reading of Lives on the Boundary confirmed John Trimbur's fear that some students would interpret the book superficially as "another comforting American success story of an individual who, through the power of education and the guidance of more experienced teacher-mentors, takes the predictable road to selfimprovement and upward mobility" (35).

Throughout the semester, the students continually countered my attempts at critique by recasting their interpretations in a rosy glow of individual success. When I pointed out the ways that schools encouraged mediocrity and self-defeat, they pointed out that Rose had escaped, by way of his mentor, senior English teacher Jack McFarland, and repeatedly brought to my attention the fact that Rose was "saving" others. It is telling that in his introduction, Brian defines alienating language as "'the culture or beliefs' of an environment in which you isolate yourself." Brian is unwilling to go beyond personal will or inclination to address the problem of isolation as a failure of the system rather than a failure of the individual. "Unable to grasp the language of college," he writes, "this separation was moving me toward failing out of college. Luckily, from the help of one of my good friends, who had already overcome this change, I was able to understand the 'books and lectures' that surrounded me." For Brian, as for most of my students, it was, finally, the efforts of individuals, not class or economic configurations, that were culpable.

Over the semester, the students' resistance to critique actually increased. So it was most apparent when we reflected on the final chapter of Lives. Here, Rose asserts that in order to create more effective learning institutions, we teachers will need, among other things, "a pedagogy that encourages us to step back and consider the threat of the standard classroom and that shows us, having stepped back, how to step forward to invite a student across the boundaries of that powerful room" (238). I remember this discussion quite clearly becausewell, it wasn't a discussion at all-it was, instead, agonizing minutes of perplexed silence - in four sections of basic writing, that's all there was, perplexed silence. Every teacher knows that almost palpable si- 
lence in a classroom: the downcast eyes, the furious turning of textbook pages. Sometimes it signals unpreparedness; this time I think that it signaled profound discomfort.

As I urged conversation, providing scenarios from the text and from my own educational experiences, my students allowed (though many of them for the first time) that power in a classroom was tipped in favor of the teacher. However, they could not understand why $I$ would want to point that out. Although the students themselves had experienced power plays throughout their educational lives and could relate them to the various scenarios in Rose, they could not accept my willingness to criticize the very institution I represented, and they seemed unwilling to support me in this effort. Leaving class that day, one student waited to ask me, "Can you do that?" and he wondered aloud if I might not find myself "in trouble" for being so "negative" about education.

The students' reactions, their silence, suspicion, embarrassment, and resistance, got me thinking about my role-all of our roles - in teaching composition. It was possible that my students did not really identify with Rose in the way that I'd hoped. That is, although many had been ill-prepared for higher education, they did not recognize themselves as members of the same socioeconomic class (or recipients of the same educational exclusions) as the students in Rose's examples. Bridget Murphy and Roberta Pierce Trooien found this to be true when they studied their white, male students' resistance to multicultural literature, which the students termed "victim stories." In "Rumblings from the Back Row," they show that their white, male students, including those from working class families, had an inflated conception of their own socioeconomic class. The authors point out that because these students cherished the American Dream of economic success, in order "to nourish their dreams" of making it, they "identif[ied] upward" (300) and thus could see the characters in the literature they were reading only as Other.

I thought back to earlier in the semester when we had talked about "I Just Wanna Be Average," the chapter of Lives on the Boundary my students had most enjoyed. During that class discussion, they had ardently agreed with Rose that low-level tracking systematically exhausts both the mind and the spirit, and they shared "horror stories" about low-tracked high school classmates. For many, their own academic lives were painted vividly in the pages of the text, yet they read the vo-tech students' assertion, "I just wanna be average," not as a declaration of frustration and bitterness, but as a "stretch" or "step up" for remedial students, and certainly not an aspiration they would share. If many of my students had been labeled as the "losers" in high school because their schools lacked the services they needed or because the services they received diminished their own sense of self- 
worth or because the school's entire system of academic support was founded on expectations about culture and race, all that was now behind them. College was the "blank slate"; success required an optimistic, uncritical outlook.

In this way, too, my basic writers seemed to parallel Rose's student Christine, who found it "rude" to write about the hardships and prejudices her relatives faced as Hispanic immigrants in Southern California. As Rose explains, in order to move on, the painful and ugly must be left behind - certainly not written about or discussed out loud in a composition classroom (178-9). My student, Felicia, begins her criticism of tracking in her high school in this way:

[If] one tries to achieve something, for example, going to college[,] and continues to have many problems in college [,] that may lead to a dropout. Only that one [person] who continues to go along with their plans, no matter how hard it may get, will achieve their goals and [gain?] even more of what they expected to achieve.

Felicia writes that obstacles are a part of life, that college is going to be very hard, but that "you must deal with the problem as a whole and never give up your goal because it can and will be achieved." Like most of her classmates, Felicia looks forward to a "happy ending," so issues of power or revolutionary politics are either taboo or beside the point.

Is it then possible to understand the students' silence in the light of Richard Ohmann's observation that many of today's students come to college "to gain social advantage, not to defect; to elaborate their individuality, not discard it; to learn the ropes, not to see who's at the other end" (329)? Certainly for most of the students whom I teach, college appears to them as the single route to economic security and upward mobility. It would seem strange that I would sit in my privileged position (white, English professor with apparent job security) and ask them (dare them) to critique it. How could they get inside that and how would they read my motives? We must "take account," cautions Donald Lazere, "of the anomaly involved in the advocacy of revolutionary politics ... to working class students desperate to get jobs" (12). Lazere further points out that

[A]cademic radicals almost inevitably must appear to be denigrating the value of their own cultural codes... - codes which they can afford to take for granted -in the eyes of students ... for whom these codes are far less accessible. For such students . . . radical teachers' belittling of [these codes] . . . is bound again not only to appear as patronizing but, in effect, 
as a denial of access to the radical possibilities in academic culture. (16)

In the end, I believe these observations are crucial. Many of my students were the first in their families to go to college. On the opening course survey, almost universally, they indicated that their primary reason for pursuing a college education was "to get a good job." About halfway through the semester, I had asked my classes to free write on this question: "At this point in your life, is there something you' $\mathrm{d}$ rather be working at rather than going to school? What benefits or advantages would that option hold for you at this moment?" Repeatedly the students argued, in various ways, that such an exercise had no real purpose. Clearly, they contended, if they wanted to "get ahead," they needed to continue in collegé, regardless of their own desires. Their passionate commitment to higher education supports Ohmann's and Lazere's observations: asking students to critique, rather than teaching them ways to negotiate, the institutions that they identify as resources for securing upward mobility may seem to them both hypocritical and cruel.

\section{But What is the Alternative?}

In a recent article in College English, Jeff Smith argues that students actually desire skills instruction, not critical consciousness, and that writing teachers should abandon their misguided efforts to promote democratic social relations within and outside of higher education and simply provide students with what they want: linguistic formulas for entrepreneurial success. While we instructors are not obligated to service corporate society by producing particular kinds of workers, Smith asserts, "we are ethically bound by students' own aims, even if those aims seem uncomfortably close to elite values" (317; for a more nuanced discussion of skills instruction, see Lisa Delpit). According to Smith, students passively resist the radical efforts of their writing teachers; their silence reflects either their ability to "play along" with classroom authority or their relief that composition will be less rigorous than their "relevant," career-directed courses. Smith would thus read my students' confusion and discomfort in discussing issues of institutional power as evidence that another agenda might be more appropriate for the composition classroom.

It is true, as Smith indicates, that most students "seek not to resist but to join an elite [class]" (304), and it is also true that, as Rose points out, "[g]overnment and business concern about the preparation of the work force is not, of necessity, crass or malevolent, and the hope for a 
better material life for one's children has throughout this century driven participation in our nation's public educational experiment" (Possible Lives 430). But it would be irresponsible of me to teach basic writing as if it were only about learning the rules of formal English. For all instruction in language has political and ethical implications. If I am to teach students about language and power (for success in the work place or anywhere else), I must emphasize the power of language to both maintain and interrogate injustice and inequality. Phyllis Mentzell Ryder succinctly recounts the intersection of ideology and language in her (not unrelated) response to Denise David, Barbara Gordon, and Rita Pollard's proposal for uniform disciplinary principles or "guiding assumptions" for freshman writing programs based exclusively on student writing and discussions about writing:

For scholars who see language as always already imbued with multiple social and institutional forces - who see words as Burkean "terministic screens" that focus our attention and therefore exclude other perceptions, and who see larger ideological screens that limit our interpretations of what we "see" - any in-depth class discussion about "writing" blends together social, linguistic, and political analysis as well. (601)

To a teacher of rhetoric, this is not a trivial obligation.

In an urgent plea to educators to challenge popular representations bent on demonizing youth and especially youth of color, Henry Giroux calls upon "academics and cultural workers" to "redefine the connection between their roles as public intellectuals and their responsibility to address the major social problems facing young people today," in part by "redefin[ing] the purpose of public and higher education not as a servant of the state nor to meet the demands of commerce and the marketplace but as a repository for educating students and others in the democratic discourse of freedom, social responsibility, and public leadership" (194-5). Our responsibility as critical educators emerges, not because we presuppose that we should or can "save [our students] from themselves" (430), as Kurt Spellmeyer seems to suggest, but because education always entails the introduction of the new, the unfamiliar, and often the disturbing. "[A] defining characteristic of good teaching," Rose asserts more than once in Possible Lives, "is a tendency to push on the existing order of things" (428).

Taking Giroux's admonition seriously, I cannot simply accept my students' willingness to make power (or race or gender) a taboo topic for classroom discussion, for to do so is to "silence education for citizenship" (195). Their silence needs a way of being spoken. On the other hand, as Rose cautions, I must teach "in ways that do not diminish the tremendous agency [these] students ... exhibit - they're here 
struggling to master the system - " and their desire to master it must likewise be respected and addressed sensitively (Rose letter).

\section{Imagining the Possibilities}

In Rose's view, these complex, contradictory issues may be best explored through creativity and imagination. "Sometimes when head on social critique fails," he writes, "imagination and 'thought experiments' developed out of personal and school experience might work." We can begin, he suggests, by asking students "to try to find the local, immediate, familiar moment of injustice and gently urge a looking outward from it" (Rose letter). We can call to their attention the discourses that perpetuate values and institutions of injustice and inequality, but we can also help them to re-imagine and re-articulate the terms of justice and equality. In my basic writing class, for example, such an approach might have offered an alternate discourse to address the conflicts articulated by my students' silence. In an effort to imagine the kind of creative alternative Rose seems to have in mind, I will conclude by turning to an essay written by one of my basic writing students.

Toward the end of the semester, our class discussion had focused on the closing paragraph in Chapter 8 of Rose's text, entitled "Crossing Boundaries." Here, Rose calls for a epistemological reorientation in American education. In class, we had divided the passage up and examined separately each of the conceptual commitments Rose asserts will be needed to provide a truly democratic system of education. For their last paper, I asked the students to consider one of these commitments and to shape their analyses around that issue. Kara explains her topic in her opening paragraph:

In his book, Lives on the Boundary, Mike Rose says that to have any prayer of accomplishing educational excellence, we will need several "conceptual blessings." One, he said, would be "a perspective on failure that lays open the logic of error" [238]. Here Rose is trying to say that students make mistakes for good reasons, and that failure is a starting point and not necessarily a failure. Also, students need to be encouraged to learn and not be instantly judged as failures. What Rose means is that teachers need to be in touch with students ways, and seek out their reasoning of error.

While many of my students read Rose's statement as confirmation that "we learn from our mistakes," Kara saw the subtle difference: 
that it was the educational system that marked students as failures, not because they couldn't learn from their mistakes but because there was a prior responsibility on the part of teachers and programs to allow for errors, to analyze errors, and to recognize errors as logical (and intelligent) attempts to solve particular problems. Kara uses several examples from Lives to illustrate the need for a renovated perspective on failure, and in her closing paragraph she calls for "more one-toone, teacher-to-student discussions on reasoning." Kara, it should be noted, went further than many of the students, who were stuck in the abyss of individual culpability. But rather than closing down the analysis at the point where Kara has begun to understand the critical problem, Rose suggests, I might have pressed her (and the class) to consider productive alternatives: "What would have to happen to make the response to error ... more fruitful and generous? And what assumptions about people and society would have to change to make this possible?" (Rose letter). Such questions are, to use Giroux's term, "performative" in that they "affirm the critical but refuse the cynical, establish hope as central to political practice but eschew a romantic utopianism" (199).

Imagining the possibilities requires creativity on the part of teachers as well as their students. In Possible Lives, Rose models this critical approach as he describes successful teachers throughout the country. As a participant-observer, he vividly captures local classroom scenes and effective classroom teachers in an effort to

generate a hopeful vision in a time of bitterness and lost faith, and ... to do that in a way that holds simultaneously to what educational philosopher David Purpel calls the "interlocking and interdependent hinges" of criticism and creativity.... [T]o sharpen awareness of injustice and incompetence, ... to maintain the skeptic's acuity, yet nurture the ability to imagine the possible and act from hope. (412)

Rose's work is always mindful of the complexity of educational processes - indeed of all social processes - which make them difficult to assess and correct. Nevertheless, he insists, citing Maxine Greene, that a "'consciousness of possibility,' an ability to imagine a better state of things" is the mark of the best teachers he has observed (428) .

Our imaginative creativity must likewise sensitize us to the conflicting messages our students receive about the "value" of a college education. The students I meet in basic writing courses tell me repeatedly that they "want to succeed," although often they are not quite sure how this success is defined or accomplished. So it is not surprising that they should resist my efforts to raise questions about institutional power. Demonstrating that mastery of the system and individual 
effort will not guarantee economic security confounds students' motives for attending (and paying for) college and, in itself, offers no alternatives for action. If we want to disrupt silence or complacency, we must respect the legitimacy of their concerns and, at the same time, encourage them imagine alternatives.

In The Power of Silence, Adam Jaworski makes an important contribution to linguistic research by showing that silence is not simply the absence of speech; rather it functions as communicative act with definite rhetorical power. In the case of my basic writing students, silence was a means of protest as well as an expression of perplexity and confusion. Their silence charges me to address their resistance creatively and sensitively, to acknowledge and to help them to voice the conflicts and contradictions in our respective classroom goals. "To imagine a vibrant democratic state," writes Rose, "you must have a deep belief in the majesty of common intelligence, in its distribution through the population, and in the resultant ability of the population to become participatory civic beings" (Possible Lives 432). Our students' silence can be a powerful reminder to those of us who are invested in language, in discourse, in the exchange of ideas: if we read silence as absence or apathy, we will miss the complex cultural messages and contradictions in that silence and fail to recognize the many ways that silence speaks.

Acknowledgments: I am very grateful to Mike Rose for his thoughtful, generous, and extremely helpful comments. I would also like to thank Ellen Knodt, Elizabeth Winston, Tom Fox, and Lisa Birnbaum for their suggestions and careful reading of this essay.

\section{Works Cited}

David, Denise, Barbara Gordon, and Rita Pollard. “Seeking Common Ground: Guiding Assumptions for Writing Courses." CCC 46 (1995): 522-32.

Delpit, Lisa. Other People's Children: Cultural Conflict in the Classroom. New York: The New Press, 1995.

Giroux, Henry A. "Where Have All the Public Intellectuals Gone? Racial Politics, Pedagogy, and Disposable Youth." JAC 17 (1997): 191-205.

Jaworski, Adam. The Power of Silence: Social and Pragmatic Perspectives. Newbury Park: Sage Publications, 1993.

Lazere, Donald. "Back to Basics: A Force for Oppression or Liberation?" College English 54 (1992): 7-21.

Murphy, Bridget, and Roberta Peirce Trooien. "Rumblings from the Back Row: Do We Have to Read Another Victim Story?" Teaching English in the Two-Year College 23 (1996): 296-303. 
Ohmann, Richard. "Afterward." Left Margins: Cultural Studies and Composition Pedagogy. Ed. Karen Fitts and Alan W. France. Albany: State U of New York, 1995. 325-31.

Rose, Mike. Letter to the author. 17 March 1997.

- - - Lives on the Boundary. New York: Penguin Books, 1990.

- - - . Possible Lives: The Promise of Public Education in America. New York: Penguin Books, 1995.

Ryder, Phyllis Mentzell. "Will Your Disciplinary Umbrella Cover Me?" CCC 47 (1996): 599-602.

Smith, Jeff. "Students' Goals, Gatekeeping, and Some Questions of Ethics." College English 59 (1997): 299-320.

Spellmeyer, Kurt. "Out of the Fashion Industry: From Cultural Studies to the Anthropology of Knowledge." CCC 47 (1996): 424-36.

Trimbur, John. "Articulation Theory and the Problem of Determination: A Reading of Lives on the Boundary." JAC 13 (1993): 33-50. 


\title{
Eileen Biser, Linda Rubel, and Rose Marie Toscano
}

\section{MEDIATED TEXTS: A HEURISTIC FOR ACADEMIC WRITING}

\begin{abstract}
Student petitions for alternative demonstrations of competency in academic writing led to the investigation of the use of "mediated texts" as a classroom practice which meets the requirements of "accommodation" as defined by the Americans with Disabilities Act (ADA). This paper defines mediated texts, describes case studies which use these texts with deaf college students who are basic writers, and shows the connection between this heuristic and the development of academic writing skills for ESL and basic writers. Finally, it analyzes the theoretical issues raised by this approach and discusses their implications for classroom implementation.
\end{abstract}

The passage of the Americans with Disabilities Act, ADA, in 1990, has challenged colleges to find ways of helping non-traditional students succeed in mainstreamed environments. Under ADA, an institution must provide such students with appropriate accommodation to ensure them equal opportunity to participate in the academic setting. Because accommodation is not meant to alter the fundamental nature of a program or its standards, either for entrance or exit, it is incumbent on us as teachers to find ways of creating pedagogies and practices which optimize success for students with special needs.

As a federally-funded institution, the National Technical Institute for the Deaf (NTID) - one of the seven colleges of the Rochester Institute of Technology (RIT) - has been, since its opening in 1968, at the forefront of accommodation. At the institutional level, where mandates are clearly defined, making necessary accommodations has

Eileen Biser is Associate Professor of Language and Literature at the National Institute for the Deaf, one of the eight colleges at the Rochester Institute of Technology. Ms. Biser has taught deaf college students for over 30 years. Her scholarship has been in the areas of composition, gifted education, deaf education, and cognitive organization. Linda Rubel is Assistant Professor of Language and Literature at the National Technical Institute for the Deaf. Dr. Rubel has held positions at a variety of universities and has taught deaf college students since 1985. Her scholarly work has been in the arens of composition, nineteenth century British literature, and women's literature. Rose Marie Toscano is Associate Professor of Language and Literature at the National Technical Institute for the Deaf. Ms. Toscano's disciplinary background is in linguistics and ESL. She has been teaching deaf college students for over 15 years and presents regularly on the teaching of writing and literature to non-traditional students. 
proven manageable. For its 1000 deaf students, services such as professional tutoring, interpreting, notetaking, academic advising, personal counseling, and job placement assistance have been routinely provided. And, because of its research mandate, NTID has been able to study and refine many of these services over time. At the classroom level, however, providing appropriate accommodation that goes beyond these "services" has been more challenging. Without compromising the traditional goals and standards within higher education, faculty have grappled with designing the kinds of pedagogical accommodations that will ensure student "success" within the classroom and beyond.

The case studies we have undertaken and the resulting methodology which we recommend in this paper were prompted by our struggle with accommodation within the writing classroom. Although the focus of our discussion is on students who are deaf, the concept of the "mediated text" as a writing heuristic has implications for all teachers who work with non-traditional college students, particularly ESL and basic writers.

\section{Phase I}

The initial phase of our study began when several students offered a radical interpretation of their rights of accommodation under ADA. Beyond the services guaranteed them, like interpreters and classroom notes, they defined performance measures based on written English as "academic barriers" and suggested substitute activities and measures which would fall under their interpretation of "accommodation." In lieu of RIT's test of minimal writing competency - an exit test from English Composition - students suggested a videotaped response which they would deliver in American Sign Language (ASL) to an exit writing test question. Although this substitution of a nonwritten for a written medium may seem a reasonable request in content-based courses, for those of us who teach writing, such an alternative undermines some traditional academic writing assumptions - particularly fluent, independently-produced academic writing that meets minimum college standards. We were both intrigued and worried about this alternative to demonstrating academic writing, and what it could mean to our students' present academic progress and to their future success.

Although our response to our students' proposal was somewhat reluctant, we agreed it was worthy of examination. Consequently, we designed a classroom research project, in the form of case studies, to investigate the feasibility of an alternative approach to producing a written text that meets minimum writing competency. We chose three 
students in the " $\mathrm{D}$ " range in Composition with a high probability of failing the exit text. We videotaped the students signing their response to an exit test question. Each videotape was then voiced by four different interpreters who produced "translations" from one language, ASL, into spoken English. The resulting audiotapes were then transcribed into written English. Finally, the students chose from the four transcriptions the one text that best represented their intent and style to submit as their exit test. We labeled these final written products "mediated texts" because of the involvement of second and third party "mediators" - the interpreter and the transcriber-in producing the final text.

On a practical level, we found many aspects of the experiment to be problematic. The four different transcriptions for each student varied significantly in length, development, level of sophistication, lexicon, and style. There were discrepancies in the interpretations of certain signs that drastically changed meaning. Beyond the problems of transcription and interpretation, the texts themselves raised issues regarding style and content. For example, when we asked for a response to these transcripts from the director of RIT's writing program, he described two of them as "too oral," as "not writerly enough." He saw them as "transcriptions of a monologue," not essays. Furthermore, none of the mediated texts chosen by the students as their exit test satisfied the criteria for minimum competency. On a more serious level, moreover, the transcriptions raised questions for us about the ability of students to produce independent texts and about ownership of the text.

These results illustrate the on-going tension within the academy between reforming existing practices to accommodate non-traditional student writers and preserving long-standing assumptions about the production of written texts. As reformists, we believe that students should be able to demonstrate knowledge in various ways and that there is no single literacy that should dominate the academy. In fact, the academy should make room for different forms of discourse and should value these disparate ways of knowing and of demonstrating knowledge. Our own collaborative work is evidence of this belief.

Additionally, we have spent much of our professional lives seeking ways to integrate marginalized groups, like our deaf students, into the dominant culture. As composition teachers, we have allied ourselves with postmodernists, feminists, and multiculturalists, because we recognize how the academy and the workplace perpetuate traditional power structures and eurocentric, mainstream - "hearing" values. For many basic writing students, but particularly for deaf students, these "power structures" are often linked to issues of language, especially the requirement to produce standard written English. So, despite how we perceive our efforts and our theoretical positions, our 
students see us as "gatekeepers" in their progress toward their college degrees and, therefore, their professional lives.

Allan Luke, in his book, The Insistence of the Letter, criticizes both gatekeeping and the gatekeepers: "English language and literacy courses thus stand as the significant gatekeepers for regulating membership and access to dominant discourses and traditions, relations of knowledge, power, and authority" (Luke vii). Linda Brodkey echoes this sentiment, describing the function of writing courses as "guard[ing] the gates of the profession" (221). In theory, abandoning the gatekeeper role is attractive. However, we continue to see on a practical levelwhere our preservationist side emerges - that traditional print literacies affect the academic success and potential upward mobility of basic writing students.

One driving force behind the mission of RIT as a technical institute is to prepare its students for the workplace, and the parallel mission of NTID is to move its students into a different work force, freeing them from print shops and auto-assembly lines. Students choose to attend NTID/RIT, we assume, because of this stated mission and their desire to join the professional class. In a recent College English article, "Students' Goals, Gatekeeping, and Some Questions of Ethics," Jeff Smith reiterates this contention that students attend college because they want "rewarding jobs" and "career advancement" (303). He argues that we prefer to ignore students' motivation for pursuing a college degree - they want to be "credentialed" (303). As their teachers, then, we have to accept that a critical part of this credentialing process requires that students "learn those rules" of written English and demands that we "are there to teach them" (304). Smith further describes this teacher-student relationship as an "enterprise" (312) which consists of the teacher and of the students who are now "clients" and eventually become professionals who will also have "clients." For him, a teacher "cannot ignore the claims of that larger enterprise" (312) - college, community, workplace. Smith describes himself - and us - as "agents" of this enterprise, one consequence of which is the "obligation" of "gatekeeping" (312).

As composition teachers, we cannot abdicate the role we play in preparing basic writing students for the current political, social, and economic realities of the workplace and beyond. In Rochester, for example, as the local industries like Kodak and Xerox downsize, a large number of deaf employees have been either terminated or kept from promotion because of their weak written communication skills. While we might like to think that a more flexible work environment would not penalize productive workers for this specific "deficiency," the bottom line mentality is not that flexible. As proficient as these deaf employees might be in ASL or in other literacies, their proficiencies have not been sufficient to save jobs or facilitate promotions in the work- 
place.

These same forces which control local industry now dominate Washington as well. When ADA was passed, we believed that, instead of our students having to adapt to the workplace, that the workplace would be forced to find ways to adapt to them. We relied on the good intentions of people and the spirit of the law. Now, the only news we hear is that of budget cuts, the end of Affirmative Action, and the end of unfunded mandates like ADA. These realities have moved us closer to the preservationist stance than we normally would be or would we feel comfortable.

\section{Phase II}

As we grappled with the tensions between our reformist and preservationist selves, we understood that our resistance was to the concept of mediated texts as alternatives to print literacy. Therefore, we decided to look at mediated texts as a strategy in acquiring academic writing skills, hoping there would be less dissonance. Shirley Brice Heath used a similar strategy for disadvantaged hearing students who, she says, "have judged themselves entirely unsuccessful in writing" (Langer 99). She asked them to "transcribe a short portion of their talk from [a] tape and to work with the teacher and another student to turn the oral language into a written form" (Langer 99). We recognized from the success of her work that this translation technique had potential for our students. Rather than looking at the mediated text as an alternative to academic writing, which connotes substitution, we were drawn to this technique as a way of helping students develop their academic writing.

For the second phase of this study, then, we modified many variables - the student profile, the translation process, and the students' involvement with the mediated texts.

\section{Student Participants}

First, we targeted a different group of students - those whose compositions ranged between " $C$ " and " $B-$ " but who had not yet passed the timed exit exam. These students were successful in many of their other college courses which emphasized discipline knowledge and technical expertise rather than writing fluency. We thought them to be good candidates for a study of how mediated texts could help them demonstrate what they know through writing.

\section{Changes in Methodology}

Second, while in phase one the students were given the exit test question and asked to respond to it on video without any other prepa- 
ration, in the next phase, two students - Chad and Mark - were asked to follow a more traditional drafting process. These students began by independently producing their written response to a question. We then asked them to continue the drafting process on another day by meeting, along with one interpreter and their instructor, in a small conference room. Each student responded in an informal conversational way to the same exit test prompt using American Sign Language. The interpreter simultaneously translated the ASL into spoken English and voiced it onto an audiotape machine. The audiotape was later transcribed; each student's transcription was given to him as his second draft, to be used in the revision process. For his final paper, each student had access to his first draft and his mediated text.

This change in the translation process, which produced the mediated text, involved the elimination of the video; student feedback in the initial experiment suggested that videotaping was overly formal and intimidating. Simultaneous voice translation corrected these problems. Using one interpreter instead of four reduced the complexity of the process, which allowed the students a more natural, interactive way of developing their thoughts on a topic. The resulting audiotape transcriptions also had a quicker turn-around time, which resembled a more natural drafting process.

In phase one, the students simply chose one out of four mediated texts and submitted it as their final product. The decisions they made were a "matching" process rather than a production one, more passive than active. In the second phase, students assumed responsibility for writing both the first and the final drafts themselves, using the mediated text as a significant part of the heuristic.

\section{Findings - Student One}

As a way of reporting the findings of the second phase of our study, we first want to focus on one student writer-Mark-and his mediated text. Mark is a twenty-one-year-old, Cambodian-born student pursuing an associate's degree in Industrial Drafting Technology and aspiring toward a bachelor's degree. He became deaf at the age of five and moved to Massachusetts two years later, where he began to learn signed and written English. He has some lip-reading ability and uses voice occasionally, but he prefers a combination of signed English and American Sign Language without voice as his mode of communication. With hearing people, including his parents, Mark uses written English. His parents speak Cambodian and some English at home. Mark has attended mainstreamed programs since kindergarten and is experienced using interpreters. He is a very conscientious and successful student who, like many basic writers, considers his major obstacle in composition to be putting down his thoughts in appropriate words and grammatically and syntactically correct sentences. 
For his first draft, Mark wrote, without time limitations, a response to the following prompt-a typical exit test question given to all students in RIT's English Composition courses:

Modern technology helps us in our everyday lives. Select one invention that has had a significant impact on modern life (i.e., personal computer, TTY [teletypewriter], TV captioning, Internet, etc.). Describe the ways in which your life would be different without this invention. Develop your essay with specific examples and details.

In looking at the introductory paragraph of Mark's first written draft, we see many of the problems deaf students face in writingsyntax, grammar, and diction:

Since the invention of TTY devices, there have been a better life for those people who lost a voice and speech and their relationship with hearing people. Without these new technology, many deaf people such as me would not have a good life as well as socializing with hearing people. Modern technology such as TTY devices have helped our everyday lifes for those people who lost a voice and cannot speak.

More important than the problems with surface features, however, this introductory paragraph makes essentially only one sweeping point: that people without voice and speech are helped by the invention of the TTY, because it gives them a connection to the hearing world. That point is repeated explicitly in the first and second sentences and is implied in the third.

Later, Mark responded to the same prompt in American Sign Language to create his mediated text, which shows noteworthy differences:

My topic of modern technology will be about the TTY. I'd like to talk about the different evolutions of technology in the world. There have been a lot. Before any technology was invented, there were just deaf people, and words were nothing to deaf people. They were just mute. There was nothing there. How do people communicate with them in the world? I'd like to explain about modern technology and how it's helped us communicate, receive information, and become more independent.

At a glance, the changes from his first draft seem minimal. However, when we take a closer look, we find some interesting shifts. In the 
mediated text, Mark establishes a larger context for the invention of the TTY - the "evolution" of modern technology. In his first draft, the phrase "people who lost a voice and speech" focuses on the pathology of deafness, while in the mediated text, the phrase "words were nothing to deaf people" connotes more about the nature of spoken language itself and its role in the communication of deaf people. Also, Mark's use of the first person pronoun in the mediated text helps establish him as an authority in his argument. The first draft hypothesizes about life's difficulties without the TTY ("would not have a good life as well as socializing with hearing people"), while the mediated text focuses on communication, not just socialization ("how do people communicate with them in the world?"). The word "mute" in the mediated text conveys not only a physical condition but also the marginality and isolation that accompany this condition ("there was nothing there"). Finally, regardless of how we feel about a formulaic thesis statement, Mark's final contention in the mediated text is much more specific than the repetitive and general final sentence of his first draft.

Mark's use of the mediated text to compose his final draft allows him to move towards a more coherent presentation of his thesis:

There have been a lot of different evolution of modern technology in the world right now than before. Most of them have helped a lot of deaf and hearing people become united together than before. For instance, TTY is a new modern technology that has changed a lot of deaf and hearing people life after it has been invented, such as deaf people could communicate with hearing people and more. TTY also helped deaf people receive information and become more independent very quickly.

We find it interesting that in this final draft Mark provides a place for hearing people to benefit from this technology and that he sees it as a site for community. What we miss, however, is Mark's "presence" in the text and the imagery of his still-unpolished prose.

Mark's third draft-his final revision - was a minimally passing exit exam. The improvements from the first through the third were substantial enough for all readers to agree that it should pass. The examples offered earlier, all from the introductions of his three drafts, represent the kinds of revisions he made throughout his texts. The organization of the essay, the improvements in sentence structure and syntax, the clear use of the first person stance on the issue, and the development of the idea through examples all point to the positive influence of the mediated text. Consider, for example, the following sentence from the first draft: 
Another reason [why the TTY is important] is to receive many new informations easier by themselves such as asking the operator for company phone numbers, emergency phone numbers, etc. than depending on other people, who could hear and speak, to speak on the phone for them.

In the mediated text, Mark devotes four-and-one-half pages to a discussion of how to receive information through the TTY and disperses many examples over several different paragraphs. In the final draft, Mark writes three sentences which revise the original one sentence while including many of the ideas and examples which had been clarified through the mediated text. The final version reads:

Another reason [why the TTY is important] is receiving information. For instance, we as deaf people, could call the police, the fire department, the operator, the hospital, or whatever very quickly when we have a last minutes emergency. There are just many different uses for the TTY.

Although Mark had the opportunity to produce an error-free paper by submitting the mediated text, he chose instead to continue the revision process with the third draft. He explained to us that he wanted to expand his ideas in certain places and was not content with the mediated text - the second draft - even though it was syntactically and grammatically better than the third. Because we had not asked the question directly, we can only hypothesize why Mark made this decision. Was it his sense of integrity or his fear of plagiarism? Or was it his need to own his text? In our next case study, we attended to these specific questions while we continued to analyze the value of the mediated text.

\section{Findings - Student Two}

In order to further our investigation of the mediated text as a heuristic, we looked at the drafting process of a second student, Chad. $\mathrm{He}$ is a twenty-year-old, Canadian-born student who has been deaf since birth. Chad attended residential institutes for the deaf in both the United States and Canada through high school; at RIT he had his first experience with a mainstreamed academic setting. Chad is a second-year Information Technology major, pursuing a bachelor's degree and aspiring to a master's degree. His preferred mode of communication is American Sign Language (without voice) in academic situations; at home, with his hearing family, he uses sign language that follows English word order and incorporates a great deal of fingerspelling. With hearing people who don't sign, he relies exclusively on writing. Chad sees himself as a "satisfactory writer" whose writing is "com- 
prehensible," but identifies his lack of English vocabulary as a problem (in contrast to his extraordinary fluency in ASL), and he feels limited in getting his points across, a frustration often voiced by many other basic writers.

Chad wrote a response to the same prompt which Mark had been given-one aspect of modern technology that has had a significant impact on his life. The introductory paragraph of his first draft clearly shows his skill with introducing the general topic and narrowing it down to a thesis. Although it is more fluent than Mark's text, it is still marred by grammatical errors:

Internet is today's modern technology that makes life easier for everyone - the deaf, blind, crippled, and so forth. For this reason, internet is an electronic way of getting any kind of information through a modem to another modem all over the world. One of the most useful place to find information is using the world wide web where it have everything you need to know about. In other words, it's also known as our electronic encyclopedia. Internet made life easier and what would it be like if we never had internet?

Life without the internet would be very difficult because there would be no easier access to information. Secondly, there wouldn't be equal opportunities; especially for the deaf. Lastly, this world wouldn't be much of a friendlier place to be in because we wouldn't be able to make friends internationally.

The focus of this introduction is clearly on the beneficial aspects of the Internet, particularly for information-gathering. Rhetorically, Chad is moving toward the traditional three-paragraph development of the thesis. Perhaps the most innovative aspect of this introduction is that it is spread over two paragraphs and the thesis statement is cast as a question and a series of answers.

The next time we see Chad's ideas on the topic is in the mediated text. The most apparent difference between his first draft and his mediated text is the contrast in length - a six-paragraph essay versus five full pages of information and ideas. What immediately strikes us in these pages are the changes in direction which Chad chooses. Initially, he takes the same attitude toward his subject (the positive aspects of the Internet), although making a much more detailed argument to support his opinion. By the second page of his mediated text, however, Chad is beginning to explore the "dangers" of the Internet as well as its benefits; he briefly likens it to a "drug" to which a person can become "addicted." We also see a more sophisticated way of broaching and expanding ideas raised in the first draft. So, for example, in the 
first draft Chad devotes a whole paragraph to the ways in which the Internet helps to develop equal opportunities for people who are "deaf, blind, and crippled," describing how the "text on the Internet doesn't reveal our disabilities." In the mediated text, Chad continues this theme of the Internet preventing discrimination, but doesn't fall into generalizations as he had in his first draft. He also introduces the idea of discussing the Internet as "neutral space":

Well, blind people can use the internet, because I was chatting with this one guy on the internet and I just wanted to let him know I was deaf. As we were talking through the conversation, he said "oh well, by the way I'm blind." And I was puzzled as to how he could use it, but he had a keyboard ... a specialized keyboard or something that transcribed his voice into the typed text. So with the internet if he wanted a job or just to chat with somebody or conduct business over internet, he would be able to, was just normal. You don't have to worry about ... being, you know, the most articulate or skilled writer and I was really surprised when I found out that this person was blind.

So I think that the Internet will help to prevent discrimination. It seems to be a very neutral space, and it will force us to judge each other on. . . you know, the words and the intelligence and the vocabulary. You know, it's uh sometimes you think it's uh, you know, this person you're conversing with, you're "wow, this person is very smart by the way this person speaks and types and the words he uses," and then later you find out that the person is disabled whether he be deaf or in a wheel chair or blind and then another person might use very simplistic vocabulary and think well "gee, he's a knucklehead," and you find out that he's a regular hearing person. So, in that respect it's a very neutral space.

In the mediated text Chad includes other points not in his first draft, like the ways in which the Internet makes research outside the library possible. Mark, the other student writer present during the taping of the mediated text, commented that the Internet might contribute to the "demise of libraries," which led Chad to see the negative effects of Internet technology on the postal system as well. Mark asked Chad to consider the effects of "the different questionable things that are on the Internet, like porno." Chad then considered how the Internet seems to progress without our taking careful stock of it and finally suggested limitations that should be placed on it.

By the final draft, Chad had the opportunity to sift through his 
initial draft and the mediated text, extracting those ideas which he found most useful to the development of his thesis. Chad writes:

Internet is today's technology that allows us to communicate with everyone in the world and access to information via a computer hooked up with a modem. Today, isolated internet users sit in front of a monitor using addictive internet applications such as Internet Relay Chat, World Wide Web, newsgroups, E-mail, conference rooms, and many more. What would happen to our society if the government shut down the internet?

Remind yourself that our life are a lot easier because of the internet. For this reason, we can use inexpensive Internet Relay Chat to your families and friends without paying phone bills. We can use World Wide Web for the following: we can get free electronic newspaper daily, go shopping in your home on a rainy day, obtain a lot of information for your research paper without going to the library, and many more. In addition, we can write letters to our friends and families and they can get it in a matter of seconds without the need of stamps. The bottom line is, we are living in a society full of people who no longer wants to wait and requesting speedy services. Internet is here to satisfy our luxurious needs.

Chad has maintained the two-paragraph introduction and the question-answer format of his first draft. The reference to "isolated internet users" and their "addictive internet applications" immediately picks up the drug metaphor which he had begun in his mediated text; he also takes a critical stance which had not before existed. The second paragraph is filled with details regarding various ways in which one can use the Internet, including an embedded reference to libraries and post offices being rendered obsolete by the Internet. His final assertion is stronger; the phrase "luxurious needs" reinforces the criticism inherent in the drug metaphor.

Perhaps the most interesting and valuable emergence from text to text is the drug metaphor. As a passing remark, made halfway in jest in the mediated text, Chad signed, "And some people really are addicted to the internet. I think they really should set up some kind of rehab or recovery program for them (smile). It's getting serious, like a drug." In the final draft, this germ of an idea from the mediated text becomes the basis for his critique of the Internet. Chad sets up a comparison between drug use and addiction to the Internet by focusing on the progression of use; as a person escalates in his/her drug use from pot to crack and finally to cocaine, so an "Internet addict" progresses 
from e-mail to newsgroups to "the addictive World Wide Web." $\mathrm{He}$ compares the effects of a possible government shutdown of the Internet to a drug user experiencing withdrawal symptoms.

The rest of his final draft proceeds in a more balanced way than had his first draft, which focused only on the benefits of the Internet; in the final draft, Chad brings together both its positive and negative aspects. He maintains the point about the Internet providing equal opportunity for marginalized groups, like the deaf, the blind, and so forth. He again mentions the influence of the Internet in helping families communicate more easily across distances. New, as a result of the mediated text, is the reference to the threats to the postal system, to workers who will be replaced by this technology, and to children's "innocence" because of the amount of nudity and sex available on the Internet.

Chad's final draft also points out that we have come too far to retreat to life before the Internet. The addictive aspects of the Internet, the threats it poses - they are mitigated by its ease and our dependence on this new technology. He writes, "We have to accept that we cannot go back to the hard labor days anymore because the internet is our new oxygen."

If you remember, we had wondered about our first student, Mark, and his decision not to adopt for his final draft the error-free sentences of the mediated text. Chad made the same decision. He created a new text that took ideas, but not sentences (again, error-free), from the mediated text. We had not asked Mark about this choice, but this time we explicitly discussed with Chad the decision he made. Chad did not feel that he wanted to borrow the exact wording of the mediated text but instead to make it his own - "no cheating." He felt strongly about writing in his own style and language, using his own "voice." His response supports Maurice Nevile's contention - with reference to J. Gee - that "any language use cannot be separated from the 'identities' of the users, which represent 'socioculturally characteristic ways of being in the world-associations among ways of thinking. . . acting. . . valuing. ..' " (qtd. in Nevile 39). Clearly, Chad saw, even in the errors of his prose, some cultural-linguistic identity.

\section{Overall Implications}

We started this series of case studies from a recognition that our students, who represent a unique, non-traditional population within the academy, could benefit from a broad interpretation of "accommodation" as defined by ADA. This "accommodation" is critical because our students are entering a world of academic discourse, which for all students is alien and new, but which, for non-traditional students, be- 
comes a serious obstacle. For students using English as a second or third language, as well as for all basic writers, expectations of academic writing are more mysterious than they are to the traditional, if uninitiated, college student. Producing academic writing that demonstrates a critical understanding of specific problems, persuasiveness, an integration of diverse perspectives and multiple sources, and currency (Nevile 43) becomes a Herculean feat. The mediated text as an accommodation specifically designed for all these students provides one strategy which can facilitate the process of developing academic writing skills.

The issue of accommodation as mandated by ADA does not extend to ESL and basic writers in the same way in which it applies to deaf students. However, this heuristic can have practical and significant classroom applications for both groups. The parallel for certain ESL writers would lie in the use of a first-language voiced "draft" which would allow them to express their ideas, unencumbered by problems of correct English usage. Their spoken language would be simultaneously translated into English on an audiotape (just like the voiced translation of Mark and Chad's signed responses). The transcribed audiotape text would then serve as the mediated text for an ESL student to use either as a drafting heuristic - as a basis for developing academic discourse - or as a "workbook" for sentence-level language learning. A second population that could benefit from the mediated text is comprised of those basic writing students who use English as their first language but who produce a type of inter-language because of dialect and home-language influences. For these students, the audiotape of their ideas would be transcribed into academic discourse, providing them with a heuristic that can be used as a draft of an essay or as a source of language study. Chad told us, for instance, that, "It is interesting to see my ideas in standard written English," a comment which reflects the experience of many of our students. Finally, the mediated text would become an effective strategy for those basic writers whose complex thoughts are often lost as they try to compose in academic discourse and whose products, like Mark and Chad's, do not accurately represent the full scope of their thoughts. Not only would it support student development in composing more sophisticated, complex, and engaging products, but it would also provide the students with more control over a process which has always limited the expression of their ideas. For those of us engaged in the teaching of writing, the possibilities of using this heuristic over time could mean that, as V. Beasley suggests, instead of remediating students, we initiate them into the world of academic discourse (qtd. in Nevile 49).

Freed from the constraints of having to think in one language and write in another, students can express more complex and complete ideas when producing and then using the mediated text as a heu- 
ristic. In fact, Chad's final draft - to a greater extent than Mark's demonstrates what Cheryl Geisler calls the "multi-modal approach." According to Geisler, "expertise in academic literacy can best be conceived as the ability to negotiate three distinct worlds of discourse: the domain content world of logically-related truths, the narrated world of everyday experience, and the rhetorical world of abstract authorial conversation (44)." "Domain-content" involves taking discipline or domain knowledge and putting it into English, recognizing multiple worlds of discourse, and negotiating among those multiple worlds. The "narrated world" requires using narrated experience in a hypothetical way, manipulating stories to develop new arguments, and applying stories to other arguments as a way of testing the logic. The "rhetorical world" combines the content knowledge and the rhetorical process.

As a result of using his mediated text, Chad's final draft in particular reflects a new fluidity in his movement among these three domains. Chad's creation of the drug metaphor, for example, shows how stories from everyday experience can be re-created to develop a new argument. Chad goes beyond citing a story as an example or an illustration of a claim. The final draft, then, demonstrates Chad's progress within the "content domain" when he embeds opposing viewpoints by creating an analogy between the world of the Internet and the drug culture.

We have thus far concentrated on the successful use of the mediated text. We cannot ignore, however, the various problems that may arise in adopting this strategy. On the most practical level, using the mediated text requires a great deal of time (from the instructor) and a significant investment of resources (for the interpreter and transcriber) - issues inherent in any attempt at change. In addition, there is always the possibility of abuse. One of our students, not involved in this study, recently admitted that he signed his ideas for his short story essay to his roommate, who then wrote them down in standard English. The "translator" became the "writer," even though the student saw himself as the author merely dictating his ideas. However, if mediated texts are part of a sequenced, guided pedagogy, the misuses would be minimized.

On a more philosophical level, some will suggest that using a mediated text discourages independence in writing; some will have concerns over the consequences for these students once they leave the academic environment, enter the work force, and are asked to produce their own texts. There is also the thorny question of ownership when students have access to the language and syntactic structures produced by others.

It was, in fact, these issues of independence and ownership, coupled with assessment, that prompted our initial skepticism in us- 
ing the mediated text as an alternative to the traditional demonstration of print literacy. Our first phase of this study confirmed the legitimacy of our concerns. But, in revising our research question and adapting our methodology, we found that the issues of independence and ownership were minimized. In order to reduce the possibility of students co-opting the language and syntactic structures of the mediated text, we recommend that instruction in the appropriate use of this heuristic be an integral part of its implementation.

The use of the mediated text proved to be successful for Mark and Chad in allowing them to pass their exit exams, but it was an isolated event in their experience in college writing courses. We strongly suggest that students have multiple opportunities to take advantage of this heuristic in their writing courses. Mediated texts could also prove valuable in other discipline-based courses that rely on written texts to demonstrate mastery, mirroring and augmenting the benefits gleaned from the writing across the curriculum movement. In addition, students experienced in using this heuristic appropriately - as a stage in the drafting process which allows them to move toward a product - will become more adept in producing academic writing, in yoking the domain, content, and rhetorical worlds which Geisler has identified.

When we began this study, we were uncertain about the implications of using this heuristic in an academic setting where it could be seen as giving some students an unfair advantage. The case studies, however, demonstrate that students felt so strongly about their own voice and thoughts that they did not sacrifice them for linguistic perfection or grammatical fluency. Instead, they took advantage of this heuristic to express their ideas more thoroughly and with increasing sophistication. Given these preliminary results and the potential of the mediated text as a heuristic, our hope is that teachers will convince colleges and institutions to support the development and use of this approach as a viable way of meeting the needs of non-traditional students.

As we step back and think about what this project has meant, it is clear that its benefits have been not only for the students, but also for us as teachers. When we listened to our students and attempted new ways of accommodating their needs, we had the opportunity to challenge our long-held assumptions about the production of academic writing, consider new ways of "doing business," and embrace the resulting innovations. 


\section{Works Cited}

Brodkey, Linda. "Writing Permitted in Designated Areas Only." Higher Education Under Fire. Ed. Michael Berube and Cary Wilson. New York: Routledge, 1992. 214-237.

Geisler, Cheryl. "Exploring Academic Literacy: An Experiment in Composing." College Composition and Communication 43.1 (1992): 39-54.

Heath, Shirley Brice. "The Literate Essay: Using Ethnography to Explode Myths." Language, Literacy, and Culture: Issues of Society and Schooling. Ed. Judith A. Langer. Norwood, NJ: Ablex, 1987. 89107.

Luke, Allan. The Insistence of the Letter: Literacy Studies and Curriculum Theorizing. London: Falmer, 1993.

Nevile, Maurice. "Literacy Culture Shock: Developing Academic Literacy at University." The Australian Journal of Language and Literacy 19.1 (1996): 38-51.

Smith, Jeff. "Students' Goals, Gatekeeping, and Some Questions of Ethics." College English 59.3 (1997): 299-320. 


\title{
Liza Bruna, Ian Marshall, Tim McCormack, Leo Parascondola, Wendy Ryden and Carl Whithaus
}

\section{ASSESSING OUR ASSESS- MENTS: A COLLECTIVE QUESTIONING OF WHAT STUDENTS NEED - AND GET}

\begin{abstract}
What follows is a colloquium zolose participants are all doctoral candidates at the Graduate School and University Center of the City University of Nerv York (CUNY). They are students of rhetoric and composition zuho are also teachers advocating for their ozvn students, presenting, in public forums, arguments and testimony about current and proposed assessment practices in CUNY. United against screening assessments that would keep some students out of mainstream courses, senior colleges, even college altogether, they nevertheless represent a range of perspectives, not least of all because of their sensitivity to the complexity of the issues they address. Recently, they presented as a panel at a conference called "Confronting Extremes" and sponsored by the CUNY Grad Center's English Students'Association. Their presentations zvere compelling (and would fill an issue ofJBW), but so was their conversation over coffee aftenvard, and so we asked them to develop an online discussion that would run about the length of an article and air the issues they zuere zurestling zuith in a zuay that could engage a national readership. Here's zohat they said:
\end{abstract}

CARL: So much of our attention is on the testing situation in CUNY. How do we expand this to have national interest?

LIZA: I think it won't be difficult to broaden this discussion, especially if we begin with Wendy's call for an end to all assessment. I am stuck between respecting the work of revolutionary composition theorists like Freire and Shor and worrying that the revolutionary agenda is just not what most students want. What about the fact that working-class and low-income students have next to no "cultural capital" in our society? What about helping them gain access to the information and economic independence that would give them the options their professors have? Where do they weigh in on the question of what education is for and what acquiring "writing skills" is for? What do they want from their language?

IAN: I think Liza here has asked really important questions. But in answering them we should not forget the role of ideology. Helping 
students gain access to the information and economic independence that would give them the options their professors have does not exclude them from the ramifications of the ideas espoused by Freire and Shor. What I wonder about is how well we help them see that, as Leo pointed out to me one day, "Freedom isn't free." What are they going to do when they get these jobs and the added economic independence?

What comes to mind also is Jean Anyon's essay, "Social Class and the Hidden Curriculum of Work." I think much more work needs to be done with the findings of her essay to examine social control mechanisms vis-a-vis ideology and its effects.

LEO: Leaving Anyon's essay to the side for a moment, I think we need to evaluate more closely how "cultural capital" functions in a society that divides mental from manual work and that rewards them unequally. We would need to consider phenomena such as corporate and university downsizing (including but not restricted to racist attacks on affirmative action and open admissions), how labor is evaluated and purchased in this society (proliferation of "flexible" part-time cheap labor), and the division of labor within the family and the relegation of women's "cultural capital" to the bottom of the socioeconomic scale. And what kind of "cultural capital" is writing? Is it primarily a technology for transmitting information? How will our students and their future employers value writing? I' $m$ reminded of the inescapable question of our field: what makes writing good? Cultural capital is never politically innocent.

I question any analysis that attempts to explain inequality as a "lack" of cultural capital. That might just be conflating correlation with causeand-effect. Such an analysis accepts the notion that U.S. society is a meritocracy in which talent, hard work, and "results" are rewarded appropriately. Well, even the most cursory glance at the distribution of skills against the distribution of income indicates that our economy is not, in fact, based on a meritocratic division of rewards. Everyone ought to receive as much education as they want, and it ought to be free. But increasing access to education, which has always been unequal, has not and will not - on its own - substantially change pervasive inequality. Inequality is structural, and, however much it hurts us to hear it, education plays a role in perpetuating it.

TIM: Hmmmmmm. Not sure any of us would disagree with Leo here: Education certainly plays a role in perpetuating inequality, especially given higher education's somewhat hidden capitalistic agenda, and the students' overt desires to gain better employment through education. But I think we are all dancing around the task of the writing 
teacher. Even though education is politics, the writing classroom should never become a space where politics is in the foreground and writing is in the background. The writing classroom is a contact zone, no doubt. And we are the mediators of that contact zone. But more importantly, our primary job is as facilitators of a writing environment. In a writing classroom where plenty of writing is going on - where writing is being discussed and read aloud, where writers talk about how writing works, where writers see the power of writing in action-discussions of inequality, gender, race, class and others will certainly arise. It's the nature of writing to reveal.

LIZA: I think students (including myself) get a lot out of seeing their work in print, "experiencing" the reading public when they see their work being read and thus recognizing the other side of writing: being read, responded to, and writing again with a more visceral understanding of the community or contact zone that is their audience. With this in mind, my question for Wendy is what I would be concerned to call a complete erasure of product in a process-only approach.

WENDY: What is the goal of the writing class is the essential question. I don't think it should be producing essays - at least not the kind that have been traditionally elicited in the composition class. (And what I mean by that is a whole other question, isn't it? Because there really is no agreement about what we are looking for in product.) Anyhow, I am calling for an end of product, or at least a big de-emphasis of it. (I'm not calling for an end to assessment altogether - I "just" want a radical shift of criteria, which probably would sufficiently sabotage our concept of assessment to the point where it would be unrecognizable.) In Jasper Neel's Derridean discussion of form, he says, "The one thing the act of writing cannot be is structure. At the moment of structure, writing has ceased to be read because the writer is what must be gone for the reader to take over. As long as the writer is still the writer, any analysis of structure is precluded" (39). I think I'm interested in the writer staying the writer. Rather than this being an elitist position I see it as being democratic. I know Neel's project is to rescue writing from what Plato has Socrates do to it in the Phaedrus, but for a moment I would like to treat the condemnation of writing there transparently. What if we breathed life back into dead absent writing by keeping the writer and the writing together in the public space of the classroom where both could be interrogated rather than trying to produce this thing that will leave the writer and stand alone (like the cheese in the Farmer in the Dell). Maybe what I'm looking for (like Socrates?!) is a more dialectical approach to writing and what we want to be the goal of the writing classroom. This to me is also a move towards putting the rhetoric back in the composition because I envision students using 
their writing in this sort of public space to persuade (and perhaps even plot action). And I do think that somehow by reintroducing literacy to students in this more "vital" way that their facility with language would eventually increase in ways that it doesn't for most people with the way writing is taught now.

CARL: I want to get back to Liza's question: What about giving our students what they want? Specifically, students often request that we teach them "proper" English, the language of business (and, not so incidentally, the language of academia). Are we doing them a disservice by advocating for alternative methods of writing evaluation?

The issue of students desiring Standard English is a difficult question. I find this challenging because a fundamental principle of democratic education is that students should be able to decide what they want to study. Yet I think in many ways a request from a student to learn proper English is not solely (or even primarily) a request for grammar exercises. Rather we must consider the motivation behind the students' request; the request for instruction in proper English results from years of education during which the student was exposed to teaching which emphasized correctness over communication.

I've often found that students who ask this type of question are really inviting me into a dialogue about my teaching methods and the uses of language. That is, the students are asking about the context of language. They know that the code they use at home is not the code of business or of the academy. Logically, then, they are demanding access to power through access to language that matters.

Our job, I would argue, is not - and I don't believe any of us are advocating this - to exclude students from discourses of power, but rather to provide them with a way into that discourse. Yet the goals of a transformative, democratic pedagogy are not simply assimilationist but rather ask students to maintain their home identities, their home discourses (codes) and to understand (perhaps transform) the discourses of power.

To answer Liza's question, when a student asks, "Why aren't we learning more about 'proper' English?" we cannot tell them just to write what they feel, write any way they like, write about what concerns them (expressive writing has a place but is not the only agenda in writing); rather, we must take this question as a moment to bring up a discussion of context and codes. We should also think about the moment this question arises as a chance to invite students to rethink the university; it's time we stopped merely pretending to allow students 
to regulate themselves and their discourses without helping them to see how they're situated and conditioned. Here I'm reminded of Pat Bizzell's insistence that "the cultural values and content" of the classroom need to be determined by both the instructor and the students. This question seems to me a great moment to encourage students to help us see the university from the bottom-up rather than the top-down. A transformative pedagogy must answer the question of "proper" English and grammatical correctness, must provide students access to discourses of power, but it also must provide students the chance to challenge and maybe even change the discourse of power.

TIM: My first impulse is to suggest that all language users have to worry about grammatical correctness. I mean, regardless of what group you are speaking and writing to, don't you have to use grammar to ensure that you are understood? The problem is typically that the students perceive Standard English to be the language/dialect and their own language and dialect to be inferior or worse. They do not realize that all languages and dialects have reasons for existing, reasons that give them real integrity - grammatically and otherwise.

LEO: I want to comment about something Liza said earlier. She points out that many students really expect and need to learn Standard English and that it's our obligation to teach it. No disagreement there. I just think we have to be very careful about how we characterize that desire and that need. The facts are indisputable. We live in a class society, and within it (risking a gross reduction here), there are dominant and dominated classes. Those in the dominant classes use, endorse, and require their own class dialect for the purposes of formal, business, and academic writing and communication. This dialect has become known as Standard English. Our professional obligation is to help students understand and implement the syntax and punctuation of Standard English. I only dispute why.

Students come to us with all kinds of needs, and, as writing teachers, we greet them with all kinds of demands. For example, placement instruments such as the decontextualized timed impromptu indicate of the irrational nature of some demands that students have to negotiate. I think it's fair to say that we agree that tests such as the CUNY WAT (Writing Assessment Test) are bankrupt. They don't measure what they claim to measure, in part, because they were never intended for use as placement instruments.

Students' anxiety over their failure to command Standard English is no doubt substantially produced by the recognition that only those who can speak and use this dialect proficiently have a chance at the 
economic rewards of a capitalist society. That is to say that the way our students read the relationship between inequality and language is produced by the same system that creates inequality. They are often ideologically predisposed to blame themselves (i.e., their failure to command SE) for their own oppression. Put differently, ask yourself: if every African American teenager (who did not already do so) could learn to speak and write SE overnight, would it make an appreciable dent in unemployment among black youth? I think not. Racism and economic oppression are structural elements of our society. They can be decreased but not obliterated through an increase in literacy. This doesn't mean we shouldn't fight as hard as we can to win whatever reforms will ameliorate these conditions. We should! But learning the codes of Standard English is not proof of cognitive capacity, nor is it a ticket to prosperity.

WENDY: I want for the moment to separate the radical from the efficacious and point out as Carl does that no one wants to keep students in the dark. If I had a magic wand, I'd give everybody command of Standard English, including myself. Clearly it won't happen through red-lining papers or doing all the other things that are traditionally done because if that were the case, there'd be no problem. When my students "invite me into a dialogue about my teaching methods and uses of language" (as Carl puts it), they often show concern about having their grammar corrected and their essays structured. My response is if this is how they have been taught in the past, then something must be wrong, because they are not happy with the results. They still don't think they write well. Maybe it's time to try something different.

CARL: Here's something from Freire. It seems important in working toward an answer to the question of teaching Standard English. "Indeed, the interests of the oppressors lie in 'changing the consciousness of the oppressed, not the situation which oppresses them' [Freire quoting de Beauvoir] for the more the oppressed can be led to adapt to that situation, the more easily they can be dominated. To achieve this end, the oppressors use the banking concept of education in conjunction with a paternalistic social action apparatus, within which the oppressed receive the euphemistic title of 'welfare recipients.' .... The solution is not to 'integrate' them into the structure of oppression, but to transform that structure so that they can become "beings for themselves"' (55).

WENDY: I agree, and I have found this tension between traditional expectations and "my" new-fangled ways to be beneficial (although not always exactly pleasant) in producing transformations in usage. 
It's no longer business as usual, let the teacher fix what's wrong. People have a heightened awareness about their use of language, which affords the opportunity to produce real change in their relationship to that language. So I think those questions about why they are not being taught the "regular way" are exactly the kinds of questions critical pedagogues want because now students are questioning their educational experience. It's essential to give space for this in the class, to make it part of the class and in this way allow, or perhaps insist, on that discussion of contexts and codes. If it were an easy thing to "assimilate" people, you might even be able to convince me to do it. But it seems only a very few can make it that way. Everybody else gets left behind.

And just another thing to throw into the mill here: A student just sent me a copy of an application statement she wrote to try to get a scholarship - it was really terrible, and I don't think she'll have time to make it better, but I sent her my suggestions anyway. That created a very different context for me as an instructor, reader and editor. I responded in a very practical way. Does anybody ever ask students to write letters or application statements for assessment purposes?

TIM: Wendy's question about assessment "product" is applicable to process as well. Recognizing that we are mediators between language communities rather than teachers of a single standard is step one of a sound critical pedagogy. I use language communities as a plural here not because I mean two; I mean many. There are the language communities the students bring, the language communities of the academy, and the language communities of the work force (just to name some arbitrary divisions). All of these can be split into smaller divisions: certainly the language community of someone from Bay Ridge is different from someone from Park Slope; just as, the language community in the history department talks differently from biology; and in the business world, the marketing department talks a different game than R\&D. All of these communities have rules and grammars and styles and forms to be followed. The problem is for a multitude of reasons (not the least of which is the subjugation of Composition under Literature) that students (and some academics) are led to believe that the language community of the academy is all one, and that it mirrors the language community of the white-collar working world. This is simply not true. But students come to us asking for THE language, as if we can teach one, without realizing the relationship between their languages, dialects and codes, and what it is they seek to know. So, I agree with Carl: when students ask for Standard English, they open up a great opportunity to discuss language use in context. If we can help them realize they already have multiple languages (codes) 
and that they already code-switch all day long, that's certainly a critical pedagogy in action.

What is so bad about giving students the opportunity to learn a new code? Teaching Standard English does not have to be offensive, identity-stripping, colonizing behavior. If it is taught under the right conditions - where it is not the only validated language-Standard English can be a powerful weapon in the arsenal of any student. And perhaps, as Liza suggests, once they are more proficient members of this new language community some students can transform the hierarchy of language and end our use of Standard English as the pinnacle of language learning, and as the gatekeeper to the university and other institutions of status and class.

The problem is not whether we should listen to our students' requests and teach them what Jesse Jackson calls the "cash language" "cash code"?). We should. But we need to make sure we foreground the question Liza posed. (Her question sounds like a great way to begin a writing class.) Students need to see Standard English for what it is: a meaningless term for multiple language communities which is used as a panacea to control and limit access to society; not for what it is not: a magic elixir, which, if they obtain it, will transform them into Bill Gates, or at least Donald Trump.

LIZA: I agree with Tim that "Standard English(es)" are not one language, nor the only language with a grammar, and I especially see value in helping students recognize their use of code-switching and their adherence to the grammars governing the codes they use as a point of entry into discussions of "the code formerly known as standard English." It reminds me of an article by Nan Elsasser and Pat Irvine about a curriculum Elsasser used at the University of the Virgin Islands, which centered on the theme of perceptions of Creole(s). These students spent a semester discussing the varieties of Creole they spoke, negotiating their grammar rules, discussing why no one wrote in Creole, and writing in Creole themselves, thus developing their mastery "of their own codes" and developing the language itself by using it for academic pursuits. This work was necessary, Elsasser found, in order to contextualize the dominant code for the students who had felt that they did not speak a language at all, but a "broken" form of English. It seems to me this type of curriculum answers the invitation to discuss the context of language and the relationship between certain codes and power that Carl spoke about.

Some practical problems I see are: a) heterogeneous classrooms where one cannot invite all the speakers necessary to discuss the grammars 
governing all the different codes in use (as Elsasser did), b) the unlikelihood that one teacher will be familiar with and thus able to help students develop skills in their own codes, c) the question of where ESL students stand: do Russian speakers who are learning English speak a variety of English that needs to be validated in the same way that speakers of Tex-Mex or of Caribbean Creoles do? In classes where the population is diverse, the issues students have with the particular code used in English classrooms are going to be quite different.

IAN: I see problems too. I wonder about Tim's earlier point about students transforming the hierarchy of the institution through language and also Liza's point about the problematics of validating one language over another. It seems to me that both these comments talk around, but not directly to, the tie to racism and sexism and their necessary function in capitalist USA, as Leo suggests earlier. To respond directly to Tim, in a way the problem isn't language so much as its insidious use. History seems to point out that speakers of other dialects rarely get to use these dialects to change the nature of the academy, but instead these dialects are used to help reinvent the hierarchy. The different dialects are used as weapons in the academy on the one hand to give the illusion of inclusiveness and on the other hand to accentuate difference in unhelpful ways such as complicated ESL and Basic Writing policies. The dialects get enveloped by the academy. This leads me to Liza's point. The accentuation of difference in this way makes it unnecessary to treat Russian speakers the same way we would treat speakers of Tex-Mex or Caribbean Creole. Different signals go off in heads when we hear Creole dialects for example than when we hear Russian dialects. In a way, you might call this passive racism.

Thinking about what others have said here, I was reminded of something Leo said. He was quoting someone, I cannot remember who, and he said, "If speakers of non-Standard English truly felt they had an investment in learning Standard English, you couldn't prevent them from mastering it." This is telling for me because it says that students know what the academy is all about. They don't trust it, and they don't feel a part of it. I've been thinking that it might be possible to evaluate a student's proficiency at "Standard" English as proportional to their belief that they are a part of the academy. Also, they are in no particular hurry to be transformed by something that does not accept them. I would also say that I think if you learn a different language, then, to some extent, you become someone different. You become a part of the group that speaks that language. I'm not sure how much I buy the idea that we can simply code switch. To me, code switching is not merely assuming one identity over another when we have a mind to or perceive that we should. I see it as a potentially painful, perhaps 
even contradictory thing. We are not different and multiple identities: we are one identity, though various facets of this identity may show themselves at various moments. I see some code switching as nearly impossible for some people without betraying something dear and important.

I for one don't mind if my students want to learn Standard English. I'll be glad to teach it to them. However, I would want them to know and understand that there are consequences to learning it: both personal and public, both good and bad. I want them to understand why they want to learn it. And I would want them to understand also that there is a difference between learning the language and learning Standard English in the academy. When we learn the language in the academy, we learn it in the stew of its politics I mentioned. What we have to do is not limit the students' ability or access to this language but change the political climate and atmosphere that they learn it in. We must see things like assessment and harking toward standards as social control mechanisms, particularly the way they have manifested themselves in the academy at the moment.

Tim's comments reminded me of a conversation I had with Wendy. We were talking about students' desire to acquire new language without recognizing that they have to change as a result. What seems inevitable, in fact, is that they must change. Our job, I think, is to teach that some changes are better than others. Some may be interpreted liberally as accommodations rather than true transformations; others may amount to true and helpful change - and the helpful change may be the more painful. I think if we want students to change, really, transformatively, and thereby change institutions, we have to see, and help them see, the systematic connections between the CUNY Writing Assessment Test and scarcity of Ph.D. positions or the South East Asian economic crisis and boom time on Wall Street with an increase in poverty nationwide. These are important connections to make.

WENDY: I thought I'd just add something Ian and I spoke about with regard to the Standard English question: remember the standard doesn't stay standard; it is also in flux so that the codes of students change the code of the academy they enter. The standard is not an unassailable bastion that stands protected from the rabble it tries to exclude: the conqueror, too, is changed by the conquest. Baldwin says he doesn't know what English would look like if there were no Black people in America, but he knows it would be a very different language indeed.

LIZA and TIM: (This reply to Ian is coming from Liza and Tim working collaboratively, which may be an effective rhetorical strategy for 
producing dialogic discourse, though we are having difficulty over ownership of this discourse, so there may be disparity in the use of pronouns.)

We understand where Ian is coming from when he says learning a new language or code changes a person. We have talked about this in regard to our own experiences going "home" from the academy and feeling alienated. But we're not convinced that identity is not fluid, or that we cannot move through many roles and feel somewhat comfortable in each of them. Personally, though sometimes alienated by or in some contexts, we would have felt trapped if confined to the narrow language communities we grew up in. Which of course brings us right back to agency. Regardless of whether we take an essentialist or fluid view of identity, if a person (like me or us) wants to attain a new community, it would be oppressive not to be allowed to do so. So, we think, we all agree that student agency should remain our prime concern, and we all agree that students learn language more adeptly if they are driven by their own interests. So we agree with Ian that academia can or at least should be transformed in and through the classroom by making students aware of the hierarchies and contextspecific nature of language communities. We appreciate, too, the harm that the attaining of a new language or code can do to personal identity. Taking such things into account can lead to a meaningful transformative pedagogy. The stakes are higher for some than for others because those who can "pass" are more easily able to assimilate or perform multiple identities. Learning "Standard English" should be done in a context that emphasizes "transculturation," Mary Louise Pratt's term for usurping the "master's tools" for one's own purposes.

LEO: I'd like to throw something in here about fluid identity and the trap of one's home (or any other self-selected) dialect or language. Many working-class academics have testified to a sense of shame about their former status as "nontraditional" students - the fish-out-of-water syndrome (see Janet Zandy's collections Liberating Memory and Calling Home; This Fine Place so Far From Home edited by C.L. Dews and Carolyn Leste Law; also, forthcoming texts by Gary Tate and Sherry Linkon). Tim and Liza's reference to a language trap reminds me of my own situation, having worked so long as a transit worker. I discovered there what my college education had made nearly invisible - that college graduates do not have a purchase on intelligence; they merely have an advantage in credentials. Cognitive capacity has nothing whatsoever to do with speaking a "nonstandard" dialect (see Labov's The Study of Nonstandard English).

If we have felt trapped in the past, and feel "empowered" now that we 
have facility in Standard, that is all to the good. The problem is that the feeling of liberation that often accompanies code switching is nearly always attached to the cognitive dissonance of mixed social identity. We all know that you don't get nuttin' for nuttin'; there's always a price. The price for the nontraditional student is that as they become more comfortable in Standard dialect, they are inevitably required to speak, think, and write as if they were someone else, someone not from the working class. The social "emancipation" or "liberation" we often identify as one result of higher education cannot change the dominant social relations of the culture. As Freire and even Dewey have pointed out, education is politics. In this case, the politics is usually that of the reproduction of the dominant social relations of capitalism.

CARL: If one of the goals of a transformative pedagogy is teaching (or facilitating) "transculturation," how do we put this into practice? I'm especially thinking about how we do this when administrative constraints and agendas are opposed to this type of teaching.

I think Liza and Tim are suggesting that students learning "cash language" (or "cash code") is a positive move because it creates an opportunity (access) for them to enter into the discourse(s) of (economic) power. And while I understand the desire to give students this access, I wonder if we can do this and create a transformative system of education. That is, if students learn to use "Standard" English, switch codes in the context of the university classroom, don't we miss a chance to reform the context, to reform - or transform - the university?

There is a tension between an approach that uses a "non-academic" code to challenge academic definitions (and rethink the college context) and an approach that argues for code switching as access and empowerment. Can we do both? If we argue for switching, do we leave "cash language" (and all its problems) in place, or can that method also challenge the status quo?

LEO: In this context, I will throw a monkey wrench into the conversation and suggest we ought to problematize our students' desire for social mobility. Hey, did I really just say that? Social mobility is one of the fundamental claims (like equal opportunity and political and legal equality) of U.S. political democracy. And higher education is one of the tickets out of the working class. However, the implicit paradox is that as more people "climb the ladder of success" (social mobility through increased education), inequality increases.

Radical economists and sociologists deny the routine claims to correlation between a general increase in education and higher income. In 
their Schooling in Capitalist America , Herbert Gintis and Samuel Bowles attempt to disprove this claim by arguing that since the end of World War II, the general increase in access to higher education has not produced a corresponding increase in income equality. As a matter of fact, economic inequality is worse now in 1998 that it was when they first published in 1977. All economic indicators point toward a consistent reduction in "real wages" since the early 1970s right through the 1990s. There is currently a greater disparity between upper and lower income groups in the U.S. than ever before. This is all true in a country in which there are nearly 15 million college students, more than in all the countries of Western Europe combined. More people are going to school than ever before - and for a longer time. Nevertheless, just like my grandma always told me, the rich get richer and the poor get poorer. You could look it up! (See Doug Henwood's Left Business Observer for more recent research on the correlation between increased education and higher income.) I'm working on a Ph.D., and my grandma never made it out of elementary school. Who's smarter?

CARL: Leo's monkey wrench-his problematizing of social mobility - hits directly upon the "tension" I was talking about between academic and "nonacademic" discourses. How can we use, and invite our students to use, ways of thinking about the world that have traditionally been excluded from the academy? The works of Zandy, Dews, and Law open the door for alternative methods by acknowledging the tensions those of us in the academy feel with working-class backgrounds. Yet, as the product of a working-class family that used education as a tool for social mobility, I find it hard to deny my students a similar opportunity. I don't want to deny my grandfather's (nor Leo's grandmother's) ways of knowing and speaking. Forty-some years of working on the bottling line for Anheuser-Busch and being a union man taught my grandfather that his daughter and grandson had a right to social mobility and that social mobility required education! A college degree and the economic benefits it brings are not myths. Yet the current university structure wasn't designed to change the inequalities in society; to apply Freire's critique of education, we could say that colleges "'integrate' [working-class students] into the structure of oppression." Our goal should be "to transform that structure." The question is how?

LEO: Conceding to students that they have a "right" to social mobility may just be an encouragement to prolong oppression. It ought to be challenged. Everyone has a right to education. This is significantly different from encouraging expectations of social mobility. Universal education is a position on which we should never compromise. The question is to what uses people put their education and what rewards 
they expect for their work.

As I mentioned before, this society encodes powerful differences between mental and manual labor, with immense differences in rewards. Our pedagogy should include a segment that challenges students to recognize when and under what conditions their education puts them in a position to reproduce inequality. It seems if we want to make a claim to a radical, critical, and "transformative" pedagogy, we should think about what is being transformed - the student or society. In Critical Teaching and Everyday Life, Ira Shor asserts that writing involves negotiating between competing interpretations of reality. I think he says that reading and writing are "occasions for questioning social reality." Education and culture provide one set of critical lenses; they are not and cannot be neutral. James Berlin and Richard Ohmann have said much the same thing in their discussions of education, ideology, and the writing classroom. A truly "critical" writing pedagogy ought to keep these distinctions in the foreground. Transformative education needs to keep a sharp focus on the goal of social equality and "transforming" and questioning the university as we attempt to make that a reality.

WENDY: Carl's use of the term "discourse" reminds us that the students are not just about the learning of Standard English; they are also supposed to learn standard forms and conventions - and to perform well on "standardized" assessment. Can we envision other kinds of assessment, ones that ask for some other kind of writing? Like a letter, for example, or an application for getting a scholarship? (I'm thinking of that experience I had helping a student do this recently, and how I found it a very different experience from the way I respond to a student's writing in class). Doesn't it make sense that we should move away from a fixation on the essay, that different genres should be tested? And would this get us anywhere in a critical pedagogy?

IAN: Both Carl and Wendy's comments here suggest to me that the role of the academy is not so much to teach practical things on the one hand and is hardly a site for real social change on the other. Would it be crazy for me to suggest that we should change the structure of our courses in radical ways? For example, make things more dynamic by doing more things outside of the classroom like attending a local rally organized against racism, sexism or the WAT and then talk or write about the experience in the classroom afterwards. What I mean to suggest is that if we are truly against something like racism, shouldn't we both practice what that means as well as theorize about it? Doing something outside of the classroom like attending a rally would be doing something. The more I think of this the more I question the 
academy's purpose and role. At the Conference on College Composition and Communication, this year I was in a workshop with, among others, Ira Shor and Gary Tate. Gary asked a question that went something like this: "What is it that separates you from the people you grew up with?" My first thought was that I spent much of my free time thinking and reading about the things I was interested in. Forming and attending reading groups and talking about stuff like politics, history and literature. Very often this time spent reading and thinking introduced me to alternative ways of seeing what I did in school. I even read at my part-time job while my friends worked at jobs that didn't necessarily allow for reading or did other things with their spare time. As I was thinking this, Ira said almost verbatim what I was thinking. The point I want to make here is that most people, working class people, at least, don't learn these critical skills or discipline knowledge in school. Of course, this may not be a surprise to us, but my further point is that school as we know it may never be positioned in a way to allow real critical evaluation of itself to take place or real change. Something drastic or radical is needed.

LIZA: I know you are asking about "standardized assessment attempts," but I wanted to share my attempt to use a standard writing format subversively, and to create a final exam that asked for alternative forms of writing, for what it's worth. I just finished teaching an adult education course through a Cornell University "off campus" program. They employ part-time teachers to teach employees at several corporations (Am Ex, Xerox, Chase). It was the kind of thing you'd hate, Wendy: business writing for Chase Bank employees (education for the corporation, paid for by the corporation).

Anyway, for this term I asked them to pick a theme; they chose family. I began giving them stories and articles that talked about family and work, and we began discussing the family leave policy at Chase. This evolved into an assignment to write a business report on the bank's family leave policies, comparing them with policies at other corporations, and in other countries, most notably Sweden, the place where they all said they would prefer to be pregnant (even the two men in the class). Students really got into this project; even one woman who had said it had nothing to do with her because she was done having children went to the library and got extra articles on the subject to include in her report. Their "final exam" had to be in-class writing, so I gave them two choices that both drew on the context we had built through discussions in class. Choice A was to write a letter to President Clinton telling him their feelings about the FMLA (Family and Medical Leave Act) passed in 1993: they could critique the act, make proposals to expand it, tell how it affected them, or make any other 
comments about it. I told them to bring to class the articles on the act we had discussed, and to use any arguments from their business reports that applied. Choice B was to write an extended journal entry modeled after Tillie Olsen's "I Stand Here Ironing." I haven't read them yet, but I was impressed by how long and concentrated a writing session it was. Most students wrote many more pages than I had requested. To sum up then, students used the conventional business report format to assess the corporation. They, in turn, will be assessed on their reports and on the timed exam that asked for alternative forms of writing, drawn from the context we developed over the course of the semester.

WENDY: Bravo, Liza - and I just wanted to point out that I approve of corporations paying for corporate training. I think corporations should assume that responsibility. What I balk at is corporations using public money (via the public school system, not least of all that the post-secondary level) for that training.

TIM: I agree that Liza deserves applause and I think the academy could learn from her assessment measure. Unfortunately, had her students been in the academy, they would have had to take a standardized, timed, impromptu test at the end of her class. A test that she would not grade, and a test determining whether students failed and would not be "promoted." This is the conundrum we face as writing teachers: we are not in charge of the assessment. The assessment measure is exterior to the class, and the students know it. Although I try to create a classroom atmosphere that is not manufactured and contrived, although I work hard to have my students write for a purpose that is connected to their real world, along comes the assessment measure which breaks that connection. Assessment thrusts students back into the clinic - the laboratory. They have been in the educational maze for so long, they smell it a mile away: the goal is to get the cheese in the fewest tries. So, no matter the form or genre of the exam, when they smell assessment, they return to a manufactured discourse to fulfill what they think the academy wants from them. And in most cases, if they deliver the dull five paragraph essay, they will in fact get the tasty morsel of cheese.

I think the issue here is less about writing, more about control and money. I don't subscribe to the idea that any single assessment measure really tells us much about how well students can write overall, and certainly no single assessment measure can tell us whether students should be allowed to stay in school or not. Though a choice of readings or genres can improve an assessment's validity and reliability somewhat, the improvement is negligible because the whole sys- 
tem is flawed. The idea of a "standard" for writing gives it away. In order to produce a standard, everyone has to read and write the same way. Without that control you don't have a standard; you have individual teachers deciding who can write and who cannot. This is exactly what they don't trust writing teachers to do. Sometimes I think the whole issue of standardized assessment is a slap in the face of faculty. Standardized tests are really saying: "Hey, teachers, you are not doing your jobs. Your students are passing your classes, but they can't meet our standards."

For the sake of argument, let's say that the college writing classroom is not doing the job for the majority of its constituents. Why punish the students for what the system has not delivered? Why aren't we improving the instruction (shrinking class size, increasing teacher training, exploring new pedagogies) rather than adding assessment barriers to a system that already assesses students more than any other system, anywhere in the world?

LIZA: That seems to be a rhetorical question, so I'm going to ask a question that isn't, but it will take a little setting up. At a local conference held just recently, I related the "literature" the speakers were celebrating to student writing (apparently to the great surprise of all in attendance). One presenter gave a paper on the "transcultural" writing of Guaman Poma de Ayalla (a mestizo Peruvian who, in the late 16th century, wrote a 1200-page letter to the King of Spain in Quechua and Spanish asking him to stop the violent abuses in the New World and telling him how the colony could be better managed); this same presenter also celebrated the projects of current U.S. Latino/a writers as creating new spaces in language as well as in the territories they inhabit. I asked if he shares such writings with his undergraduate students and suggests them as models students could draw inspiration from. I also questioned whether he had thought about current assessment measures that do not allow for the kind of new "hybrid" languages and identities which he celebrates as particularly "American" in Poma's writing. I thought this so relevant to his talk as to be something he must already have considered. I was wrong. He responded, somewhat bemused, somewhat irritated, that he thought the project I suggested was an interesting one, but one he has not undertaken, though he might respond at some other time and "in a more appropriate forum." The woman to my left muttered something indicating she was relieved that I was thus dismissed. What was inappropriate about making connections between "literature" and student writing? How could someone whose knowledge of Guaman Poma's text owed much to Mary Louise Pratt's analysis of it (in her famous "Contact Zone" piece) completely miss the point of that analysis, her 
notion of the political act of transculturation and the larger issues it implies about all writing productions? Must we assume the sort of response I got is only to be expected now and in the future?

WENDY: It's funny (or rather not) what an enormous gap there is between what the academy will let in as the subject of literary study and what we will allow students to write. We can ask students to study somebody like, say, Anzaldua in the colonized space of the literature class in such a way that it has no effect on our expectations about student writing and transculturation.

LEO: I'm a little surprised, Liza, that you didn't anticipate the speaker's response or even the dismissal by the woman in the audience. The lit conference is a venue that is, after all, specifically organized to allow literary scholars to shine on their home turf. The artificial split between interpretation and invention (read Literature and Composition) is a fundamental aspect of the way English has been organized as a discipline in the American university for about 100 years. (See histories of English studies by, among others, Ohmann, Berlin, Miller).

TIM: Leo suggests that Liza shouldn't be surprised. I disagree. I'm constantly surprised - and perplexed to the point of astonishment - at the continued lack of connections made between how we read and study texts as literature, looking for their various representations of repression, yet fail to analyze how we are complicit in oppressing our students every day.

LIZA: I'd like to thank Leo for crediting me with more political savvy (and finesse) than I have ever claimed for myself. I guess I did not understand the context of the event (familiarity with rhetorical conventions may be more important than some of us would like to admit) and spoke from this position of naiveté. But frankly, reading the context just as Leo has suggested I should have, I would ask the same sort of questions (Blake's Idiot as provocateur). Watching literature scholars so completely isolate and privilege published literary productions over student literary productions was an experience I will not soon forget. (Perhaps a single experience is worth a thousand pages of theory?) And I would encourage us all to hang on to some outrage; for me, anger is the emotion of agency and activism.

CARL: Clearly, although Liza is responding to a specific exchange at a specific event, the tendency to wall off literary studies from work with student writing seems to be a broad problem with how English departments are constructed and run (See Scholes' Textual Power). Liza's question about Poma's New Chronicle and its relation to student writ- 
ers seems entirely appropriate. What is interesting here-and what I think may be overlooked in discussions of literature and composition divisions - is that literary scholars early in their careers often teach "ba-

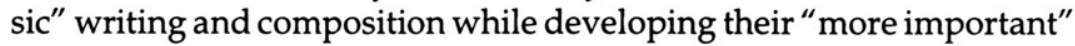
literary work. The connections between these activities (the pedagogical interaction with students and the research) occupy two distinct areas - not only in the department structure but often in scholars' minds. Thus a lit/composition division is internalized and allows one to work comfortably with the "radical" in literature (as a relatively safe and privileged object of study) while denying the contemporary existence of the radical in student writing (which is far from safe but, as an object of study, is as marginalized as the students it examines).

TIM: Carl's comment about how the mechanisms of the English Department continue to replicate the hierarchy of literature over composition scholarship is key here. One of the main reasons composition remains a subjugated discipline - despite the fact that it generates car loads of cash for the university - is that the mechanisms of the discipline privilege the study of Poma's relatively ancient letter, while ignoring the student letter written yesterday. What is to be gained by studying Poma's letter if we don't recognize the class system within the academy that validates it as something to be studied in the first place?

LEO: Tim is making an important point. Transculturation may allow the oppressed to use the master's tools to "speak truth to power," but there's no guarantee that the master will listen or make changes. If memory serves, Poma's 800 -page letter on improving the management of Spain's colony was never delivered. But again, if memory serves, Poma was a mestizo prince, hardly a paragon of Freirean resistance, merely a local ruler with local grudges against the Spanish. I prefer the much shorter and (perhaps) apocryphal demand a seventeenthcentury King of the Congo delivered to the King of Belgium about the African slave trade: "Cut it out!" This is unruly language of the type that creates aesthetic recoil from the guardians of the language of academe. Students might very well write to the administrators or the trustees that are calling for more testing, "Cut it out!" Their own unruly language more often than not lacks the potency of the Congolese king's three-word message. It will take an expanded vision of the nature of English studies to encompass all the issues posed by the relation of literature and literary scholarship to the teaching of writing to poorly skilled, inexperienced writers.

LIZA: A few clarifications on Guaman Poma. Contrary to what Leo remembers, he was not a "mestizo prince" but an Incan who claimed 
some noble ancestry. He was not a local ruler, but held a low position in the colonial administration. He did years of ethnographic research among his fellow Incans before composing his 1200 page letter (400 pages were diagrams), which gave voice to their grudges and concerns as well as his own. While his goal was better management of the Spanish colony (rather than outright resistance), his struggle to create a self that could write to a powerful authority, his subversion of the notion of the king's authority in his presumption to advise, and his creation of a hybrid language, part Quechua, part ungrammatical and, one might say, "broken" Spanish in order to fulfill the act he felt compelled to perform - these are all issues that our students can relate to.

WENDY: But one of the implied issues here takes us back again to the question of transformative pedagogy and the questions Leo raised about Poma's intentions: to what extent was Poma a collaborator rather than a resister? More broadly, when does the strategy of transculturation become the strategy of collusion in our pedagogy and elsewhere?

LEO: Yes, but we don't want our students' writing to lay dormant for 800 years!! Unfortunately, that's an attitude I see too often among composition instructors. Student writing carries no weight and bears little importance inside the academy. How do we present "occasions for questioning social reality" as we structure assignments or collaboratively build them with our students? I think one answer may lie in Carl's reminder that the dominant paradigm in English studies "allows one to work comfortably with the 'radical' in literature (as a relatively safe and privileged object of study) while denying the contemporary existence of the radical in student writing." If for our own purposes we can substitute the word "critical" for the word "radical," then that safe object of study remains comfortable because it is static, frozen in time, inconsequential. There's a lot to be said (and much good recent scholarship) about the glorification of radical U.S. writers as dead-and, therefore, safe-objects of study. The essence of the writing is lost without reminders of its connections to specific rhetorical purposes, and the old poststructural bogeyman, intentionality.

This is the all-too-commonly held view of student writing. It's dead, and that's good. It's safe because it's dead. Who wants thousands of college students writing about real social confrontation or, worse yet, class struggle? Not administrators and trustees. Richard Ohmann reminded us (in English in America) of the composition student who sits, pen poised, contemplating a "theme" with "no compelling reason to write." Compelling reasons are the essence of all good writing. It matters because the writing makes a difference, it means something in 
the world. It changes something, if only an attitude or perception. Perhaps, a better question to the panelist would have been whether his/her students ever have the opportunity to write with the same compulsion that motivated Guaman Poma (or the King of the Congo). What type of writing could students produce under those circumstances?

LIZA: I agree with Leo that it is this compulsion, the need to effect change, which is "the essence of all good writing," and which is almost always ignored in the classroom. And while I agree that "there's no guarantee that the master will listen or make changes" to indigenous or student demands, I do not think it is helpful to grant said "master" all the power in any rhetorical or other situation. The media can ignore, the think tanks discredit, the politicians disdain, but student agency affects the power structure; and in order for our students to have more effect than Guaman Poma or the Seventeenth-century King of the Congo, we faculty have to make sure they are heard.

LEO: Point granted. But I also think that we could push the literature and composition split too far in this particular conversation. Secessionist sentiment and recriminations have not yet produced any meaningful solutions to this problem. Perhaps, we should all look again more closely at Berlin's and Eagleton's suggestions for alternative conceptions for English studies. We may have valid reasons to protest the fact that literary scholarship is privileged, but our energies might be better spent articulating broader visions of literature and composition that are interdependent in new and creative ways. Has anyone seen Mary Soliday's description of the first-year writing course at City College of New York that mainstreamed basic writers and urged students to do research on their own language use? I'm convinced that learning to use language in powerful, critical, "radical," and purposeful ways is connected to the type of linguistic, ethnographic, and literary exploration demanded in such a course.

TIM: Hey, we've lost the students in all of this. Although the composition and literature split has a long history of discussion, it never has been framed in terms of the students, which would or should give us new angles on how the split reinforces composition's function as the university's gatekeeper. By subjugating composition to non-discipline status under the rubric of a literature department-and by staffing composition with so many part-time faculty - universities are able to use writing classes for their own goals. These goals are developed at too great a distance from the students and those faculty who know them best. I find no better way to outline the consequences (and provide provisional closure for our discussion) than by posing the kinds of questions that keep coming up in our talk: How come we need 
externally imposed assessment measures in composition but virtually nowhere else? How does the reliance on adjunct labor in composition, combined with the control of composition by literature professors, contribute to the subjugation of composition as a teaching profession and as a field of scholarship? Why is statistical, ethnographic, anecdotal, historical and outcome oriented research by composition specialists so ignored? And there is one more question we keep dancing around, the most difficult of all because it turns the mirror back on us: if we all agree that mandated assessments disrupt our writing pedagogy and hinder our students' development as writers, why - as individuals do we continue to participate in the system, accommodating such assessments and living with their outcomes? (As scholars who know better, are we complicit in faulty assessment measures that keep our students from succeeding?)

And since I don't want to end on an accusatory note, I want to thank you all individually and collectively for at once expanding and challenging my views on a whole range of important issues. I can't recall learning so much so quickly, or enjoying the process so completely. And I think "process" is the key word, too: our conversation shows that the scholarly writing process does not have to be an isolated experience bound by traditional forms. Clearly, collaborative/conversational discourse like ours can also produce "useful" knowledge and offer alternative forms of inquiry and presentation.

IAN: I'd like to add to Tim's closure by saying I think he's absolutely right! I'd also like to add that what I think he's describing here, in part, is a culture of liberalism both in our profession and throughout the institution itself. I don't mean to end by suggesting that we should all walk around saying mea culpa, mea culpa! What I think should be explored is the ways in which we in the academy reform on the one hand and compromise on the other. If we truly believe in quality education for everyone, free of the things that seem to disrupt and hinder it, then we should teach, act, protest and disrupt the institution in ways that demonstrate that belief. We are, as Tim suggests, complicit in miseducating students as well as controlling their access to the limited comforts our society offers. We should continually seek to push the envelope (without losing our jobs, of course) with our institutions, exploring ways to demonstrate in action the shortcomings of its policies and ideology as well as articulate them with words. 


\section{Works Cited}

Anyon, Jean. "Social Class and the Hidden Curriculum of Work." Journal of Education 162, (1980).

Berlin, James. Rhetoric and Reality: Writing Instruction in American Colleges, 1900-1985. Carbondale: Southern Illinois University Press, 1987.

Bizzell, Patricia."Rhetoric and Social Change." Responding (On)Off-Line to Three Works in Progress/A CCCC 97 Roundtable Discussion to be presented by Min-Zhan Lu, Diana George, and Tom Fox 14 Aug. 1997 <http://www.mtu.edu/cccc/97/bizzell.html>.

Eagleton, Terry. Literary Theory: An Introduction. Minneapolis: University of Minnesota Press, 1983.

Elsasser, Nan and Pat Irvine "English and Creole: The Dialectics of Choice in a College Writing Program" in Harvard Educational Review, 55, (1985), 399-415.

Freire, Paulo. Pedagogy of the Oppressed. trans. Myra Bergman Ramos. New York: Continuum, 1995.

Gintis, Herbert and Samuel Bowles. Schooling in Capitalist America Basic Books/HarperCollins, 1977.

Neel, Jasper. Plato, Derrida, and Writing. Carbondale: Southern Illinois University Press, 1988.

Ohmann, Richard M. English in America: A Radical Viezu of the Profession Middletown, Conn.: Wesleyan University Press,1996.

Pratt, Mary Louise. "Arts of the Contact Zone" (Keynote at the 2nd MLA Literacy Conference, 1990). Reading the Lives of Others. Bartholomae and Petrosky eds.

Scholes, Robert. Textual Power: Literary Theory and the Teaching of English New Haven: Yale University Press, 1985.

Shor, Ira. Critical Teaching and Everyday Life Chicago: University of Chicago Press, 1987.

Soliday, Mary and Barbara Gleason. "From Remediation to Enrichment: Evaluating a Mainstreaming Project." JBW16.1 (1997) 64-78.

Soliday, Mary. "Towards a Consciousness of Language: A Language Pedagogy for Multicultural Classrooms." JBW16.2 (1997) 62-75. 


\title{
Harvey S. Wiener
}

\section{THE ATTACK ON BASIC WRITING - AND AFTER}

\begin{abstract}
Attacks on collegiate basic writing have increased sharply. Despite a sense of success in many basic zuriting programs, we have not marketed our product well enough to shape positive public perceptions about the endenvor and to infucnce policy makers appropriately. University colleagues do not acknozuledge basic zuriting's utility, have little understminding of zelant it is, nut hine undermined its efforts. Minn Shnughessy's colleagues contimue to complain nbout how she "rwined" the City University of Nere York. One teacher, reinforcing both error hysteria and a false generic audience imperative, writes to the New York Times and assails some woriting teachers for what she sees as their own bad writing. Respected theorists and teachers have made brondside attacks on the enterprise. In truth, the profession has done little to link the specifics of bnsic woriting instruction with datn to support its long-term future and fundability, nind the lack of valid research allows legislatures and academic executives to call for swift and offen unsystematic change. Wint does the futture hold for basic zuriting? We zuill sce that reduced funding will alter familiar classroom formats; that two-year colleges zuill have increased responsibilities for teaching basic zuriting; that colleges will recruit instructors other than typical English and writing faculty; that units other than postsecondary institutions will provide basic skills instruction; and that demands will grow for precise research and reliable assessment. Despite wrenching changes in basic writing instruction, moral obligation insists that we continue our zoork to surmount the now commonplace challenges and assaults.
\end{abstract}

Attacks on college basic writing are legion these days. In New York the attacks have grown more and more vitriolic. At the end of January of this year, New York's Mayor Rudolph Giuliani shifted his target from the City University of New York's senior colleges' basic skills programs (which he had criticized sharply) to the skills programs at the community colleges. A New York Times reporter quotes the Mayor: "There comes a point after 15 years of tragically plummeting graduation rates and a total evisceration of standards that somebody has to say: 'This isn't working'" (Levy B1). Never mind that little evidence supports his conclusion. Among CUNY associate degree entrants in 1988 (the most recent year for which data exist), those who passed all their required basic skills courses were more likely to gradu-

Harvey S. Wiener oversees adult and community outreach programs at Marymount Manhattan College. Formerly University Dean for Academic Affairs at the City University of New York, zuhich included responsibilities for the multicampus Freshman Skills Assessment Program, he helped develop and had access to data on student achievement locally and nationally. For over thirty years Wiener has taught zuriting at every level of education from elementany through graduate school and has written a number of articles and books for beginning zuriters and their teachers. 
ate than students who took no remediation at all. On the baccalaureate level among 1988 freshmen, those who successfully completed basic skills courses graduated at a 42.8 per cent rate; those who took no remediation graduated at a 48.2 rate-a very small difference indeed. Other University data support the general effectiveness of skills programs, particularly in writing and math.

How do we account for the hostility directed at collegiate basic writing, to the fact that "Top officials of the City University of New York want to get out of the business of providing extensive remediation" (Schmidt A33)? Those of us teaching in basic writing programs can attest to our successes, the transformations we effect among students often just learning to write for the first time, despite their age or academic levels. We know that we have a good product. However, not to be too crass about it, we have not marketed it well. Mina Shaughnessy, the public academy's literacy conscience of the 1970's and an ardent advocate for Open Admissions, was justifiably rhapsodic about the untapped potential of students hitherto unwelcome in the university. These were the "strangers in academia, unacquainted with the rules and rituals of college life, unprepared for the sorts of tasks their teachers were about to assign them" (3) - the students newly served by energetic basic skills programs. Yet only two decades later Shaughnessy's song plays to deaf ears among policymakers who see only punishment by exclusion as the appropriate heritage of untraditional learners, those who defy arbitrary standards of accomplishment through the schools and attempt to make their mark in what Shaughnessy called "this eleventh hour of my students' academic lives" (vi).

Those with the responsibility for writing programs have not attended appropriately to public perceptions about the basic writing enterprise. Perhaps we cannot prevent the unenlightened barbs of politicians with an eye on budgets or reelections, but certainly we ought to have educated our University colleagues systematically and thoughtfully about what we do. Yet we have failed here, and, as a result, we continue to suffer uninformed comments and criticisms by the professorate beyond (and unfortunately sometimes within) our English and writing skills departments. Colleagues do not acknowledge basic writing's utility, have little understanding of what it is, and, to a large degree, have undermined our efforts. One need turn only to Jane Maher's recent piece on writing Shaughnessy's biography for confirmation. Interviewing faculty in the 1990's, Maher writes, "one of Mina's colleagues at Hunter refused to talk to me ... .; it's people like Mina, he claims, who 'ruined' the City University of New York" (56). Countless references to colleagues' negative attitudes appear in Maher's piece. Many, she says, "wring their hands in dismay-even disgust-claiming that these students couldn't read or write properly, therefore they 
didn't belong in college" (54). The fact that basic writing programs often can safeguard success as students move through the University is irrelevant to those who choose the virulent-punish-the-victim model.

Many who oppose basic writing have resisted what practitioners have taught over the last twenty-five years or so: that writing is a process, that its assessment is not error driven, that writers write for different audiences, that gradations of public and private writing exist, each having its own protocols. And, most sadly, some of those who teach on the basic skills frontlines have learned little and applied less to their views of writing and how to teach it. In "Johnny's Teacher Can't Write Either," an op-ed piece for the New York Times, Rachel Erlanger, an English as a Second Language teacher at Queens College, blasts Ira Shor, James Berlin, and me as she reinforces both an error hysteria and a false generic audience imperative that writing teachers have struggled for years to combat. First, she assails Berlin, Shor, and others for bad writing - that is producing Latinate, needless, elaborate, and pretentious words and phrases. Yet she misses the point of writers always needing to write for carefully defined audiences. Surely to a general readership an essay title such as "Holistic and Performative Assessment of ESL Writing" may invoke puzzlement, even snickers from a general readership; but for the audience of its readers-members of the National Testing Network in Writing and other writing teachers and administrators - such a title that Erlanger taunts is perfectly clear and useful as a marker of the content within. In Erlanger's scheme there are no gradations of writing, public or private. "Perhaps we should require [the teachers] to take a course in basic writing before they teach one," she says. My fateful blunder was what Erlanger saw as an utterly egregious and unforgivable misuse (a "mistake in syntax" she labels it) of "among" in place of "between." But a thoughtful reader, seeing the whole sentence and not just the phrase she wrests from context, easily would recognize the error as a typo. "Which writers," Nora Eisenberg, a colleague and collaborator, responded in an unpublished letter to the Times, "including those of the Times, are not pursued by these little devils in print - a dropped word here, an extra word there, a misspelling which an editor occasionally can miss?" Elevating to the level of shocked dismay small errors and language not meant for general readers - how such a mind set must paralyze students learning English! How for basic writing students such a teacher must "bloody their efforts with red ink on the most minor matters," Eisenberg continues. I received vicious hate mail from New York Times readers as a result of my among-between transgression. James Berlin told me that he had collected more letters after Erlanger's piece than he had as a result of all his books combined. One irate reader demanded of Berlin's dean that that the professor resign from the academy for writing the sentences Erlanger wrests from context and runs up the 
righteous writer's flagpole for the newspaper audience.

Even renowned theorists and teachers have made broadside attacks on basic writing. At a basic skills conference in Garden City, New York in 1993, Peter Elbow called for the end to basic writing and the mainstreaming of students into "regular" freshman composition classes. Mindful of the challenges to teachers' jobs, Elbow recommended that basic writing instructors serve as tutors or curriculum assistants for faculty across the disciplines. And Ira Shor has attacked basic writing even more severely. "Curricula for containment and control" (98), basic writing, he says, secures "unequal power relations" and is "part of the undemocratic tracking system pervading American mass education." He sees our purpose in placing students in basic writing courses "a new field of control to manage the time, thought, aspirations, composing, and credentials of the millions of non-elite students marching through the gates of academe" (93). Karen Greenberg, one of the most convincing and articulate speakers for basic writing, has with her usual passion taken Shor to task for stereotyping basic writing students and for turning into negative politics of empowerment what are simple realities of poor reading and writing skills. "The instruction provided by basic writing courses," she insists, "enables students to acquire the academic literacy skills, motivation, and selfconfidence to persevere and achieve in college" (94).

Who listens to such pleas in light of the current times-times marked by what Greenberg (and many others) see as "reactionary political forces" trying to bar access and reduce the "size of colleges across the country," returning a people's University like CUNY "to the elitist institution it was before 1970, when Open Admissions began" (94). In an editorial, the New York Times, long critical of CUNY, has sounded a cry perhaps too late in coming: "the need for remedial courses is so widespread that confining them. ... [to the junior colleges] would almost certainly reduce the number of minority college graduates, further whitening New York's professional work force.... Anything that discourages poor students, and immigrants from attending college damages the city's long-term prospects" ("Assault").

Yet basic writing, like other skills programs, has done little to link the specifics of instructional programming with data that would support its long-term future and fundability, leading to continuing assaults on current practices and the rush to ban or sharply modify remedial programs across the country. It is hard to see clearly through Shor's basic-writing-as-politics-only lens, but he captures the target in the cross hairs when he insists, "I want to see hard evidence that BW courses shelter more than they shunt" (96). A U.S. Department of Education-sponsored study (by Stanford University, the University of Pennsylvania, and the University of Michigan) reviewed the national literature on basic skills and found little reliable inquiry or research on the 
impact of remedial programming and best practices (Koski and Levin). The point here is the lack of research: it is a complaint I have made many times before, urging mainly to the indifferent the need to document the effectiveness of what we do. Instincts, sixth sense, and anecdotal reports: these never serve the policymakers and money holders who want only evidence. How do you know that drill and grammar work? they ask. How do you know that fifteen-week terms of three hours a week best teach basic writing skills? How much writing do students do in college classes anyway? And how does basic writing in fact affect the way a student writes for freshman comp and for courses in the disciplines?

Few studies address those questions, and the absence of study gives rise to calls for swift and often unsystematic change. A 1997 member survey by the State Higher Education Executive Officers Association, summarized by Alene Bycer Russell, points to a number of states engaged in active review of remediation at the college level. In many cases, basic writing instruction is shifting away from senior colleges and into the two-year colleges. Additionally, about $25 \%$ said that postsecondary institutions limited the length of time for completion of basic skills work. Legislatures have restricted funding for remediation; to take one example, the California State system in 1996 began reducing remedial offerings to $10 \%$ of current levels over a $10-$ year period. In Massachusetts, state colleges and universities limit the number of freshmen who can enroll in remedial courses to $10 \%$ in 1997 and $5 \%$ thereafter.

Continued poor preparation of elementary and secondary school youngsters (despite some progress here) and increasing immigration to the United States of speakers of other languages will assure the survival of some form of basic writing on the post secondary level. CUNY may in fact succeed in terminating college remedial instruction through the efforts of Mayor Giuliani and New York State Governor George E. Pataki, "making CUNY virtually alone among public universities and barring remedial classes for students" (Arenson B8). Yet like the rumors of Mark Twain's death in his lifetime, the news of basic writing's imminent demise is grossly exaggerated. But what does the future hold? Some current trends, in New York and elsewhere, suggest a number of factors that will influence direction over the next decade.

Sharply reduced funding will alter dramatically familiar classroom instructional formats. At CUNY a small but statistically significant higher passing rate for basic writing students appears in new intensive modes, which generally are condensed courses for several hours a day over the summer or intersession. These new formats reduce teacher-student contact, making up lost classroom hours with concentrated instruction and dependence on computer word-processing programs to speed draft development, revision, and editing. Some fac- 
ulty are germinating a different kind of computer-based course that draws on the Worldwide Web, Listservs, and OWLs (On-line Writing Labs) as well as on on-line and live tutorial support. Here too, actual classroom hours shrink, even more substantially, as students and teachers rely on e-mail comments and responses. Experienced instructors still must work out the protocols for these courses: how much time does each student get from the teacher? From other students? Many on-line courses, intending to cut instructor time, actually increase it sharply, but flexible sign-on sessions for teachers and students may outweigh the burden of extra hours.

Increased basic writing instruction will take place at the twoyear college level. As legislators and policy makers insist on proscribing remedial studies from the senior colleges, two-year institutions, already overtaxed with basic skills programs, will bear much of the burden. Currently, in Arizona, Colorado, South Carolina, and Utah senior colleges expect community colleges to perform all remedial services; in Florida only one state university has authority to offer basic skills instruction. This trend will expand, and two-year colleges will have to experiment with alternative teaching-learning modes that give students necessary skills without killing faculty with excess workloads. Certainly the stress on skills education will affect associate degree programs and course instruction over the disciplines as thin resources grow thinner.

Colleges will recruit instructors other than typical English and writing faculty. In further efforts to cut costs, postsecondary administrators and policymakers will turn to low-cost programs, such as continuing education, to provide basic skills services. Continuing education courses generally require no faculty senate or state approval, they rely on inexpensive teachers who get no benefits, and their costs are low enough that students might pay on their own without applying for State aid, even if allowable. Issues of quality control will rise, and conventional writing faculty numbers no doubt will shrink.

Institutions other than postsecondary units will provide basic skills instruction. As both political and financial pressures minimize the role of basic writing in a four-year college student's education and as two-year colleges strain under their increased load of skills instruction, community youth organizations, union instructional programs, workforce "universities," and private, for-profit higher educational institutions like the Berkeley School and the DeVry Institute will expand basic skills offerings at cut rate prices. These entities will turn enthusiastically to basic skills programs as a way of drawing students to the for-profit institution both for short and long-term enrollment.

Demands for precise research designs and reliable assessment measures will grow hard-edged and uncompromising. Much of CUNY's institutional research relates to longitudinal studies that ex- 
plore persistence, attrition, and graduation rates. But only individual colleges and departments through focused investigation can determine successful instructional paradigms - and these institutions have not attempted the studies or, if they exist, broadcast them. Legislators, academic executives, state and federal agencies will link grants and other funding much more substantially than in the past to demonstrably successful programs. Given an undistinguished past history of research in instructional efforts by college and university teachers and department managers, I'm not sanguine that colleagues ever will see the urgency of research as a way of assuring appropriate support for our basic writing efforts.

These factors will affect profoundly basic writing as we know it, and I believe that we will have to struggle to keep a humanistic sensibility in the endeavor. Yet after twenty-seven years or so of serving students who otherwise would have little chance for survival in college, we have a moral obligation to continue our work, despite wrenching changes in time-on-task and curriculum delivery. United, I believe that we can surmount the odds and continue our endeavor, brought into focus by the great social experiment of Open Admissions. Everybody loses when good products face challenge, even extinction, through bad marketing, poor strategic planning, inertia, or lack of imagination. These elements are contributing to the decline of a vital university service: through basic writing instruction to give underserved and poorly prepared students the skills to make their voices heard as they move through the academy and into a complex world.

\section{Works Cited}

"An Assault on Open Admissions." Editorial. The New York Times 19 Mar. 1998, late ed.: A20.

Arenson, Karen W. "Pataki-Giuliani Plan Would Curb CUNY Colleges' Remedial Work." New York Times 7 May 1998, late ed.: A1+. Eisenberg, Nora. Unpublished letter to the New York Times. 16 June, 1991.

Elbow, Peter. Address. Conference of Redefining Basic Skills. Adelphi U, Garden City, NY, 7 Nov. 1993.

Erlanger, Rachel. "Johnny's Teacher Can't Write Either." New York Times 12 June. 1991, late ed.: A 27.

Greenberg, Karen. "A Response to Ira Shor's 'Our Apartheid: Writing Instruction and Inequality.'" JBW16.2 (Fall 1997): 90-94.

Koski, William S. and Henry M. Levin. Replacing Remediation with Acceleration in Higher Education: Preliminary Report on Literature Review and Initial Interviews. Draft ms. National Center for 
Postsecondary Improvement, Stanford U., 1997.

Levy, Clifford J. "Giuliani Demands Community Colleges Drop Remedial Help." New York Times 30 Jan. 1998, late ed.: B1+.

Maher, Jane. "Writing the Life of Mina Shaughnessy." JBW16.1 (Spring 1997): 51-63.

Russell, Alene Bycer. Statewide College Admissions, Student Preparation, and Remediation Policies and Programs: Summary of a 1997 SHEEO Survey. Denver: ACT and State Higher Education Executive Officers, 1998.

Schmidt, Peter. "A Clash of Values at CUNY Over Remedial Education." Chronicle of Higher Education 20 March 1998: A33-34.

Shaughnessy, Mina. Errors and Expectations: A Guide for the Teacher of Basic Writing. New York: Oxford UP, 1977.

Shor, Ira. "Our Apartheid: Writing Instruction and Inequality." JBW 16.1 (Spring 1997): 91-104. 


\section{INEQUALITY (STILL) RULES: REPLY TO COLLINS AND GREENBERG}

Question basic writing and all hell breaks loose. Terry Collins accuses me of belonging to a "crazy" Left and Karen Greenberg says my ideas are "pernicious." Still, the problems of comp/BW are a longstanding dilemma in our field; not only have first-year writing courses served to sort students by race and class, but they are also of dubious intellectual merit. Does it make sense to have a course teach something like "General Writing Skills Instruction"? On this issue, I refer readers to Joe Petraglia's volume Reconceiving Writing and particularly to David Russell's extraordinary essay in it, "Activity Theory and Its Implication for Writing Instruction." Doubts about GWSI and first-year writing courses dog our field. If writing instruction has a future that makes theoretical and practical sense, it lies in disciplinebased, field-oriented, project-situated, student-centered, critical social activities, not in the comp/BW service courses built on a "myth of autonomous literacy" as Brian Street called it.

Further, in terms of comp/BW being a cash cow, I made clear in my original article that I was referring not to Terry's BW program but rather to "the former comp program" at Minnesota whose much-respected director was summarily dismissed without apparent cause in 1996 and replaced by an 18th-century literary scholar, a scandal at that time. While in Minnesota then, on a visit, I met with Terry's General College writing staff and found them to be an impressive group. Terry has every right to be proud of his staff. But this pride is not the same as justifying the functions of BW there or elsewhere. In justifying the functions and outcomes of BW, one problem is that Terry speaks in generalities rather than specifics vis-a-vis how much revenue his GC BW program might be generating. His assurance that his writing program is not a cash cow for the university will be convincing when he provides data. Moreover, the racial makeup of General College's student body has to be clarified and compared to that of the University of Minnesota as a whole for Terry to deny my metaphor of educational apartheid. Are the colors and income-levels of the two student bodies equivalent? Lastly, is my proposed Labor Policy really in effect at General College? From Terry's own reply, I see that his BW staff includes only four full-time tenure-track faculty. The "others" on the 
staff include "four full-time academic professionals on annual tenuretrack appointments at reasonable load and nine half-time graduate students" (97). Is this an equitable labor hierarchy? Seems like the parttime grad students outnumber the full-timers, and the full-timers are divided into two castes of teachers, real faculty vs. people mysteriously labeled "academic professionals" in Terry's own words. How is this different from the unequal division of labor in $\mathrm{BW} /$ comp in general?

In addition, Terry says that " $100 \%$ of the General College students who successfully transfer into degree-granting colleges at Minnesota complete the Basic Writing sequence. ... And we know that those who find a way to avoid the Basic Writing courses or who postpone enrolling tend to fail to transfer into degree programs, and they drop out at elevated rates" (97). To be honest, I'm not sure what this information means. It may be good news endorsing his BW program. I don't doubt that Terry and his staff labor prodigiously for the success of the students. But it's not easy to read what the data here means because of the paucity of detail and explanation. The $100 \%$ figure seems like a soft measure of "success" unless some questions are clarified: how many BW grads from Terry's program don't successfully transfer to a degree-granting institution? How many BW students don't finish the BW courses? To say that all successful "transfers" completed the BW courses has to be put in relation to the numbers of non-successful students who never reach the transfer stage. Terry does say that students who avoid BW or who postpone enrolling tend to fail to transfer into degree programs and also drop out at elevated rates, supporting the value of his BW. But, when they avoid BW, do they take other writing and academic courses which they fail or pass or do they take no courses at all? What exactly are they doing when they evade BW? Peter Dow Adams wrote about BW-evaders at his college who took freshman comp instead and did as well as or better than BW grads. At Terry's place, do BW-evaders drop out for academic reasons or for economic reasons? The information is simply too skimpy. Lastly, if Terry did publish the racial and economic makeup of BW students in GC compared to those of students in the University of Minnesota's College of Liberal Arts, that could help answer Karen's charge against me that "most basic writing students are not 'Blacks' and 'the children of poor and working families'" (90). From Terry and from Karen, I'd like to see their evidence that students from lower-income families and from communities of color are not over-represented in BW classrooms. The case at CUNY is clear enough (see David Lavin's research on the impact of new admissions criteria, with its appended statistical tables indicating the racial character of students who pass entry tests, BW, and graduate [CUNYTALK Digest, 15 March 1998-16 March 1008, \#1998-72]). 
On another note, Karen misrepresents my "mainstreaming" position as a sink-or-swim policy, something I never advocated, and which my support for Soliday, Gleason, Grego, and Thompson contradicts. I join others in the field who propose abolishing remediation and replacing it with effective alternatives; I despise and reject the conservative politicians, pundits, trustees and think-tankers who want to abolish the students. This is the crucial distinction missed by Terry and Karen: some progressives want to abolish bogus testing, remediation and disembodied writing instruction; the right wants to expand testing, abolish non-elite students, and end open access.

Karen and Terry, can you imagine a mass college that does not test and sort its incoming students? We did that at Staten Island Community College from 1971-1976. On this crowded, low-budget, working-class campus of the City University of New York, we developed a BW program that had no formal testing mechanism. Anyone who would like a description of our entry process back then should contact me for details. Let me say here, briefly, that we did just fine in those days in our writing classes and felt no need for a testing regime. In fact, our experimental BW unit was hailed as one of three nationally successful programs by the NCTE in 1974. I taught BW there for fifteen years until 1986, by which time the dogs of the culture war had cannibalized the promising Open Admissions project, imposing tuition in 1976 for the first time and restrictive entry exams in 1978, including the infamous City University of New York Writing Assessment Test (WAT), which led to a huge failure rate, a large testing office, and an empire of remediation with ten or more courses where we originally had one. About WAT-style placement tests, Mina Shaughnessy wrote that

Without strategies for generating real thought, without an audience he cares to write for, the writer must eke out his first sentence by means of redundancy and digression, strategies that inevitably disengage him from his grammatical intuitions as well as his thought. (Errors and Expectations 82)

More recently, Barbara Gleason said this about the WAT at CUNY:

the WAT's numerical score itself fails to capture the complex potential of the students. The timed writing test and its interpretative scoring mechanism cannot begin to assess a student's history, motivation, ingenuity, creativity, work habits, sense of self, interpersonal intelligence, or sheer courage in the face of seemingly insurmountable obstacles. ("When the Writing Test Fails," 322, in Writing in Multicultural Settings, eds. Carol Severino, et al., MLA: New York, 1997, 307-324) 
Gleason reported that "whites consistently pass the test more frequently than do Asians, blacks, and Latinos and Latinas," suggesting that the apartheid function of remediation and its testing regimes is a reasonable metaphor. (See also Hazel Carby's "The Politics of Difference" for one African-American scholar's application of the apartheid metaphor to American education and society, [MS. Magazine, September/October 1990, 84-85].) About the depressant effects of remediation, Mike Rose said that

the curriculum in developmental English breeds a deep social and intellectual isolation from print; it fosters attitudes and beliefs about written language that, more than anything, keeps students from becoming fully, richly literate. (Lives on the Boundary, 211)

Forty years ago, Burton Clark discovered how writing courses and testing were useful to the "cooling-out function in higher education":

In one junior college the initial move in a cooling-out process is pre-entrance testing; low scores on achievement tests lead poorly qualified students into remedial classes. Assignment to remedial work casts doubt and slows the student's movement into bona fide transfer courses. The remedial courses are, in effect, a subcollege. The student's achievement scores are made part of a counseling folder that will become increasingly significant to him. An objective record of ability and performance begins to accumulate. ("The Cooling-Out Function in Higher Education," 572 American Journal of Sociology, 65 [1960], 569-576)

My respect to my hard-working veteran colleagues Terry and Karen, and to others who labor in writing classrooms. Smart people with good intentions often find ourselves working in structures with bad functions. Intelligent people sometimes invent the wrong structures for the right reasons, which is how I feel now about the experimental BW program I helped build with my gifted colleagues at Staten Island. We didn't know then what we can know now about language, literacy, learning, and teaching, thanks to 25 years of research and debate in our field. The wrong thing to do is to dig in our heels, nest in our positions, and make ourselves only more vulnerable to conservative assaults by defending weak turf rather than transforming it into something strong in theory and practice. Unfortunately, many folks feel that there are no better alternatives to the courses and programs now predominant. But, fortunately, others are already testing alterna- 
tives based on democratic theories of literacy and learning. It's time for our field to move past the conundrum of our first-year writing courses which have served inequality well but have served students and teachers poorly from their inception at Harvard over a century ago. Disembodied language arts - writing for no particular purposewriting without a meaningful content or context-the myth of autonomous literacy - the notion that "academic discourse" or "basic skills" or "critical thinking" can be taught in special writing classes segregated from social practice or from the rest of the curriculum-comprise a grandly deluded edifice built on the sands of bogus testing, a race and class hierarchy of undemocratic language arts vulnerable to the tsunami of conservative authorities, clearly the dead-ends of our still-evolving history. 


\section{News and Announcements}

The Summer Seminar in Rhetoric and Composition, Millikin University, June 7-12, 1998. The purpose of the seminar is to introduce college teachers to composition theories, pedagogies, and practices in ways that allow participants to apply these ideas at their home institutions. Keynote Speaker: Ira Shor. Workshops with: Peter Elbow, Patricia Bizzell, Tony Silva, Randy M. Brooks, Nancy DeJoy, and Krista Ratcliffe. For more information contact Nancy DeJoy, Director, Summer Seminar in Rhetoric and Composition, Millikin University, 1184 W. Main St. Decatur, IL, 62522-2084. Registration fee is $\$ 675$.

Reflections: Practice, Theory, Reflection, and Action: Transforming Classrooms, Schools, and English Studies. June 18-20, 1998, Seattle, Washington. Keynote Speakers: Sondra Perl and Dan Kirby. For more information call NCTE's Professional Development Services at 217-328$3870 \times 203$ or email pds@ncte.org.

Call for Proposals: 22nd Annual CAWS (CUNY Association of Writing Supervisors) Conference will be held Friday, October 30, 1998, in Manhattan. Conference theme: For the Sake of Our Students. Marilyn Sternglass (author of Time to Know Them) will be the keynote speaker. Proposals sought for papers, panels, workshops, and roundtables. Submit abstract and title to: George Otte, Director of Writing Programs, Baruch College/CUNY, 17 Lexington Ave, New York, NY 10010. Deadline: July 1, 1998.

Call for Papers: The 1998 Conference on Fundamental Controversies in Rhetoric and Composition will be held at the University of Arizona, November 12-13, 1998. Richard Miller will be the keynote speaker. Send title of paper or session proposal and one-page abstract to: Terrel Ratchford, Dept. of English, University of Arizona, Modern Languages 445, Tucson, AZ 85721. e-mail: ratchfot@u.arizona.edu. Deadline: July 1, 1998.

Conference Announcement: E.G.A.D. (English Graduates for Academic Development) will hold its 8th Annual Interdisciplinary Symposium July 25, 1998, at Texas A\&M University-Commerce. Contact: Colin Charlton (EGAD), Dept. of Literature and Languages, Texas A\&M University-Commerce, Commerce, TX 75429-3011; e-mail charlton@boisdarc.tamu-commerce.edu or phone 903-886-5208 for more information.

The Thomas R. Watson Conference on Rhetoric and Composition, "Multiple Literacies for the 21st Century," will be held October 8-10, 
1998, at the University of Louisville, Louisville, KY. Featured speakers include Arthur Applebee, Charles Bazerman, Deborah Brandt, Sarah Freedman, Shirley Brice Heath, Glynda Hull, Min-Zhan Lu, John Ogbu, and Cindy Selfe. Conference website is at http:// www.louisville.edu/ watson. For information and registration contact: Annie Tarbox, Asst. Dir., 502-852-1252; e-mail WATSON@HOMER.LOUISVILLE.EDU.

Call for Papers. Working-Class Studies: Class, Identity, and Nation, the Fourth Biennial Conference of the Center for Working-Class Studies at Youngstown State University. Conference dates are June 9-12, 1999. Proposals sought for presentations, panels, workshops, performances, exhibits, and readings that address issues and/or representations of class, race, gender, sexuality and nation in workingclass life and culture. Submissions of 250-300 words, describing proposed projects with suggested presentation format. Contact: John Russo, Labor Studies Program, Youngstown State University, Youngstown, Ohio, 44555; fax 330-742-1459; or e-mail Sherry Linkon at sjlinkon@cc.ysu.edu. The CWCS website is at http://as.ysu.edu/as/ cwcs. Deadline for proposals: January 8, 1999. 


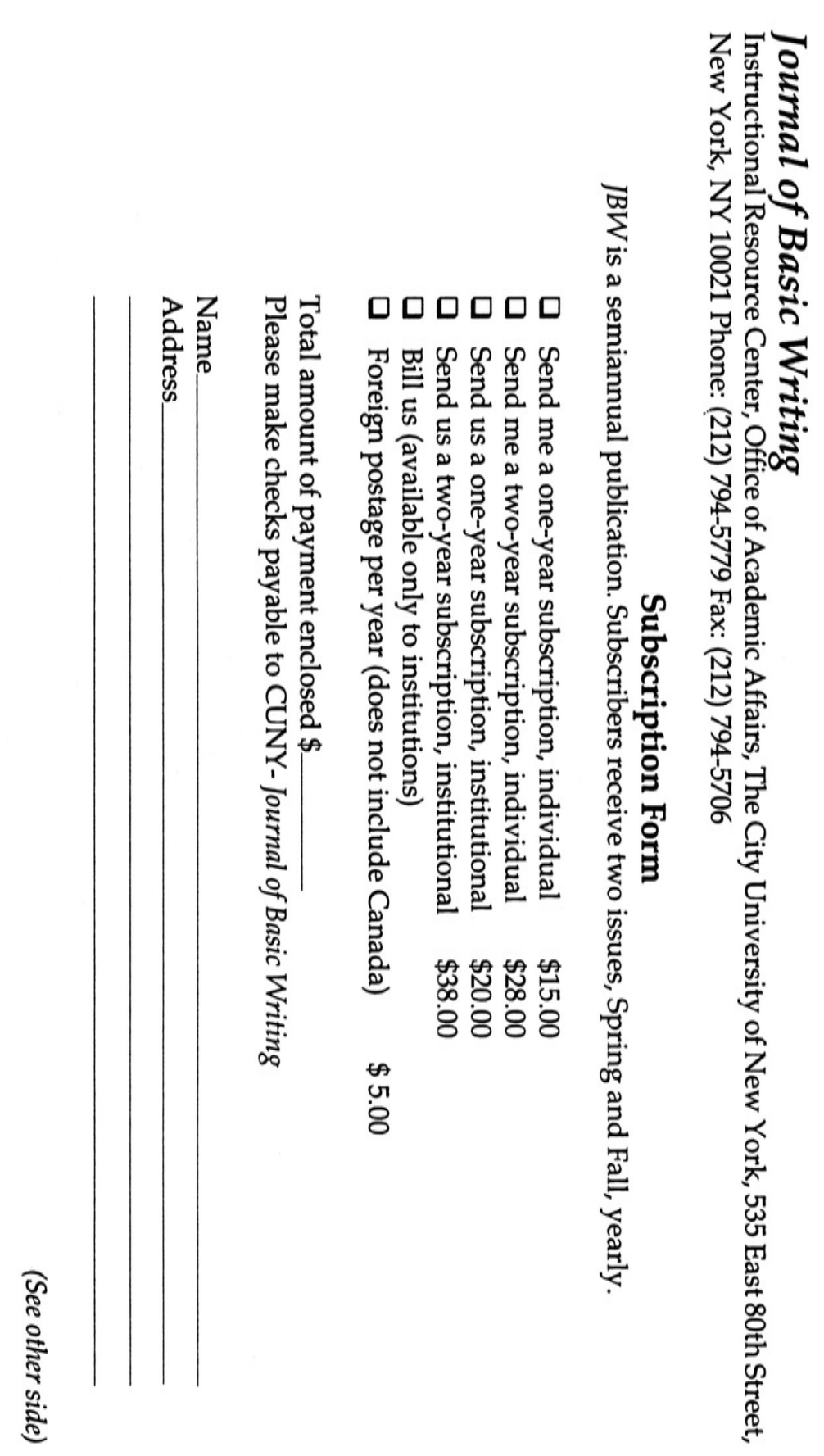




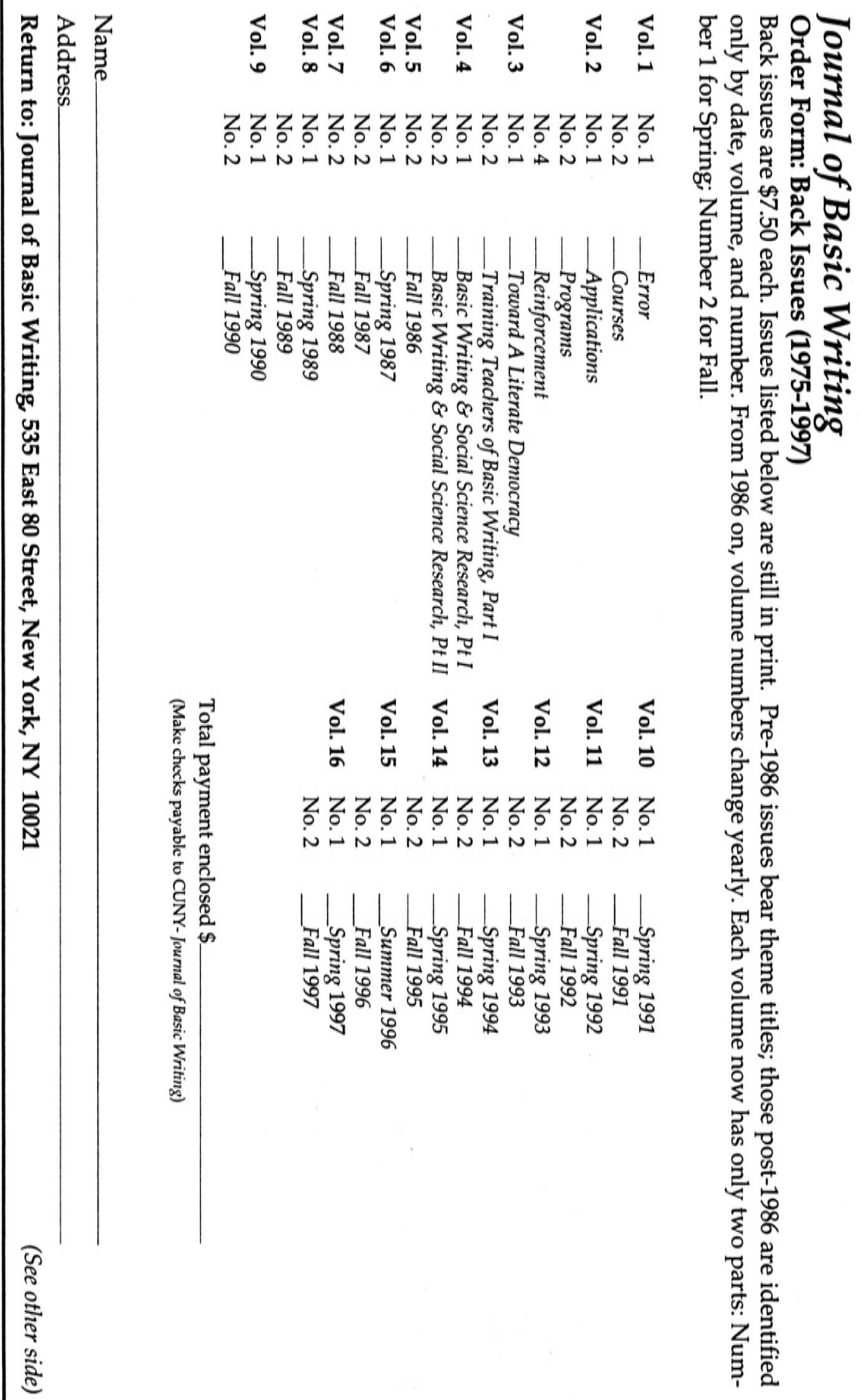





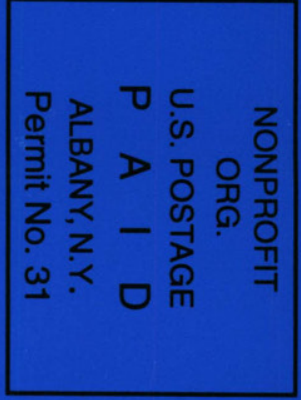

